\title{
Wage Formation: Towards Isolating Search and Bargaining Effects from the Marginal Product.*
}

\author{
Jeanne Tschopp ${ }^{\aleph}$
}

August 2015

\begin{abstract}
This paper estimates the importance of workers' outside options in wage determination. In models of search and bargaining, a worker's wage is determined by the marginal product of labour and by a weighted average of wages in alternate jobs. Thus, the nature of the wage equation makes it difficult to isolate changes in workers' outside options that are independent from changes in the marginal product of labour. This paper builds on the predictions of a search and bargaining model with multiple cities, industries and occupations to propose novel identification strategies. Using a unique administrative panel database for Germany, the study exploits differences in both the employment composition across cities and in job-specific skill transferability as sources of variation for identification. The main finding of the paper is that a $10 \%$ increase in the outside options of a worker generates a $7 \%$ wage increase.
\end{abstract}

JEL classification numbers: J30, J31, J60, J62.

Keywords: Wages, search and bargaining, marginal product, sectoral and occupational mobility, cities.

\footnotetext{
* I would like to thank Paul Beaudry, David Green, Benjamin Sand, anonymous referees, participants at the brown bag workshop at the University of British Columbia and Victoria, seminar participants at Copenhagen Business School, Dartmouth College, Ryerson University, Université Laval, Université de Sherbrooke, University of Leicester, University of Vienna, York University, and participants at the 19th Meeting of the Society of Labor Economists 2014 in Arlington for helpful comments and discussions. I am grateful to the Swiss National Science Foundation for their financial support and to the Research Data Centre of the German Federal Employment Agency at the Institute for Employment Research for providing data access.

${ }^{\aleph}$ Department of Economics, Ryerson University, 350 - Victoria St., Toronto, ON, Canada, M5B 2K3; jtschopp@economics.ryerson.ca.
} 


\section{Introduction}

It is increasingly accepted that labour markets are not perfectly competitive and that frictions of various kinds generate rents to the employment relationship for both workers and employers. These frictions imply that wages depart from the marginal product of labour and partly reflect workers' outside options. In the particular case of search and bargaining models, wages are determined by both the marginal product of labour and a weighted average of wages in alternate jobs. ${ }^{1}$ Since an industry-specific shock will be passed through into wages via two channels (the marginal product and workers' outside options), comparative statics of search and bargaining and perfect competition models will differ. Yet, despite these differences, the marginal product hypothesis remains the benchmark for wage formation and only few empirical attempts have examined the relevance of workers' outside options for wage formation. The goal of this paper is to propose a strategy to examine whether wages conform to the predictions of search and bargaining theory and test the relevance of this strategy using an administrative panel database on workers in Germany.

A key difficulty in identifying search and bargaining mechanisms is that a worker's marginal product is not directly observable. The main contribution of the paper is to show that it is possible to use observational data to separate the respective effects of outside options from those of unobserved productivity. In particular, the paper argues that if one is willing to place some restrictions on the production function, a triple difference estimation combined with an instrumental variable strategy can correct observed wage movements for changes in the marginal product of labour and what is left can be interpreted as search and bargaining effects.

The most recent approach to identifying search and bargaining mechanisms has been suggested by Beaudry et al. (2012). The authors propose a multi-city multi-sector model of search and bargaining in which a worker's outside option is formed by all the industrial wages of the city in which the worker lives. The authors show that in such a framework, a worker's outside option can be written as a weighted average of industrial wages, where the weights are given by the corresponding industrial employment as a share of city employment. Thus, a direct implication of the proposed model is that, conditional on productivity, a city with a larger proportion of high-paying industries benefits from higher wages in all its industries.

The authors argue that variation "within industry across cities" can be used to identify the

\footnotetext{
${ }^{1}$ For a survey on search-theoretic models of the labour market, see Rogerson et al. (2005).
} 
effect of workers' outside options on industry-city wages. Consider an environment with 2 cities (A and $\mathrm{B}$ ) and 2 industries (manufacturing and natural resources). In this environment, the natural resources sector is located in city A only. Imagine that for some exogenous reason, the price of natural resources goes up. Assume that following that increase, wages go up in both sectors and both cities but that, for simplicity, no labour movements are observed across sectors. Further assume that shifts in productivity in the manufacturing sector are identical in both cities. Since the natural resources sector is only located in city A and since no labour movements are observed, workers' outside options remain identical in city B and the increase in wages in the manufacturing sector in city B can be entirely attributed to a shift in productivity (possibly due to the fact that the manufacturing sector works to process natural resources). In city A, however, the increase in wages observed in the manufacturing sector reflects both an improvement in workers' outside options and a shift in productivity. In this particular environment, the identification strategy proposed by Beaudry et al. (2012) consists in taking the difference between periodical changes in wages in the manufacturing sector in city $\mathrm{A}$ and those observed in city $\mathrm{B}$, and attributing the residual wage variation to changes in workers' outside options in city A.

Beaudry et al. (2012) make an important step towards identifying search and bargaining effects. However, their approach has two limitations which this paper attempts to address. First, the authors assume a technology in which factors are perfect substitutes. Since this assumption implies constant marginal product of labour within an industry and city, it is unclear whether independent effects of workers' outside options are also identified when technology is of a different form. This study adopts a more flexible formulation of the production function and discusses the conditions under which the restrictions placed on technology do not allow for a separate identification of the effects of workers' outside options.

Second, the authors implicitly assume that workers are identically mobile across any two pairs of occupation-industry (hereafter 'job') cells. A consequence of this assumption is that measured outside options are identical for all workers of the same city. Imagine for instance that the manufacturing sector employs both white and blue collar workers but that the natural resources sector only uses blue collar workers. The Beaudry et al. (2012)'s assumption implies that white and blue collars in the manufacturing sector in city A have the same outside options and the same probability of being employed in the natural resources industry, even if the latter only employs blue 
collar workers. However, one may think that the ability to transfer skills across jobs affects whether and how wages offered in other jobs enter the measure of outside options. This paper recognizes that workers potentially face heterogeneous barriers to mobility and explores the importance of the treatment of mobility across occupations and industries for wage formation.

To implement these changes, this paper builds on Beaudry et al. (2012)'s model and adapts it to allow for multiple occupations and differences in occupation-industry-specific skill transferability. In this framework, the outside options of a worker are given by a weighted average of the wages in all jobs of the city in which the worker lives. The most important difference with Beaudry et al. (2012) is that the weights are represented by transition probabilities between the job currently occupied and the alternate jobs in which the worker could potentially be hired. These transition probabilities reflect the idea that the importance of a job in a worker's outside options depends not only on the relative number of vacancies available in that job but also on the ability of a worker to actually perform the job. Since these weights depend on the job that the worker is currently employed in, workers' outside options differ across jobs in the same industry and city.

The treatment of mobility across jobs plays an important role for the identification strategy. To see why, consider the previous example but assume that following the increase in the price of natural resources, city A and B experience differential shifts in productivity in the manufacturing sector. Under Beaudry et al. (2012)'s approach using variation "within industry across cities", all of the differential in wage growth in the manufacturing sector between the two cities would be attributed to search and bargaining effects, thus effectively ignoring that changes in the value of the marginal product of labour within industry may differ across cities. The identification strategy proposed in this paper can deal with this issue by exploiting differences in workers' outside options within an industry and city. In particular, identification can be achieved using a triple difference estimation based on variation "within industry-city across jobs" and "within job across cities". In this example, the triple difference consists in first, taking the difference between changes in wages for blue collar workers in the manufacturing sector in city A and the equivalent wage variation for white collar workers, and second, calculating the difference between that change and its particular counterpart in city B. The first difference removes changes in productivity common to all occupations within an industry and city, and the second one eliminates job-specific shifts in productivity.

This paper proposes to apply the logic of this example to an environment with multiple jobs 
and multiple cities, and to the more realistic situation in which employment moves unconstrainedly. However, when employment moves unconstrainedly, the triple difference estimation has to be combined with an instrumental variable strategy. In fact, there may be an endogeneity problem because changes in productivity may affect the employment composition in a city which, in turn, affects the weights used to calculate workers' outside options. Hence, the triple difference by itself may not be enough to identify independent effects of workers' outside options. The paper uses Bartik-style instruments to isolate changes in workers' outside options that are uncorrelated with labour movements. These instruments are similar to those used by Beaudry et al. (2012) and predict workers' outside options by combining national job wage premia with the local structure of employment that would prevail if job-city employment had grown according to the national trend. The paper shows that these instruments are valid if shocks to comparative advantages are uncorrelated with past job-city-specific comparative advantages.

The empirical strategy is implemented using an administrative panel database on workers in Germany provided by the employment statistics of the Institute of Employment Research (IAB) for the period 1975-2001. This paper finds that while the treatment of mobility is an important issue, placing restrictions on the technology does not appear to be an important source of bias. Overall, results suggest that job-city wages conform to the predictions of search and bargaining theory. The wage spillover effects from a shift in workers' outside options are strong and consistent over a wide range of sensitivity checks: specifically, a $10 \%$ increase in workers' outside options generates a $7 \%$ wage increase. ${ }^{2}$ Results from a variance decomposition suggest that a framework that ignores search and bargaining effects would explain on average $11.5 \%$ of the cross-sectional variance in city wage growth, while a model that accounts for the effects of workers' outside options is capable of explaining a much larger fraction of the variance. This fraction amounts to $18.9 \%$ in the case of constant mobility and increases to $68.8 \%$ in a model that incorporates differences in job-specific skill transferability, suggesting that the framework of this paper may also be helpful for understanding the sources of the rise in wage inequalities that has been observed over the past 25 years in Germany.

Using a similar database, Card et al. (2013) provide descriptive evidence of the role of establish-

\footnotetext{
${ }^{2}$ Imagine, for instance, that the only option a secretary in the tertiary sector has access to is working in the car industry. This results means that a $10 \%$ wage increase for secretaries in the car industry will generate a $7 \%$ wage increase for secretaries in the tertiary sector.
} 
ment, worker and match-specific components in explaining the rise in wage inequality. The authors find that a considerable fraction of the rise in inequality is due to rising variation in the wage premia that are offered by different employers. In this paper, search and bargaining mechanisms create wage disparities across employers for workers with otherwise similar characteristics and imply that the rise in workplace heterogeneity may have been caused by an increase in the dispersion of workers' outside options. Therefore, this paper provides a theory of wages consistent with Card et al. (2013)'s findings and offers a potential explanation of the source of rising workplace heterogeneity that differs from traditional explanations based on institutional or supply and demand factors.

This paper proceeds as follows: Section 2 presents the model. Section 3 discusses how identification can be achieved. The empirical setting is described in Section 4. Section 5 presents results. In Section 6, the paper quantifies the importance of changes in workers' outside options in explaining the cross-sectional variance in city wage growth. The last section concludes.

\section{Model}

This section generalises Beaudry et al.'s (2012) multi-city, multi-sector model of search and bargaining to a framework with occupational and sectoral mobility.

\section{$2.1 \quad$ Setup}

Consider an environment with one final good $Y$, assembled from the economy-wide output of $I$ industries, as given by

$$
Y=\left(\sum_{i=1}^{I} a_{i} Z_{i}^{\chi}\right)^{\frac{1}{\chi}}
$$

where $\chi<1, a_{i}$ is a parameter reflecting aggregate demand for the industrial good $i$ and $Z_{i}$ denotes the economy-wide output of industry $i$. The price of the final good is normalised to one. The economy is segmented into $C$ local labour markets, hereafter cities, indexed by $c$. Each city is populated by $L_{c}$ individuals who are either employed or unemployed. The economy-wide output $Z_{i}$ is given by the sum of $Y_{i c}$, the output produced in each city. The price of the industrial good $i$ in city $c$ is $p_{i c}$.

For clarity, production involves labour only and uses $Q$ occupations indexed by $q$. The paper 
starts without explicitly specifying a functional form for technology and discusses later on the implications of placing restrictions on the production function. In what follows, an occupationindustry cell is referred to as a job and indexed by $j$, i.e. $j=(q, i)$. $S$ denotes the set of job and since each industry uses $Q$ occupations, the cardinality of $S$ is $Q \times I$.

The number of firms and aggregate employment in an industry and a city are endogenously determined by a free entry condition within a framework à la Fonseca et al. (2001). In this framework, an individual receives the option of creating a firm in industry $i$ and city $c$ with probability $\Omega_{i c}$. Upon learning $\Omega_{i c}$, the individual finds out $n$, the amount of labour he or she can manage, where $n \sim G(n)$. Within an industry and a city, differences in entrepreneurial ability to manage jobs are the only source of firm heterogeneity. Finally, to enter the production market, he or she faces a constant start-up cost, denoted by $K$. Free entry implies that individuals with expected payoffs larger than the fixed entry cost $K$ become entrepreneurs.

The labour market considered is characterised by search and matching frictions. For simplicity, assume that workers can move within but not across cities. Appendix C of the Supplementary Material discusses the implications of workers' mobility across cities and demonstrates that the results are robust to an extension allowing for this type of mobility. For the majority of the analysis, this paper focuses on random search and ignores resignations as well as on-the-job search. However, implications of directed search across occupations as well as on-the-job search are discussed in Appendix D and K-3 of the Supplementary Material, respectively. Once matches are made workers and firms bargain over the wage rate, through Nash bargaining in a complete information context. Layoffs occur at an exogenous rate, denoted by $\delta$.

The model is couched in continuous time. Workers and firms live forever, discount the future at an exogenous rate $\rho$ and are risk neutral. Workers seek to maximise the expected discounted sum of future utility flows, and firms are profit maximisers. Let $E R_{c}$ denote the employment rate in city $c, w_{j c}$ be the wage in job $j$ and city $c$ and $\eta_{j c}$ denote employment in job $j$ and city $c$ as a share of city $c$ employment. The steady state is characterised by values of $E R_{c}, w_{j c}$ and $\eta_{j c}$. Prices adjust such that markets for industrial goods clear and react to shifts in the demand for industrial goods, as captured by $a_{i}$. 


\subsection{Search and matching}

In each city, there is a pool $U_{c}$ of unemployed workers drawing job offers from the entire local labour market. Workers face barriers to mobility and their appointment to a particular job depends on three components: labour market frictions (as captured by the matching function), vacancies in that particular job and on the job performed prior to unemployment.

The rate at which unemployed workers meet any vacancy is governed by a city-specific matching technology

$$
M_{c}=M\left(\left(L_{c}-N_{c}\right),\left(J_{c}-N_{c}\right)\right),
$$

where $N_{c}$ denotes the total number of employed workers in city $c, L_{c}$ the total number of workers in city $c$ and $J_{c}$ the total number of existing positions (filled and unfilled) in city $c .\left(L_{c}-N_{c}\right)$ is the number of unemployed workers in city $c$ and $\left(J_{c}-N_{c}\right)$ is the number of vacant positions available in city $c$. The matching function is of the Cobb-Douglas type, exhibits constant returns to scale and is increasing in both arguments. These features imply that $\eta_{j c}$, the proportion of employment in each job, equals the proportion of existing positions (filled and unfilled) in job $j$ and city $c$. That is, $\eta_{j c}=\frac{J_{j c}}{\sum_{j^{\prime} \in S} J_{j^{\prime} c}}$, where $J_{j c}$ denotes the total number of existing positions in job $j$ and city $c$. In steady state, the number of positions that are destroyed equals the number of matches such that

$$
\delta E R_{c}=M\left(\left(1-E R_{c}\right),\left(\frac{J_{c}}{L_{c}}-E R_{c}\right)\right)=\left(1-E R_{c}\right)^{\sigma}\left(\frac{J_{c}}{L_{c}}-E R_{c}\right)^{1-\sigma}
$$

where $\sigma$ is the coefficient of the Cobb-Douglas matching function.

Given the matching function, the probability that an unemployed worker meets any vacancy is given by $\psi_{c}=\frac{M_{c}}{L_{c}-N_{c}}$, or in steady state, $\psi_{c}=\frac{\delta E R_{c}}{1-E R_{c}}$. Then, the probability that the vacancy is from a particular job type is determined by $\eta_{j c}$, the proportion of employment accounted for by that type in the local economy. Finally, whether workers actually fulfil the match is based on their ability to transfer skills across jobs. Workers' skill transferability from job $j$ to $k$ is captured by the measure $\varphi_{k \mid j} \in[0,1]$, where $k$ indexes the destination job cell. This measure is zero if the cost of transfering skills between two jobs is prohibitive, and one if workers are perfectly mobile. Combining employment shares together with the skill transferability measure, one obtains the probability that a worker previously employed in $j$ (e.g. as a secretary in the automobile industry) finds a job in $k$ (e.g. as a legal assistant in the tertiary sector) in city $c$. This transition probability is given by 


$$
\psi_{k c \mid j}= \begin{cases}\mu & \text { if } k=j \\ (1-\mu) \chi_{k c \mid j} \eta_{k c} & \text { if } k \in S \backslash\{j\},\end{cases}
$$

where $\mu$ denotes the probability that a worker previously employed in $j$ is re-employed in the same occupation and industry and

$$
\chi_{k c \mid j}=\frac{\varphi_{k \mid j}}{\sum_{k^{\prime} \in S \backslash\{j\}} \varphi_{k^{\prime} \mid j} \eta_{k^{\prime} c}}
$$

such that $\sum_{k \in S} \psi_{k c \mid j}=1 .^{3}$ The term $\chi_{k c \mid j}$ can be interpreted as a measure of relative mobility. In the following $3 \times 2$ example, $\chi_{L T A \mid S C}$ reflects the ease with which a secretary in the car industry transfers skills to a legal assistant job in the tertiary sector, relative to moving to any other job in city $\mathrm{A}$.

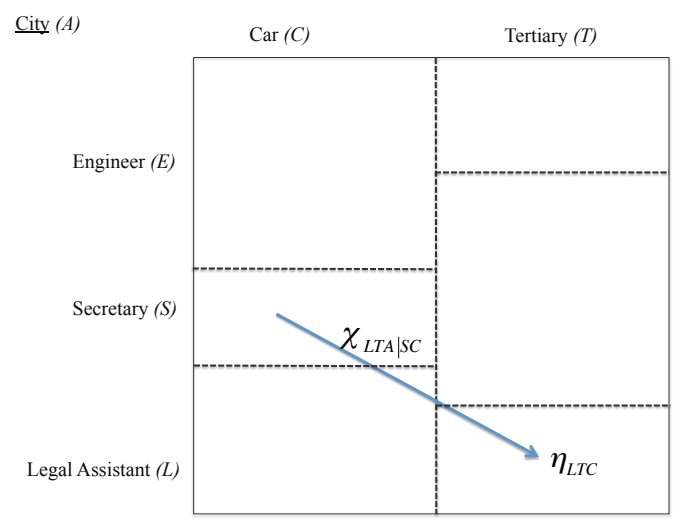

\footnotetext{
${ }^{3}$ The transition probability $\psi_{k c \mid j}$ sums to 1 because

$$
\begin{aligned}
\sum_{k \in S} \psi_{k c \mid j} & =\mu+(1-\mu) \sum_{k \in S \backslash\{j\}} \chi_{k c \mid j} \eta_{k c} \\
& =\mu+(1-\mu) \underbrace{\sum_{k \in S \backslash\{j\}} \frac{\varphi_{k \mid j}}{\sum_{k^{\prime} \in S \backslash\{j\}} \varphi_{k^{\prime} \mid j} \eta_{k^{\prime} c}} \eta_{k c}}_{=1} \\
& =\mu+(1-\mu) \\
& =1 .
\end{aligned}
$$
}


When workers are homogeneous and thus identically mobile across jobs (i.e. when $\varphi_{k \mid j}=\varphi$ ), the (conditional) probability of finding a job equals the proportion of vacancies for that particular job $\left(\psi_{k c \mid j}=\eta_{k c}\right)$. Finally, the probability that a firm fills a vacancy is given by $\phi_{c}=\frac{M_{c}}{J_{c}-N_{c}}$. In steady state, this probability is given by $\phi_{c}=\left(\frac{1-E R_{c}}{\delta E R_{c}}\right)^{\frac{\sigma}{1-\sigma}}$.

\subsection{Wage determination}

Let $V_{j c}^{f}(n)$ and $V_{j c}^{v}(n)$ be the discounted value to a firm with managerial ability $n$ of a filled position and a vacancy in job $j$ and city $c$, respectively, and the difference between both values be the match surplus for the firm. Let $U_{j c}^{e}(n)$ and $U_{j c}^{u}(n)$ be the discounted value to a worker (in a firm with managerial ability $n$ ) of being employed and unemployed in job $j$ and city $c$, respectively, and the difference between both values be the match surplus for the worker. Wages are set by Nash bargaining with disagreement points $V_{j c}^{v}(n)$ and $U_{j c}^{u}(n)$ for firms and workers, respectively

$$
\left[V_{j c}^{f}(n)-V_{j c}^{v}(n)\right]=\left[U_{j c}^{e}(n)-U_{j c}^{u}(n)\right] \kappa
$$

where $\kappa$ is the relative bargaining power of firms and workers. To understand the nature of the wage equation, it is useful to write down the Bellman equations. Step-by-step details on how the following equations are derived can be found in Appendix A of the Supplementary Material.

Let $V M P L_{j c}(n)$ be the value of the marginal product of labour in job $j$, city $c$ and in a firm with managerial ability $n$. If a position is filled, it generates a flow of profits of $\left[\operatorname{VMP} L_{j c}(n)-w_{j c}(n)\right]$, where $w_{j c}(n)$ is the wage in job $j$, city $c$ and firm with managerial ability $n$. The probability of a worker being laid off in the subsequent period and the position becoming vacant is $\delta$. Thus, the discounted value to a firm of a filled position is given by

$$
\rho V_{j c}^{f}(n)=\left[V M P L_{j c}(n)-w_{j c}(n)\right]-\delta\left[V_{j c}^{f}(n)-V_{j c}^{v}(n)\right]
$$

The probability of the vacancy being filled in the following period is $\phi_{c} \cdot{ }^{4}$ Hence, the discounted value to a firm of a vacancy is

$$
\rho V_{j c}^{v}(n)=\phi_{c}\left[V_{j c}^{f}(n)-V_{j c}^{v}(n)\right] .
$$

\footnotetext{
${ }^{4}$ For simplicity, assume that if a firm does not fill a job, there is no cost to maintain the position.
} 
Combining equations (3) and (4), the match surplus for the firm can be written as

$$
V_{j c}^{f}(n)-V_{j c}^{v}(n)=\frac{V M P L_{j c}(n)-w_{j c}(n)}{\rho+\delta+\psi_{c}}
$$

An employed worker in job $j$, city $c$ and firm with managerial ability $n$ receives the wage $w_{j c}(n)$ and is laid off with probability $\delta$ in the next period. ${ }^{5}$ Therefore, the discounted value to a worker of being employed is

$$
\rho U_{j c}^{e}(n)=w_{j c}(n)-\delta\left[U_{j c}^{e}(n)-U_{j c}^{u}(n)\right]
$$

The probability of an unemployed worker previously employed in $j c$ being matched to job $k$ in city $c$ is $\psi_{c} \psi_{k c \mid j}$. The probability of him or her remaining unemployed in the coming period is $\left(1-\psi_{c}\right)$. Thus, the discounted value of being unemployed is given by

$$
\rho U_{j c}^{u}(n)=\psi_{c} \sum_{k \in S} \psi_{k c \mid j} U_{k c}^{e}-\psi_{c} U_{j c}^{u}(n)
$$

where $U_{k c}^{e}$ is the average discounted utility of employment in job $k$ and city $c$, averaged over all firms that operate in city $c$. This paper assumes that if an unemployed worker is matched to a particular job, then he or she develops skills which are identical to those of his co-workers, which means that the measures of relative mobility satisfy $\chi_{k^{\prime} c \mid k} \chi_{k c \mid j}=\chi_{k^{\prime} c \mid j}$. This assumption implies that the summation term can be rewritten as follows

$$
\sum_{k \in S} \psi_{k c \mid j} U_{k c}^{e}=\frac{\rho+\psi_{c}}{\rho\left(\rho+\delta+\psi_{c}\right)} \sum_{k \in S} \psi_{k c \mid j} w_{k c}
$$

where $w_{k c}$ is the wage offered in job $k$ and city $c$, averaged over all firms that operate in city $c$. Combining equations (6), (7) and (8), the match surplus for a worker is given by

$$
U_{j c}^{e}(n)-U_{j c}^{u}=\frac{1}{\rho+\delta} w_{j c}(n)-\frac{\psi_{c}}{(\rho+\delta)\left(\rho+\delta+\psi_{c}\right)} \sum_{k \in S} \psi_{k c \mid j} w_{k c}
$$

The match surplus for a worker is a decreasing function of workers' outside options in other jobs of

\footnotetext{
${ }^{5}$ For clarity, any relevant city-specific features such as amenities and unemployment benefits are normalised to zero. Local amenities and unemployment benefits are captured by an entire set of city time-varying dummies in the empirical section.
} 
the city's economy. For example, if the probability to be matched to high-wage jobs increases (either because of a greater concentration of employment in high-wage jobs or because the mobility cost to access high-wage jobs decreases), then the value of a match in job $j$ relative to unemployment decreases.

Substituting the expressions (5) and (9) into (2), and solving for the wage offered in a firm with managerial ability $n$, one obtains

$$
w_{j c}(n)=\gamma_{1 c} V M P L_{j c}(n)+\gamma_{2 c} \sum_{k \in S} \psi_{k c \mid j} w_{k c}
$$

where $\gamma_{1 c}=\frac{(\rho+\delta)}{(\rho+\delta)+\kappa\left(\rho+\delta+\phi_{c}\right)} \in(0,1)$ and $\gamma_{2 c}=\frac{\kappa\left(\rho+\delta+\phi_{c}\right)}{(\rho+\delta)+\kappa\left(\rho+\delta+\phi_{c}\right)} \frac{\psi_{c}}{\left(\rho+\delta+\psi_{c}\right)}>0$. The parameters $\gamma_{1 c}$ and $\gamma_{2 c}$ are functions of three exogeneous parameters: the discount rate $\rho$, the rate at which layoffs occur $\delta$ and $\kappa$, the relative bargaining position of workers and firms. $\gamma_{1 c}$ and $\gamma_{2 c}$ also depend on the local employment rate $E R_{c}$, as captured by $\psi_{c}$, the probability that an unemployed worker meets any vacancy, and by $\phi_{c}$, the probability that a firm fills a vacancy in city $c$.

Averaging (10) over all firms which operate in the market in city $c$, one obtains the following expression for the wage in job $j$ and city $c$,

$$
w_{j c}=\gamma_{1 c} V M P L_{j c}+\gamma_{2 c} \sum_{k \in S} \psi_{k c \mid j} w_{k c}
$$

where $V M P L_{j c}$ is the value of the marginal product of labour in job $j$ and city $c$. In order to avoid estimating a tautological relationship, the wage in job $j$ and city $c$ can be expressed as a function of wages in alternate jobs only. Using (1) and solving for $w_{j c}$, one obtains

$$
w_{j c}=\tilde{\gamma}_{1 c} V M P L_{j c}+\tilde{\gamma}_{2 c} \sum_{k \in S \backslash\{j\}} \psi_{k c \mid j} w_{k c},
$$

where $\tilde{\gamma}_{1 c}=\frac{\gamma_{1 c}}{1-\gamma_{2 c} \mu}$ and $\tilde{\gamma}_{2 c}=\frac{\gamma_{2 c}(1-\mu)}{1-\gamma_{2 c} \mu}$. The parameters $\tilde{\gamma}_{1 c}$ and $\tilde{\gamma}_{2 c}$ are functions of the city-specific employment rate, as captured by $\gamma_{1 c}$ and $\gamma_{2 c}$.

Equation (12) has the form of a reflection problem (Manski, 1993; Moffitt, 2001; Beaudry et al., 2012) in which job-city-specific wages are determined by some fraction of the value of the marginal product of labour and by a weighted average of wages in alternate jobs. This weighted average 
derives from the discounted utility of unemployment and reflects workers' outside options.

On top of differences in the marginal product of labour, this equation highlights two sources of wage disparities: differences in the local structure of employment $\left(\eta_{k c}\right)$, and differences in jobspecific skill transferability $\left(\chi_{k c \mid j}\right)$, as captured by the transition probability $\left(\psi_{k c \mid j}\right)$. The first implies spatial variation in wages; cities whose employment is skewed towards high-paying jobs tend to pay higher wages in all jobs since a larger proportion of good jobs translates into better outside options. The second source results in industrial and occupational wage differentials; jobs whose skill transferability is skewed towards high-paying jobs will pay higher wages as easier access to good jobs translates into better outside options.

It is worth noting that the coefficient $\tilde{\gamma}_{2 c}$ only captures the first-round effect of a one-unit shift in workers' outside options. Imagine that a secretary can switch to a legal assistant job and that a legal assistant can become a lawyer, but that a secretary cannot directly become a lawyer. Further suppose that, everything else being equal, the wage for lawyers goes up and translates into a oneunit increase in the outside options of legal assistants. Equation (12) indicates that legal assistants' wages would first increase by $\tilde{\gamma}_{2 c}$. Due to the feedback dynamics inherent to the wage equation, this first-round effect modifies the outside options of workers who can directly switch to legal assistant jobs, therefore generating additional rounds of wage adjustment. The way feedback dynamics multiply themselves out depends on workers' mobility; for instance, in the case of secretaries who can only switch to legal assistant jobs, lawyers' wages enter the wage determination of secretaries only indirectly, as second-round impacts and beyond, through changes in legal assistants' wages. Most of the paper is devoted to the identification of the partial impacts of a shift in workers' outside options. In Section 6, the paper derives an expression for the total impacts.

\section{Towards identifying independent search and bargaining effects}

Identifying independent search and bargaining effects appears difficult mainly because the value of the marginal product of labour is both unobserved and correlated with workers' outside options.

To give a sense of why identification may still be possible, it is useful to start with a quite extreme example. ${ }^{6}$ Consider an environment with two labour markets (cities A and B), two industries (natural resources and manufacturing) and two occupations (white and blue collar workers). The

\footnotetext{
${ }^{6}$ The author thanks an anonymous referee for this example.
} 
natural resources industry is located in city A and employs blue collar workers only. Assume that the price of natural resources goes up and that following this increase, wages of blue collar workers increase in both the natural resources sector and the manufacturing industry in city $\mathrm{A}$, but that no other wage or employment changes are observed whatsoever.

Could the increase in wages of blue collar workers in the manufacturing industry in city A reflect an increase in the value of the marginal product? In this particular environment, it is hard to present any pathway in which the value of the marginal product would go up for blue collar workers in the manufacturing sector in city A but not for white collar workers. For instance, if the shock to natural resources had caused a shift in productivity in the manufacturing sector (perhaps because natural resources are used as inputs in the production of manufactured goods), one would have expected wages of both white and blue collar workers to increase in both cities. Therefore, given that no labour movements are observed anywhere and that wages for white collar workers do not change, one is led to conclude that the increase in wages of blue collar workers in the manufacturing industry in city A reflects independent effects of an improvement in workers' outside options and not a shift in labour demand in the manufacturing industry.

Although this example is extreme, this logic of comparing changes in wages "within an industrycity" and "across cities" can be extended to the case in which one observes some labour movements. Imagine for instance that, following the increase in the price of natural resources, blue collar workers in city A reallocate from the manufacturing industry to the natural resources sector. In this case, the increase in wages of blue collar workers in the manufacturing industry in city A cannot be entirely attributed to search and bargaining effects because the reallocation towards the natural resources sector modifies the industrial composition in city A, which in turn affects the weights used to calculate the outside options of blue collar workers. However, independent effects of workers' outside options can still be identified as long as one uses an instrumental variable strategy to isolate changes in blue collar workers' outside options that are uncorrelated with labour movements in city A. One possible strategy would consist in using a Bartik-style instrument, i.e. in predicting changes in workers' outside options using industrial employment growth at the national level. The observed changes in wages of blue collar workers in the manufacturing sector in city A could then be attributed to changes in their predicted outside options.

In subsection 3.1, the paper formalises this example and adopts a quite general formulation of 
technology to show how observational data can be used to identify independent effects of workers' outside options. The subsection then discusses the empirical implications of imposing more restrictive assumptions on the production function. Subsection 3.2 presents instruments that deal with both the feedback dynamics of wages and the endogeneity of the transition probabilities.

\subsection{Placing restrictions on the production function}

In what follows, the paper uses an occupation-industry notation whenever necessary for clarity and uses the subscript $q i$ to denote the job that refers to occupation $q$ and industry $i$. Using this notation, equation (12) rewrites

$$
w_{q i c}=\tilde{\gamma}_{1 c} V M P L_{q i c}+\tilde{\gamma}_{2 c} \sum_{k \in S \backslash\{q i\}} \psi_{k c \mid q i} w_{k c}
$$

where $w_{q i c}$ is the wage in job $q i$ and city $c, V M P L_{q i c}$ is the value of the marginal product of labour in job $q i$ and city $c$ and $\psi_{k c \mid q i}$ is the transition probability from job $q i$ to job $k$ in city $c$.

The production function in industry $i$ and city $c$ takes the following form

$$
Y_{i c}=F_{i c}\left(\theta_{1 i c} N_{1 i c}, \ldots, \theta_{q i c} N_{q i c}, \ldots, \theta_{Q i c} N_{Q i c}\right),
$$

where $\theta_{q i c}$ is a productive term associated to job $q i$ in city $c, N_{q i c}$ is employment in job $q i$ and city $c$, and where $F_{i c}(\cdot)$ is of the CES form. Note that all the components of the production function are allowed to vary over time. For clarity, the time subscript is omitted until necessary. The productive term $\theta_{\text {qic }}$ has both a national job-specific effect and a local job-specific effect; in particular, $\theta_{q i c}=\theta_{q i}+\varepsilon_{q i c}$, where $\varepsilon_{q i c}$ is a source of comparative advantage of city $c$ for job $q i$, and where by definition $\sum_{c} \varepsilon_{q i c}=0$. A key assumption for the identification strategy is that, while there is no restriction on the national component $\theta_{q i}$, the local job-specific effect $\varepsilon_{q i c}$ is well approximated by a random walk.

This formulation of technology assumes that a job is associated with a specific set of skills and entirely characterises a worker's type, which means that in a particular job-city cell, workers with the same set of individual characteristics (e.g. age, nationality, gender, education) all share the same productivity. Subsection 5.3 explores the limitations of such an assumption by allowing productive terms to depend upon previous job. 
The marginal product of labour in job qi and city $c$ that follows from (14) can be written as

$$
M P L_{q i c}=f_{i c}\left(\theta_{1 i c} N_{1 i c}, \ldots, \theta_{q i c} N_{q i c}, \ldots, \theta_{Q i c} N_{Q i c}\right) \cdot g_{q i c}\left(\theta_{q i c}\right) \cdot h_{q i c}\left(N_{q i c}\right),
$$

where $f_{i c}\left(\theta_{1 i c} N_{1 i c}, \ldots, \theta_{q i c} N_{q i c}, \ldots, \theta_{Q i c} N_{Q i c}\right)$ is an industry-city-specific aggregate that depends on the composition of employment in industry $i$ and city $c, g_{q i c}\left(\theta_{\text {qic }}\right)$ is a component that depends on the job-city-specific productive term and where $h_{q i c}\left(N_{q i c}\right)$ is a function of job-city-specific employment. If, for instance, the production function in industry $i$ and city $c$ is a CES of the form $Y_{i c}=$ $\left[\sum_{q=1}^{Q} \theta_{q i c} N_{q i c}^{\gamma}\right]^{\frac{1}{\gamma}}$, where $\gamma \leq 1$, then the components of the marginal product of labour for $q i$ are given by $f_{i c}=\left[\sum_{q=1}^{Q} \theta_{q i c} N_{q i c}^{\gamma}\right]^{\frac{1-\gamma}{\gamma}}, g_{q i c}=\theta_{q i c}$ and $h_{q i c}=N_{q i c}^{\gamma-1}$. In the limiting case where factors are perfect substitutes (i.e. when $\gamma=1$ ), the marginal product of labour is constant and given by $g_{q i c}=\theta_{q i c}\left(\right.$ as $\left.f_{i c}=h_{q i c}=1\right)$.

In order to make the relationship between job-city wages, a city's employment rate and the components of the value of the marginal product explicit, the paper performs a first-order log linear approximation of equation (13). The log linear approximation is taken around the point where cities have identical employment rates $\left(E R_{c}=E R\right)$ and where employment is uniformly distributed across jobs $\left(\eta_{q i c}=\frac{1}{Q I}\right)$, which occurs when both the value of the marginal product of labour and mobility costs are constant across jobs and cities (i.e. $V M P L_{q i c}=V M P L$ and $\varphi_{k \mid q i}=\varphi$, where $k$ is the destination job). Derivation details can be found in Appendix B of the Supplementary Material. Expressing the wage equation as the first difference between two steady state equilibria, one obtains

$$
\begin{aligned}
\Delta \ln w_{q i c \tau} & =\tilde{\gamma}_{1} \alpha_{1} \Delta p_{i c \tau}+\tilde{\gamma}_{1} \alpha_{2} \Delta f_{i c \tau}+\tilde{\gamma}_{1} \alpha_{3} \Delta \theta_{q i \tau}+\tilde{\gamma}_{1} \alpha_{4} \Delta \ln N_{q i c \tau} \\
& +\tilde{\gamma}_{2} \Delta \sum_{k \in S \backslash\{q i\}} \psi_{k c \tau \mid q i} w_{k c \tau}+\alpha_{5} \Delta E R_{c \tau}+\Delta \tilde{\xi}_{q i c \tau},
\end{aligned}
$$

where $\Delta$ denotes the time difference, $\tau$ is the time subscript and $\Delta \tilde{\xi}_{q i c \tau}=\tilde{\gamma}_{1} \alpha_{3} \Delta \varepsilon_{q i c \tau}$. Note that to reduce measurement errors, the paper averages annual data over five years, taking mutually exclusive and jointly exhaustive intervals. ${ }^{7} \tilde{\gamma}_{1}$ and $\tilde{\gamma}_{2}$ correspond to $\tilde{\gamma}_{1 c}$ and $\tilde{\gamma}_{2 c}$ evaluated at the point where cities have an identical structure of employment and $\alpha_{0}-\alpha_{5}$ are constant terms obtained

\footnotetext{
${ }^{7}$ Appendix K-7 of the Supplementary Material shows that using alternative time frames does not affect the baseline estimates.
} 
from the linear approximation. The coefficients $\tilde{\gamma}_{1} \alpha_{1}$ to $\tilde{\gamma}_{1} \alpha_{4}$ capture the effects associated with each of the components of the value of the marginal product of labour. $\tilde{\gamma}_{2}$ is the coefficient of interest and captures the importance of search and bargaining mechanisms in wage determination.

It is important to note that in this framework, whichever restrictions are placed on the production function, $\varepsilon_{q i c \tau}$, the unobserved local job-specific component of the productive factor, will always be part of the error term. In what follows, the paper examines whether $\tilde{\gamma}_{2}$ can actually be identified, assuming first that any endogeneity issue resulting from the correlation between measured workers' outside options and the unobservable term $\Delta \tilde{\xi}_{\text {qic } \tau}$ can appropriately be tackled with an instrumental variable strategy. The instruments are discussed in the next subsection.

Equation (16) suggests that the proper approach for the identification of $\tilde{\gamma}_{2}$ depends on three factors: (1) whether industrial prices include a local component, (2) the specific restrictions placed on technology and (3) how mobile workers are across jobs. The last dimension determines how wages offered in alternate jobs enter the wage determination process and whether workers' outside options are better represented using transition probabilities or employment shares to weigh wages in alternate jobs. When workers are identically mobile across jobs, then $\chi_{k c \tau \mid q i}=1$ and the measure of workers' outside options becomes $\sum_{k \in S} \eta_{k c \tau} w_{k c \tau}$, the city-specific average wage. Whether workers' outside options are job-city-specific or city-specific is critical for the identification strategy because it affects the type of variation that can be used in the data to identify $\tilde{\gamma}_{2}$.

When workers face heterogeneous mobility costs, "within job across cities" and "within industrycity across jobs" data variation can be used, making identification possible with practically any price and technology encompassed by specification (14). Consider the case in which the production function in industry $i$ and city $c$ is a CES with $\gamma \leq 1$. Then, the effect of $f_{i c \tau}$ can be captured by an entire set of industry-city-specific time-varying dummies and the impact of $\theta_{\text {qi }}$ can be controlled for using job-specific time-varying dummies. In such a case, the parameter of interest is identified by estimating

$$
\Delta \ln w_{q i c \tau}=\Delta d_{i c \tau}+\Delta d_{q i \tau}+\tilde{\gamma}_{1} \alpha_{4} \Delta \ln N_{q i c \tau}+\tilde{\gamma}_{2} \Delta \sum_{k \in S \backslash\{q i\}} \psi_{k c \tau \mid q i} w_{k c \tau}+\Delta \tilde{\xi}_{q i c \tau}
$$

where $d$ denotes a set of dummy variables. With this production function, whether industrial prices include a local component or not is irrelevant as price effects will be absorbed by $d_{i c \tau}$. It is worth 
noting that, since $d_{i c \tau}$ also captures city-time effects, equation (17) no longer has the term $E R_{c \tau}$ in an explicit form. The inclusion of both job-specific and industry-city-specific time-varying dummies implies a triple difference estimation to correct wage movements for changes in the marginal product of labour. For example, in a framework with two occupations, two industries and two cities, this is equivalent to the following: taking the difference between periodical changes in wages for blue collar workers in the manufacturing sector in city A and the equivalent wage variation for white collars, then calculating the difference between that change and its counterpart in city B, and finally estimating the importance of workers' outside options in explaining the residual wage variation.

The first difference (within city, across jobs, as captured by $d_{i c \tau}$ ) also removes any local and local industry-specific factors that the model does not capture but that may interfere with inferences. These factors include effects associated with changes in city-specific employment rate, house prices, non-tradable goods across cites, input-output linkages, local demand, the German Confederation of Trade Unions, and other local forces that may contribute to the growth of cities such as, for instance, education externalities (Acemoglu and Angrist, 2000; Moretti, 2004), employment diversity, agglomeration effects or local house prices effects (Blanchard and Katz, 1992; Glaeser et al., 1992; Glaeser and Gottlieb, 2009; Moretti, 2011). The second difference (within job across cities) purges job-city-specific periodical differences in wages from national-level movements in occupation and industry factors.

In the limiting case where factors are perfect substitutes, equation (16) becomes

$$
\Delta \ln w_{q i c \tau}=\tilde{\gamma}_{1} \alpha_{1} \Delta p_{i c \tau}+\tilde{\gamma}_{1} \alpha_{3} \Delta \theta_{q i \tau}+\tilde{\gamma}_{2} \Delta \sum_{k \in S \backslash\{q i\}} \psi_{k c \tau \mid q i} w_{k c \tau}+\alpha_{5} \Delta E R_{c \tau}+\Delta \tilde{\xi}_{q i c \tau}
$$

and whether one should include industry-city-time dummies on top of job-time dummies depends on the assumption placed on industrial prices. If industrial prices are invariant across cities, then $\tilde{\gamma}_{2}$ is identified by estimating

$$
\Delta \ln w_{q i c \tau}=\Delta d_{q i \tau}+\tilde{\gamma}_{2} \Delta \sum_{k \in S \backslash\{q i\}} \psi_{k c \tau \mid q i} w_{k c \tau}+\alpha_{5} \Delta E R_{c \tau}+\Delta \tilde{\xi}_{q i c \tau}
$$


or, controlling for a wider range of local time-varying factors,

$$
\Delta \ln w_{q i c \tau}=\Delta d_{c \tau}+\Delta d_{q i \tau}+\tilde{\gamma}_{2} \Delta \sum_{k \in S \backslash\{q i\}} \psi_{k c \tau \mid q i} w_{k c \tau}+\Delta \tilde{\xi}_{q i c \tau}
$$

where $d_{c \tau}$ denotes a city time-varying set of dummies.

When mobility costs are constant across jobs, the identifying variation can only come from "within job across cities" data variation as any set of city time-varying or industry-city timevarying dummies would be colinear to measured outside options. In other words, when mobility costs are constant, wage disparities generated from search and bargaining mechanisms stem from local differences only and can, by construction, hardly be distinguished from those resulting from standard general equilibrium local forces. For this reason, identification is only possible if the marginal product of labour is constant and if prices vary across industries only. This particular case would lead to the estimation of the following wage equation

$$
\Delta \ln w_{q i c \tau}=\Delta d_{q i \tau}+\tilde{\gamma}_{2} \Delta \sum_{k \in S} \eta_{k c \tau} w_{k c \tau}+\alpha_{5} \Delta E R_{c \tau}+\Delta \tilde{\xi}_{q i c \tau}
$$

Within the set of technologies encompassed by (14), all other cases produce a biased estimate of $\tilde{\gamma}_{2}$.

The most recent approach to identifying search and bargaining mechanisms has been suggested by Beaudry et al. (2012) and corresponds to the special case for which technology has perfectly substitutable factors and workers' mobility is homogeneous across any pair of jobs. Thus, without extending the analysis to a more general framework, it is unclear whether Beaudry et al. (2012)'s empirical strategy confounds the effects of changes in outside options with those resulting from changes in the value of marginal productivity.

The following figure summarizes the conditions under which the parameter $\tilde{\gamma}_{2}$ can be identified. As Figure 1 indicates, controlling for more flexible formulations of the value of the marginal product of labour is impossible when differences in mobility across jobs are unimportant for measuring outside options. Therefore, when presenting results, this paper starts from the most restrictive case, showing first that those mobility differences matter for wage formation, and then moves towards the most general case. 
Figure 1: Prices, technology and mobility restrictions

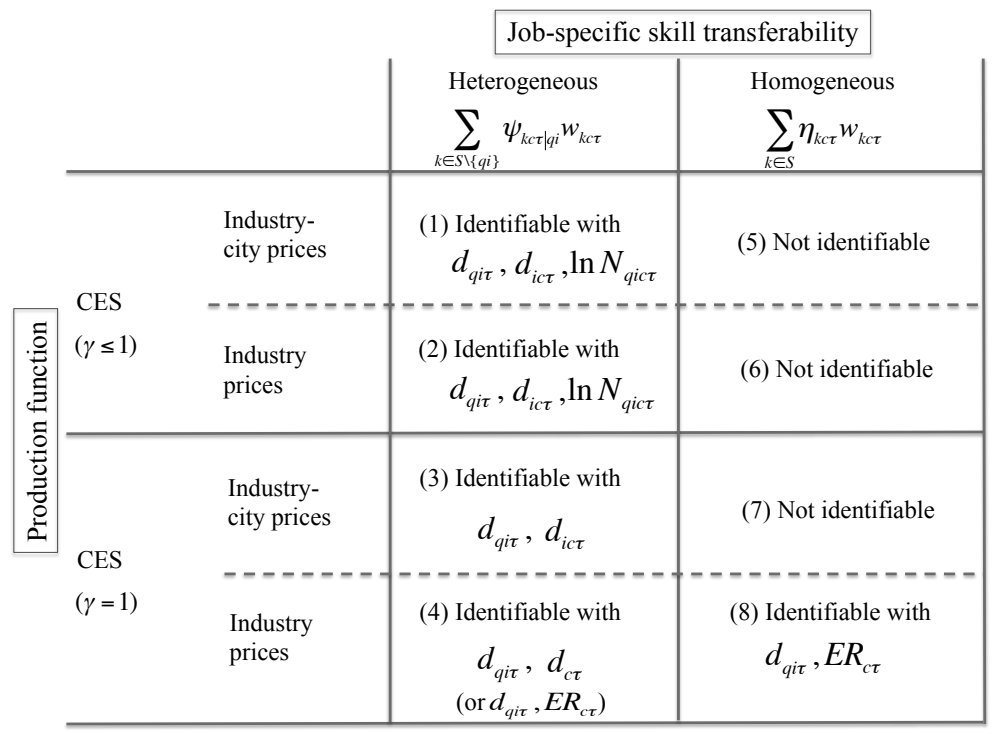

\subsection{The endogeneity of the outside options of workers}

This subsection discusses how the paper deals with the endogeneity issue that results from the feedback dynamics of wages and from the correlation between both the transition probabilities and the unobservable job-city-specific time-varying component $\varepsilon_{q i c \tau}$, left in the error term. The treatment of this issue is completely symmetric to that of Beaudry et al. (2012). ${ }^{8}$

\section{Job creation and transition probabilities}

To clarify the link between the transition probabilities and the error term, it is useful to first set up the equation that determines the number of positions that are created in a particular job and city. The time subscript is omitted where possible henceforth. Job creation is determined by a free entry condition whereby individuals with expected payoffs larger than the fixed entry cost $K$ become entrepreneurs. Thus, the total number of positions that are created in job $q i$ and city $c$ is

\footnotetext{
${ }^{8}$ For further derivation details, see Beaudry et al. (2012).
} 
given by

$$
J_{q i c}=L_{c} \Omega_{i c} \int_{n_{i c}^{*}}^{\infty} J_{q i c}(n) f(n) d n
$$

where $J_{q i c}(n)$ denotes the number of positions in job qi, city $c$ and firm with managerial ability $n$ and where the cutoff $n_{i c}^{*}$ satisfies $\sum_{q=1}^{Q} J_{q i c}\left(n_{i c}^{*}\right) V_{q i c}^{v}\left(n_{i c}^{*}\right)=K$.

Using equation (22), the transition probability from job $q i$ to job $q^{\prime} i^{\prime}$ in city $c$ can be written as

$$
\psi_{q^{\prime} i^{\prime} c \mid q i}=\frac{\varphi_{q^{\prime} i^{\prime} \mid q i} J_{q^{\prime} i^{\prime} c}}{\sum_{r=1}^{Q} \sum_{s=1}^{I} \varphi_{r s \mid q i} J_{r s c}-\varphi_{q i \mid q i} J_{q i c}},
$$

where $r$ indexes an occupation and $s$ is an industry subscript. Taking a linear approximation around the point where cities have identical employment rates and a similar employment structure, the transition probability can be rewritten as a function of current $\varepsilon \mathrm{s}$ and $\Omega \mathrm{s}$, the sources of comparative advantage of city $c$. That is,

$$
\begin{aligned}
\psi_{q^{\prime} i^{\prime} c \mid q i} & \approx \frac{1}{Q I-1}+\pi_{1}\left[\Omega_{i^{\prime} c}-\frac{1}{Q I-1}\left(Q I \cdot \Omega_{c}-\Omega_{i c}\right)\right] \\
& +\pi_{2}\left[\varepsilon_{q^{\prime} i^{\prime} c}-\frac{1}{Q I-1}\left(Q I \cdot \varepsilon_{c}-\varepsilon_{q i c}\right)\right]+\pi_{3}\left[\varphi_{q^{\prime} i^{\prime} \mid q i}-\frac{1}{Q I-1}\left(1-\varphi_{q i \mid q i}\right)\right],
\end{aligned}
$$

where $\Omega_{c}=\sum_{s=1}^{I} \Omega_{s c}, \varepsilon_{c}=\sum_{r=1}^{Q} \sum_{s=1}^{I} \varepsilon_{r s c}$ and $\pi_{1}-\pi_{3}$ are positive terms obtained from the linear approximation. The first three components are associated with the job-city-specific employment share $\eta_{q^{\prime} i^{\prime} c}$. The last component reflects workers' skill transferability from job $q i$ to $q^{\prime} i^{\prime}$. Since the last term is measured at the national level, any correlation between the transition probabilities and the error term stems from the employment shares components, and more specifically, from the fact that these employment shares depend on current comparative advantages. 


\section{Instruments}

The endogeneity issue is tackled with Bartik-style instruments. The latter are constructed using a decomposition of the following term

$$
\Delta \sum_{k \in S \backslash\{q i\}} \hat{\psi}_{k c \tau \mid q i} \nu_{k \tau}
$$

where ${ }^{\wedge}$ denotes a prediction, $\hat{\psi}_{k c \tau \mid q i}=\hat{\chi}_{k c \tau \mid q i} \hat{\eta}_{k c \tau}$ and $\nu_{k \tau}$ is the nation-wide wage premium in job $k$ relative to some numeraire job. This measure reflects predicted workers' outside options and weights each national job wage premium with the corresponding predicted job-city-specific transition probability. The terms $\hat{\chi}_{k c \tau \mid q i}$ and $\hat{\eta}_{k c \tau}$ are constructed using predicted employment, i.e. the level of employment that would be observed if start-of-period employment had grown according to the national trend. Specifically, predicted employment in job $k$, city $c$ and time $\tau$ is computed as

$$
\hat{N}_{k c \tau}=N_{k c(\tau-1)} \frac{N_{k \tau}}{N_{k(\tau-1)}},
$$

such that $\hat{N}_{c \tau}=\sum_{k \in S} \hat{N}_{k c \tau}, \hat{\eta}_{k c \tau}=\frac{\hat{N}_{k c \tau}}{\hat{N}_{c \tau}}$ and $\hat{\chi}_{k c \tau \mid q i}=\frac{\varphi_{k \mid q i}}{\sum_{k^{\prime} \in S \backslash\{q i\}} \varphi_{k^{\prime} \mid q i} \hat{\eta}_{k^{\prime} c \tau}} .9$

Since the main identifying variation is across cities and national wage premia do not vary across cities, one only needs to be concerned about the condition under which predicted employment shares are uncorrelated with the error term. This condition is met if the term $\varepsilon_{q i c \tau}$ (left in the error term) follows a random walk or, in other terms, if shocks to $\varepsilon_{q i c \tau}$ are uncorrelated with the sources of start-of-period job-city-specific comparative advantages. This can be seen by noting that an expression similar to (24) can be derived for predicted transition probabilities, where instead of being functions of current components, $\hat{\psi}_{k c \tau \mid q i}$ depends on past sources of comparative advantages.

The paper proposes two sets of instruments, constructed by decomposing (25) into four elements, each of them isolating a different type of data variation but valid under the exact same identifying assumption. These two sets of instruments are particularly useful for testing overidentifying restrictions. The decomposition uses the fact that, for example, the option of working as a

\footnotetext{
${ }^{9}$ The paper uses $N_{k c(\tau-1)}=\frac{1}{5} \sum_{t}^{t+4} N_{k c t}, \quad t \in(\tau-1)$ as start-of-period employment, which is akin to using the fifth lag to predict actual local employment. The choice of the base year from which the growth rate is computed trades off exogeneity against its potential to be a good predictor for employment.
} 
secretary in the car industry for a secretary in the tertiary sector in city A may change over time, either because of shifts in the wage offered to secretaries in the car industry in city A or because of changes in the probability of being hired there (as captured by the transition probability). Based on this idea, one can break equation (25) down into the following instruments. The first one,

$$
I V_{1 q i c \tau}=\sum_{k \in S \backslash\{q i\}} \hat{\psi}_{k c \tau \mid q i} \Delta \nu_{k \tau}
$$

isolates variations in workers' outside options that are due to changes in wage premia. The second instrument,

$$
I V_{2 q i c \tau}=\sum_{k \in S \backslash\{q i\}} \nu_{k(\tau-1)} \Delta \hat{\psi}_{k c \tau \mid q i}
$$

identifies changes stemming from shifts in transition probabilities. Since the probability of finding a particular job hinges on both vacancies (as captured by employment shares) and mobility costs, $I V_{2 q i c \tau}$ can be split into two further elements,

$$
I V_{3 q i c \tau}=\sum_{k \in S \backslash\{q i\}} \nu_{k(\tau-1)} \hat{\chi}_{k c(\tau-1) \mid q i} \Delta \hat{\eta}_{k c \tau},
$$

which is associated with changes in employment shares, and

$$
I V_{4 q i c \tau}=\sum_{k \in S \backslash\{q i\}} \nu_{k(\tau-1)} \hat{\eta}_{k c \tau} \Delta \hat{\chi}_{k c \tau \mid q i}
$$

which is based on changes in measures reflecting relative mobility. If the variation stemming from differences in sectoral and occupational mobility matters for wage formation, the first stage estimates on $I V_{2 q i c \tau}$ and $I V_{4 q i c \tau}$ should enter in a positive, similar and statistically significant manner. The first set of instruments will include $I V_{1 q i c \tau}$ and $I V_{2 q i c \tau}$, the second set comprises $I V_{1 q i c \tau}, I V_{3 q i c \tau}$ and $I V_{4 q i c \tau}$. When workers are identically mobile across occupations and industries (i.e. when $\varphi_{k \mid q i}=\varphi$ ), changes in workers' outside options can only stem from changes in wages or shifts in employment shares. In such a case, the set of available instruments reduces to $I V_{1 c \tau}=$ $\sum_{k \in S} \hat{\eta}_{k c \tau} \Delta \nu_{k \tau}$ and $I V_{2 c \tau}=\sum_{k \in S} \nu_{k(\tau-1)} \Delta \hat{\eta}_{k c \tau}$. Appendix E of the Supplementary Material discusses the validity of these instruments in more detail. 


\section{Empirical setting}

\subsection{The German labour market since 1980}

Traditionally, West German firms conformed to collective sectoral agreements that were negotiated between employer associations and large unions. Although the labour market was heavily centralised, firms were allowed by law to negotiate workplace-specific contracts or to opt out of collective agreements. Since 1990, Germany experienced a falling coverage of sectoral agreements and an increase adoption of opt-clauses. For instance, Card et al. (2013) document that the fraction of West German workers whose wages are set outside the sectoral agreements system rose from $27 \%$ in 1995 to $44 \%$ in 2007. Hassel and Rehder (2001) report that one-half of the top firms had signed opening clauses by 2000 and that $43 \%$ of their employees were affected by these pacts. This shift towards a more decentralised labour market was likely accelerated by the re-unification and the economic integration of Germany in 1989 and by the mid-1990s and early 2000s reforms that aimed at liberalising the labour market and reducing unemployment. ${ }^{10}$

\subsection{Data source}

This paper uses the factually anonymous IAB Employment Sample (IABS) for the years 19752001. ${ }^{11}$ Data access is provided via a Scientific Use File supplied by the Research Data Centre (FDZ) of the German Federal Employment Agency (BA) at the Institute for Employment Research (IAB). IAB employment statistics cover all employees registered by the German social insurance system and subject to social insurance contributions. In 1995, the data covered $79.4 \%$ of all employed persons in West Germany; the self-employed are not covered. This paper focuses on full-time workers, as information on hours worked is not available. Information on wages captures all earnings subject to statutory social security contributions and reported at least once annually. The wage measure corresponds to daily wages. The reporting of income is truncated from above and from below. The upper limit is the contribution assessment ceiling for social insurance, which

\footnotetext{
${ }^{10}$ The major reforms that took place were the 1996 labour Law Act for Promotion of Employment, the 1998 Minimum Wage for Construction Workers, and the Hartz Reforms between 2003 and 2005.

${ }^{11}$ The term "factually anonymous" means that personal information has been "depersonalised", i.e. that "information concerning personal or material circumstances can no longer or only with a disproportionate amount of time, expense and labour be attributed to an identified or identifiable individual" (section 3[7] of the Federal Data Protection Act).
} 
is adapted annually to the growth of nominal wages, and the lower limit is the minimum wage. ${ }^{12}$ The Scientific Use File provides a $2 \%$ anonymous sample of the original IAB employment database. Over the entire sample period, a $2 \%$ representative sample is drawn from four clusters, namely German nationals, foreign nationals, West German residents and East German residents. With data on East Germany available only from 1991 onwards, this study concentrates on West German residents, aged 16 to 62, over the period 1977-2001. The paper uses 19 geographical areas, "cities", built according to Kropp and Schwengler's (2011) definition of labour markets. The analysis uses 16 industries and 32 occupations (and a combination of 135 occupation-industry cells), classified according to the 1973 3-digit German classification of economic activities and the 1975 German classification of occupations, respectively. ${ }^{13}$

\subsection{Wages adjusted for workers' characteristics}

The main results are based on a common two-stage approach, which allows for individual observable characteristics to be controlled for. The second stage estimates the relationship of interest. The first stage consists of purging individual wages from components which are associated with age, gender, nationality or education, using a series of Mincer-type regressions.

For each year, log individual wages are regressed on a vector of individual characteristics and a complete set of occupation-industry-city interaction terms. Individual wages are expressed in euros and converted into real wages using the consumer price index, base 2005, provided by the German federal statistical office. The vector of individual characteristics includes age, the square of age, a gender dummy, a nationality dummy, a categorical variable for education and a full set of educationgender, education-nationality and education-age interactions. ${ }^{14}$ In performing yearly regressions, returns to skill are allowed to vary over time. The dependent variable $w_{\text {qic }}$ is constructed using five-year averages of the coefficients on the job-city dummies. As for the wage premia, the same approach is used: log individual wages are regressed on the same vector of individual characteristics

\footnotetext{
${ }^{12}$ While the baseline estimation ignores top-coding, Appendix K-4 of the Supplementary Material shows that dealing with the top-coding issue does not alter the qualitative aspect of the results.

${ }^{13}$ Kropp and Schwengler's (2011) correspondence table between districts, labour markets and regions can be downloaded at http://www.iab.de/389/section.aspx/Publikation/k110222301. Appendices F-I of the Supplementary Material provide details regarding the definition of cities, industries and occupations. Appendix J of the Supplementary Material shows summary statistics of local industrial and occupational employment shares and suggests substantial variation in the composition of employment across cities.

${ }^{14}$ The educational variable includes six categories: without vocational training, apprenticeship, highschool with Abitur, highschool without Abitur, polytechnic, university.
} 
and a complete set of job dummies. The coefficients on the dummies are used to compute $\nu_{q i \tau}$, the job wage premia. The square root of the number of observations in each job-city cell is used to create weights for the second stage estimation.

\subsection{Skill transferability measure}

As shown by Gathmann and Schoenberg (2010), moves across similar jobs are more likely to be observed than distant switches. Accordingly, this paper proxies skill transferability using observed occupation-industry-specific transitions. In order to obtain a representative number of individuals moving across cells, the data are pooled over the entire period to construct

$$
\varphi_{k \mid q i}=\frac{N_{k \mid q i}}{\sum_{k \in S} N_{k \mid q i}}
$$

where $N_{k \mid q i}$ denote the total number of individuals switching from job qi to $k$ from one year to the next.

Table 1 shows summary statistics for sectoral mobility, defined as the fraction of individuals who report an industry different from that reported one year earlier. On average, $5.6 \%$ of individuals switch industry from one year to the next. Table 1 also reports the most and the least likely job destinations and their corresponding conditional switching probabilities (conditional on being a mover). For instance, of the workers who move out of the primary sector, $13.6 \%$ switch to public administration, while only $2.8 \%$ go into sewage and sanitation. Workers in the secondary and tertiary sectors are most likely to move within their sector and are very unlikely to switch to the primary industry.

Table 2 is the occupational counterpart of Table 1. Statistics for occupational and sectoral mobility are similar: on average, $5.7 \%$ of individuals switch occupation from one year to the next. Table 2 shows that manufacturing workers are more likley to move to jobs related to travel and transport, whereas the probability of them moving to, say, arts, creative and recreational occupations is less than 1\%. Administration- and bureaucracy-related occupations are the most probable destinations for technicians, services and professionals workers. 
Table 1: Sectoral mobility and switching probabilities

\begin{tabular}{|c|c|c|c|c|c|}
\hline \multicolumn{6}{|c|}{ Overall mobility } \\
\hline Variable & Mean & Std. Dev. & Min. & Max. & $\mathbf{N}$ \\
\hline Sectoral mobility (in \%) & 5.6 & 1.8 & 2.2 & 11.3 & 6399 \\
\hline \multicolumn{6}{|c|}{ For movers only } \\
\hline & \multicolumn{2}{|c|}{ Most likely destination } & & \multicolumn{2}{|c|}{ Least likely destination } \\
\hline $\begin{array}{l}\text { Origin } \\
\text { Industry }\end{array}$ & $\begin{array}{l}\text { Switching } \\
\text { probability }\end{array}$ & Industry & & $\begin{array}{l}\text { Switching } \\
\text { probability }\end{array}$ & Industry \\
\hline \multicolumn{6}{|l|}{ Primary sector } \\
\hline Primary sector & 13.6 & Public administration & & 2.8 & Sewage, sanitation \\
\hline \multicolumn{6}{|l|}{ Secondary sector } \\
\hline Wood, chemicals, basic metals & 15.5 & Machinery, motor vehicles & & 1.5 & Primary sector \\
\hline Machinery, motor vehicles & 19.8 & Electrical & & 1.4 & Sewage, sanitation \\
\hline Electrical & 19.8 & Machinery, motor vehicles & & 1.2 & Primary sector \\
\hline Texiles, leather & 13.6 & Electrical & & 1.1 & Primary sector \\
\hline Food, beverages, tobacco & 24.0 & Retail trade & & 1.0 & Finishing trades \\
\hline Construction trades & 13.6 & Wood, chemicals, basic metals & & 1.6 & Sewage, sanitation \\
\hline Finishing trades & 15.3 & Electrical & & 1.4 & Sewage, sanitation \\
\hline \multicolumn{6}{|l|}{ Tertiary sector } \\
\hline Wholesale & 19.8 & Retail trade & & 1.0 & Primary sector \\
\hline Retail trade & 20.8 & Wholesale & & 0.8 & Primary sector \\
\hline Transport and communications & 17.9 & Wholesale & & 1.5 & Primary sector \\
\hline Finance, insurance, real estate & 14.5 & Wholesale & & 1.4 & Primary sector \\
\hline Restauration, recreational & 17.0 & Retail trade & & 0.9 & Primary sector \\
\hline Education, health, social & 35.3 & Sewage, sanitation & & 0.6 & Primary sector \\
\hline Sewage, sanitation & 48.9 & Education, health, social & & 0.7 & Finishing trades \\
\hline Public administration & 30.3 & Education, health, social & & 1.3 & Finishing trades \\
\hline
\end{tabular}


Table 2: Occupational mobility and switching probabilities

\begin{tabular}{|c|c|c|c|c|c|}
\hline \multicolumn{6}{|c|}{ Overall mobility } \\
\hline Variable & Mean & Std. Dev. & Min. & Max. & $\mathbf{N}$ \\
\hline Occupational mobility (in \%) & 5.7 & 2.0 & 1.6 & 17.2 & 18315 \\
\hline \multicolumn{6}{|c|}{ For movers only } \\
\hline & \multicolumn{2}{|r|}{ Most likely destination } & & \multicolumn{2}{|c|}{ Least likely destination } \\
\hline $\begin{array}{l}\text { Origin } \\
\text { Occupation }\end{array}$ & $\begin{array}{l}\text { Switching } \\
\text { probability }\end{array}$ & Occupation & & $\begin{array}{l}\text { Switching } \\
\text { probability }\end{array}$ & Occupation \\
\hline \multicolumn{6}{|l|}{ Agricultural } \\
\hline Farming, forestry, gardening, fishing & 20.1 & Construction & & 0.2 & Leather goods \\
\hline \multicolumn{6}{|l|}{ Manufacturing } \\
\hline Stone, jewelery, brickwork & 23.1 & Construction & & 0.1 & Leather goods \\
\hline Glass, ceramics & 16.1 & Travel, transport & & 0.1 & Arts, creative, recreational \\
\hline Chemicals, plastics, rubber & 17.1 & Travel, transport & & 0.1 & Arts, creative, recreational \\
\hline Paper, printing & 15.9 & Travel, transport & & 0.3 & Technicians (engineers) \\
\hline Woodwork & 17.1 & Travel, transport & & 0.1 & Arts, creative, recreational \\
\hline Metalworkers, primary product & 26.7 & Skilled metal work & & 0.1 & Arts, creative, recreational \\
\hline Skilled metal work & 17.7 & Travel, transport & & 0.1 & Arts, creative, recreational \\
\hline Electrical & 21.9 & Technicians (manufacturing, science) & & 0.1 & Leather goods \\
\hline Metal assembly, installation & 17.2 & Metalworkers, primary product & & 0.1 & Arts, creative, recreational \\
\hline Textiles & 11.5 & Other services, personal, leisure services & & 0.1 & Machine operators \\
\hline Leather goods & 13.0 & Travel, transport & & 0.1 & Arts, creative, recreational \\
\hline Food, drink, tobacco & 30.3 & Other services, personal, leisure services & & 0.1 & Arts, creative, recreational \\
\hline Construction & 23.2 & Travel, transport & & 0.1 & Arts, creative, recreational \\
\hline Building & 26.7 & Construction & & 0.1 & Arts, creative, recreational \\
\hline Carpenters & 19.1 & Travel, transport & & 0.2 & Arts, creative, recreational \\
\hline Painters & 17.6 & Travel, transport & & 0.2 & Arts, creative, recreational \\
\hline Goods sorters, packagers & 19.8 & Travel, transport & & 0.1 & Arts, creative, recreational \\
\hline Assistants & 15.8 & Travel, transport & & 0.1 & Machine operators \\
\hline Machine operators & 33.9 & Construction & & 0.1 & Health services \\
\hline \multicolumn{6}{|l|}{ Technicians } \\
\hline Engineers & 45.3 & Administration, bureaucracy & & 0.1 & Woodwork \\
\hline Manufacturing, science & 33.8 & Administration, bureaucracy & & 0.1 & Woodwork \\
\hline \multicolumn{6}{|l|}{ Services, professionals } \\
\hline Buying, selling & 51.2 & Administration, bureaucracy & & 0.1 & Machine operators \\
\hline Banking, insurance, agents & 75.6 & Administration, bureaucracy & & 0.1 & Stone, jewelery, brickwork \\
\hline Arts, creative, recreational & 46.6 & Administration, bureaucracy & & 0.1 & Woodwork \\
\hline Other services, personal, leisure services & 17.0 & Administration, bureaucracy & & 0.1 & Machine operators \\
\hline Travel, transport & 23.2 & Administration, bureaucracy & & 0.2 & Leather goods \\
\hline Administration, bureaucracy & 32.3 & Buying, selling & & 0.1 & Woodwork \\
\hline Public order, safety, security & 23.0 & Administration, bureaucracy & & 0.1 & Glass, ceramics \\
\hline Health services & 34.4 & Administration, bureaucracy & & 0.1 & Machine operators \\
\hline Teaching, social employment & 34.4 & Health services & & 0.1 & Stone, jewelery, brickwork \\
\hline
\end{tabular}




\section{Results}

To make this study comparable with that of Beaudry et al. (2012), this paper first examines the importance of the treatment of mobility across occupations and industries using the most restrictive formulation of prices and technology. As it turns out, it appears that the heterogeneity in workers' mobility across jobs is an important dimension for identification. The paper then exploits the variation created by differences in job-specific skill transferability to show that as one controls for sequentially more and more flexible specifications of the production function, the importance of workers' outside options does not decrease.

\subsection{Homogeneous versus heterogeneous skill transferability}

To evaluate the importance of job-specific skill transferability in wage formation, this section compares the estimates obtained by estimating specifications (19) and (21) - cases 4 and 8 of Figure 1 , respectively.

In addition to the endogeneity issue associated with workers' outside options, estimating (19) and (21) also requires dealing with the endogeneity of local employment rates. The traditional approach to dealing with the endogeneity of the employment rate is to construct the so-called Bartik instrument, used in various studies (Blanchard and Katz, 1992; Beaudry et al., 2012). Exploiting the disaggregation at the occupational level, the Bartik instrument is given by

$$
\operatorname{Bartik}_{1 c \tau}=\sum_{k \in S} \eta_{k c(\tau-1)} \frac{\hat{N}_{k \tau}-N_{k(\tau-1)}}{N_{k(\tau-1)}} .
$$

Since (32) is based on past employment shares and predicted current employment, the identifying assumption is identical to that required to ensure the validity of the instruments for workers' outside options.

By predicting local employment growth solely, the Bartik instrument focuses on the numerator of the employment rate and neglects changes driven by shifts in the labour force. Since West Germany experienced important variations in its population (especially following the immigration wave that occured after the fall of the Iron Curtain), the Bartik instrument may perform poorly if used on its own to predict the employment rate. Presumably, limited information on unemployed workers prevented US studies from creating the labour force counterpart of the Bartik instrument. 
German data, however, allow individuals to be traced over time and therefore unemployed workers to be affiliated to a particular occupation and industry. This paper takes advantage of this source of information to create a second instrument, Bartik ${ }_{2 c \tau}$, which replaces employment in equation (32) by its corresponding labour force counterpart.

Results are shown in Table 3. Standard errors are clustered at the level of the city, thus allowing the error terms to be heteroscedastic and correlated within city. ${ }^{15}$ Each of the specifications includes a full set of time-varying occupation-industry dummies to control for changes in industry and occupation aggregates, including changes in national occupation-industry wage premia and industry-wide bargaining. Thus, the estimates rely on a comparison of periodical differences in wages within occupation-industry cells across cities. In a 2x2x2 framework, this would mean comparing periodical changes in wages for secretaries in the car industry in city A with those in city B and testing the importance of workers' outside options in explaining the residual wage variation.

\footnotetext{
${ }^{15}$ Using alternative clusterings of the data (city-time, industry or industry-time) does not alter the statistical significance of the results.
} 
Table 3: Homogeneous versus heterogeneous job-specific skill transferability

\begin{tabular}{|c|c|c|c|c|c|c|c|c|}
\hline \multirow{3}{*}{$\begin{array}{l}\text { Dependent variable } \\
\text { Regressors }\end{array}$} & \multicolumn{8}{|c|}{$\Delta \log$ wages $_{q i c \tau}$} \\
\hline & \multicolumn{2}{|c|}{ Homogeneous } & \multicolumn{3}{|c|}{ Heterogeneous } & \multicolumn{3}{|c|}{ Homo- / Heterogeneous } \\
\hline & $\begin{array}{l}(1) \\
\text { OLS }\end{array}$ & $\begin{array}{l}(2) \\
\text { IV }\end{array}$ & $\begin{array}{l}(3) \\
\text { OLS }\end{array}$ & $\begin{array}{l}(4) \\
\text { IV }\end{array}$ & $\begin{array}{l}(5) \\
\text { IV }\end{array}$ & $\begin{array}{l}(6) \\
\text { OLS }\end{array}$ & $\begin{array}{l}(7) \\
\text { IV }\end{array}$ & $\begin{array}{l}(8) \\
\text { IV }\end{array}$ \\
\hline $\begin{array}{l}\Delta \text { Outside options }{ }_{c \tau} \text { : } \\
\Delta \sum_{k \in S} \eta_{k c \tau} w_{k c \tau}\end{array}$ & $\begin{array}{l}0.728^{* * *} \\
(0.034)\end{array}$ & $\begin{array}{l}* 0.416^{* * *} \\
(0.148)\end{array}$ & & & & $\begin{array}{l}0.500^{* * *} \\
(0.065)\end{array}$ & $\begin{array}{r}*-0.113 \\
(0.230)\end{array}$ & $\begin{array}{c}-0.005 \\
(0.240)\end{array}$ \\
\hline $\begin{array}{l}\Delta \text { Outside options }{ }_{q i c \tau}: \\
\Delta \sum_{k \in S \backslash\{q i\}} \psi_{k c \tau \mid q i} w_{k c \tau}\end{array}$ & & & $\begin{array}{l}0.363^{* * *} \\
(0.033)\end{array}$ & $\begin{array}{l}0.644^{* * *} \\
(0.120)\end{array}$ & $\begin{array}{l}* 0.603^{* * *} \\
(0.108)\end{array}$ & $\begin{array}{l}0.262^{* * *} \\
(0.047)\end{array}$ & $\begin{array}{l}* 0.671^{* * *} \\
(0.158)\end{array}$ & $\begin{array}{l}0.465^{* * *} \\
(0.146)\end{array}$ \\
\hline$\Delta$ Employment rate $_{c \tau}$ & $\begin{array}{c}0.014 \\
(0.056)\end{array}$ & $\begin{array}{c}0.098 \\
(0.171)\end{array}$ & $\begin{array}{l}0.193^{* * *} \\
(0.071)\end{array}$ & $\begin{array}{c}0.129 \\
(0.080)\end{array}$ & $\begin{array}{c}0.149^{*} \\
(0.088)\end{array}$ & $\begin{array}{c}0.032 \\
(0.050)\end{array}$ & $\begin{array}{c}0.194 \\
(0.164)\end{array}$ & $\begin{array}{c}0.214 \\
(0.179)\end{array}$ \\
\hline$\Delta d_{q i \tau}$ & yes & yes & yes & yes & yes & yes & yes & yes \\
\hline \multicolumn{9}{|l|}{ First stage } \\
\hline$I V_{1 c \tau}($ for $\Delta$ wage premia $)$ & & $\begin{array}{l}1.811^{* * *} \\
(0.440)\end{array}$ & & & & & $\begin{array}{l}1.880^{* * *} \\
(0.468)\end{array}$ & $\begin{array}{l}1.890^{* * *} \\
(0.458)\end{array}$ \\
\hline$I V_{2 c \tau}$ (for $\Delta$ empl. shares) & & $\begin{array}{l}2.901^{* *} \\
(0.793)\end{array}$ & & & & & $\begin{array}{l}2.981^{* *} \\
(0.798)\end{array}$ & $\begin{array}{l}2.791^{* *} \\
(0.790)\end{array}$ \\
\hline$I V_{1 q i c \tau}($ for $\Delta$ wage premia) & & & & $\begin{array}{l}1.241^{* * *} \\
(0.190)\end{array}$ & $\begin{array}{l}1.263^{* * *} \\
(0.192)\end{array}$ & & $\begin{array}{l}1.034^{* * *} \\
(0.199)\end{array}$ & $\begin{array}{l}1.047^{* * *} \\
(0.203)\end{array}$ \\
\hline$I V_{2 q i c \tau}$ (for $\Delta$ trans. proba.) & & & & $\begin{array}{l}1.237^{* *} \\
(0.452)\end{array}$ & & & $\begin{array}{c}0.766 \\
(0.443)\end{array}$ & \\
\hline$I V_{3 q i c \tau}$ (for $\Delta$ empl. shares) & & & & & $\begin{array}{l}1.077^{* *} \\
(0.434)\end{array}$ & & & $\begin{array}{l}1.264^{* * *} \\
(0.133)\end{array}$ \\
\hline$I V_{4 q i c \tau}($ for $\Delta$ skill transf.) & & & & & $\begin{array}{l}1.814^{* * *} \\
(0.452)\end{array}$ & & & $\begin{array}{l}1.141^{* * *} \\
(0.153)\end{array}$ \\
\hline Bartik $_{1 c \tau}$ & & $\begin{array}{l}1.941^{* * *} \\
(0.431)\end{array}$ & & $\begin{array}{l}2.382^{* * *} \\
(0.372)\end{array}$ & $\begin{array}{l}2.373^{* * *} \\
(0.370)\end{array}$ & & $\begin{array}{l}1.961^{* * *} \\
(0.426)\end{array}$ & $\begin{array}{l}1.953^{* * *} \\
(0.431)\end{array}$ \\
\hline Bartik $_{2 c \tau}$ (labor force) & & $\begin{array}{c}-1.829^{* * *} \\
(0.431)\end{array}$ & & $\begin{array}{c}-2.290^{* *} \\
(0.402)\end{array}$ & $\begin{array}{c}*-2.287^{* * *} \\
(0.401)\end{array}$ & & $\begin{array}{c}-1.847^{* * *} \\
(0.428)\end{array}$ & $\begin{array}{c}-1.838^{* * *} \\
(0.432)\end{array}$ \\
\hline F-stat.: $\Delta \sum_{k \in S} \eta_{k c \tau} w_{k c \tau}$ & & 11.04 & & & & & 8.28 & 24.53 \\
\hline F-stat.: $\Delta \sum_{k \in S \backslash\{q i\}} \psi_{k c \tau \mid q i} w_{k c \tau}$ & & & & 16.51 & 13.98 & & 13.84 & 31.46 \\
\hline F-stat.: $\Delta E R_{c \tau}$ & & 13.16 & & 15.58 & 12.78 & & 10.63 & 9.64 \\
\hline Over-id. p-val. & & 0.40 & & 0.36 & 0.40 & & 0.57 & 0.75 \\
\hline AP p-val. & & 0.00 & & 0.00 & 0.00 & & 0.00 & 0.00 \\
\hline Observations & 6632 & 6632 & 6632 & 6632 & 6632 & 6632 & 6632 & 6632 \\
\hline
\end{tabular}

Notes: Standard errors, in parentheses, are clustered at the city level. ${ }^{* * *} \mathrm{p}<0.01,{ }^{* *} \mathrm{p}<0.05,{ }^{*} \mathrm{p}<0.1$. 
Columns (1) and (2) show results for specification (21), which assumes homogeneous job-specific skill transferability. In both columns, estimates are positive and statistically significant at the $1 \%$ level. As expected, the OLS estimate is biased upwards. The IV coefficient indicates that a $1 \%$ increase in the city average wage generates a $0.415 \%$ positive spillover effect on wages. This first set of results is in line with Beaudry et al. (2012).

Results associated with specification (19) are shown in columns (3) to (5). The estimate obtained with OLS is large at 0.363 and statistically significant at the $1 \%$ level. Unlike previous results, the direction of the bias is a priori ambiguous. On one hand, the reflection problem and the endogeneity of employment likely create an upward bias. On the other hand, the transition probabilities are measured with errors, pulling down the OLS estimate. Column (4) shows the results obtained when using the first set of instruments, which decompose changes in predicted outside options into wage premia variations and shifts in the transition probabilities. Column (5) is based on the second set of instruments, which further isolates movements in the local composition of employment (shifts in $\eta_{k c \tau}$ ) and changes in the relative mobility measure. Whichever IV specification one looks at, the estimates are similar - 0.644 in column (4) and at 0.603 in column (5) - and statistically significant at the $1 \%$ level.

The two sets of instruments offer a test of overidentifying restrictions. Since each instrument explores a distinct type of data variation, any deviation from the identifying assumption would be weighted differently and, therefore, produce different estimates. For this reason, the similarity of the results obtained in columns (4) and (5) can be interpreted as evidence that shocks to comparative advantages are uncorrelated with past job-city-specific comparative advantages. The Hansen test statistics at the bottom of the table gives support to this argument.

The second section of Table 3 shows the first stage. Each of the $I V$ 's estimates is statistically significant at the $1 \%$ level and affects workers' outside options in a similar fashion, indicating that wages, employment shares and skill transferability are important determinants of workers' outside options. Importantly, the fact that the estimates on $I V_{2 q i c \tau}$ and $I V_{4 q i c \tau}$ are statistically significant provides support to the mechanism put forward in this paper that differences in job-specific skill transferability also enter workers' wage-bargaining process. The IV's corresponding F-statistics of the excluded instruments is above 10, confirming that the relevance condition is satisfied. For each endogenous regressor, the Angrist-Pischke p-value is zero, indicating the absence of a weak 
instrumental variables problem. As for the employment rate, the Bartik instruments enter the first stage in a statistically significant manner. Not surprisingly, the labour force counterpart of the original Bartik measure is negative.

So far, results suggest that differences in job-specific skill transferability matter for wage formation. However, since the estimates obtained across the different specifications do not statistically differ from each other, it may be the case that relaxing the homogeneity assumption only adds unnecessary complications or noise to the analysis. Columns (6) to (8) evaluate this possibility and introduce both measures of workers' outside options, $\sum_{k \in S} \eta_{k c} w_{k c}$ and $\sum_{k \in S \backslash\{q i\}} \chi_{k c \mid q i} \eta_{k c} w_{k c}$, in one single specification. Once the endogeneity of workers' outside options is accounted for, the estimate on the city average wage becomes negative and statistically insignificant while the estimate on the other measure remains unaltered. A different picture would have emerged if differences in jobspecific skill transferability had little value-added, or were simply adding noise to the estimation.

\subsection{Isolating search and bargaining mechanisms}

An important condition for the identification strategy is that the variation used to identify the effects of outside options is not very correlated with labour movements across industries and occupations within a city. Thus, this subsection starts by explicitly reporting the correlation patterns between the instruments and periodical changes in the log of job-city employment within a labour market. Table 4 shows that none of the instruments affects changes in log job-city employment in a statistically significant manner, making it even harder to argue that the IV estimates could be biased due to a correlation between the instruments and changes in the marginal product of labour. 
Table 4: Correlation pattern between the instruments and employment.

\begin{tabular}{|c|c|c|c|c|c|c|}
\hline \multirow{2}{*}{$\begin{array}{l}\text { Dependent variable } \\
\text { Regressors }\end{array}$} & \multicolumn{6}{|c|}{$\Delta \log$ employment $_{q i c \tau}$} \\
\hline & $(1)$ & (2) & (3) & (4) & (5) & (6) \\
\hline$I V_{1 q i c \tau}($ for $\Delta$ wage premia) & $\begin{array}{c}0.970 \\
(0.641)\end{array}$ & & & & $\begin{array}{c}0.997 \\
(0.656)\end{array}$ & $\begin{array}{c}0.980 \\
(0.656)\end{array}$ \\
\hline$I V_{2 q i c \tau}$ (for $\Delta$ trans. proba.) & & $\begin{array}{c}-0.344 \\
(1.521)\end{array}$ & & & $\begin{array}{l}-0.625 \\
(1.552)\end{array}$ & \\
\hline$I V_{3 q i c \tau}$ (for $\Delta$ empl. shares) & & & $\begin{array}{c}0.336 \\
(0.764)\end{array}$ & & & $\begin{array}{r}-0.516 \\
(1.596)\end{array}$ \\
\hline$I V_{4 q i c \tau}$ (for $\Delta$ skill transf.) & & & & $\begin{array}{l}-0.486 \\
(0.777)\end{array}$ & & $\begin{array}{r}-0.895 \\
(1.617)\end{array}$ \\
\hline$\Delta d_{q i \tau}$ & yes & yes & yes & yes & yes & yes \\
\hline$\Delta d_{c \tau}$ & yes & yes & yes & yes & yes & yes \\
\hline Observations & 6632 & 6632 & 6632 & 6632 & 6632 & 6632 \\
\hline
\end{tabular}

Table 5 exploits the fact that differences in job-specific skill transferability generate job-city-specific outside options to sequentially controls for more flexible formulations of the value of the marginal product of labour (thus moving up from case 4 to 1 in Figure 1).

The first three columns correspond to specification (20) which adds an entire set city-time dummies to the most restrictive formulation of prices and technology. Thus, relative to columns (3)-(5) of Table 3, specification (20) takes an additional difference that compares periodical changes in, say, secretaries' wages in the tertiary sector to those changes in any other occupation and industry within city A. In doing so, local time-varying factors are removed from the wage equation and the residual variation is attributed to the differences in workers' outside options that stem from job-specific skill transferability.

Columns (4)-(6) add industry-city-time dummies (therefore controlling for local industry-specific effects) and show estimates consistent with a specification that allows industrial prices to vary across cities, while maintaining the assumption of perfectly substitutable factors. Relative to the previous columns, the triple difference estimation focuses on periodical changes in wages across occupations in the same industry and city, which means for instance comparing wage differentials for secretaries to those for engineers within the tertiary sector of city A. Such a comparison relies on the premise that there exist sufficient differences between the mobility of secretaries and engineers (i.e. $\left.\chi_{k C \mid S T} \neq \chi_{k C \mid E T}\right)$.

Columns (7)-(9) introduce the change in log job local employment to specification (20). To deal 
with the endogeneity of this variable, this paper uses a Bartik-style instrument, constructed in a way similar to the instruments used for workers' outside options and valid under identical conditions. In particular, the instrument is given by the change in the log of job local predicted employment, computed as in equation (26), i.e. by multiplying the initial level of job-city employment with the corresponding national-level growth of job employment.

Finally, estimates consistent with the most flexible formulation of technology, such as a CES production function with $\gamma \leq 1$, are shown in columns (10)-(12), where both industry-city-time dummies and changes in log job-city employment are controlled for. In such a case, the assumption imposed on industrial prices is irrelevant as any local component will be captured by $d_{i c \tau}$. 
Table 5: Adding flexibility to the value of the marginal product.

\begin{tabular}{|c|c|c|c|c|c|c|c|c|c|c|c|c|}
\hline \multirow{2}{*}{$\begin{array}{l}\text { Dependent variable } \\
\text { Regressors }\end{array}$} & \multicolumn{12}{|c|}{$\Delta \log$ wages $_{q i c \tau}$} \\
\hline & $\begin{array}{l}(\mathbf{1}) \\
\text { OLS }\end{array}$ & $\begin{array}{l}(2) \\
\text { IV }\end{array}$ & $\begin{array}{l}\text { (3) } \\
\text { IV }\end{array}$ & $\begin{array}{l}(4) \\
\text { OLS }\end{array}$ & $\begin{array}{l}\text { (5) } \\
\text { IV }\end{array}$ & $\begin{array}{l}\text { (6) } \\
\text { IV }\end{array}$ & $\begin{array}{l}(7) \\
\text { OLS }\end{array}$ & $\begin{array}{l}(8) \\
\text { IV }\end{array}$ & $\begin{array}{l}(9) \\
\text { IV }\end{array}$ & $\begin{array}{l}(\mathbf{1 0}) \\
\text { OLS }\end{array}$ & $\begin{array}{c}\text { (11) } \\
\text { IV }\end{array}$ & $\begin{array}{l}\text { (12) } \\
\text { IV }\end{array}$ \\
\hline $\begin{array}{l}\Delta \text { Outside options }{ }_{q i c \tau} \text { : } \\
\Delta \sum_{k \in S \backslash\{q i\}} \psi_{k c \tau \mid q i} w_{k c \tau}\end{array}$ & $\begin{array}{l}0.262^{* * *} \\
(0.049)\end{array}$ & $\begin{array}{c}0.713^{* * *} \\
(0.165)\end{array}$ & $\begin{array}{l}0.655^{* * *} \\
(0.153)\end{array}$ & $\begin{array}{c}-0.065 \\
(0.069)\end{array}$ & $\begin{array}{l}0.574^{* * *} \\
(0.206)\end{array}$ & $\begin{array}{c}0.462^{* *} \\
(0.190)\end{array}$ & $\begin{array}{l}0.230^{* * *} \\
(0.045)\end{array}$ & $\begin{array}{l}0.829^{* * *} \\
(0.184)\end{array}$ & $\begin{array}{l}0.709^{* * *} \\
(0.200)\end{array}$ & $\begin{array}{c}-0.100 \\
(0.068)\end{array}$ & $\begin{array}{l}0.897^{* * *} \\
(0.292)\end{array}$ & $\begin{array}{c}0.789^{* *} \\
(0.320)\end{array}$ \\
\hline$\Delta \log$ employment $_{q i c \tau}$ & & & & & & & $\begin{array}{l}0.017^{* * *} \\
(0.007)\end{array}$ & $\begin{array}{c}0.030 \\
(0.047)\end{array}$ & $\begin{array}{c}0.046 \\
(0.049)\end{array}$ & $\begin{array}{c}0.010 \\
(0.010)\end{array}$ & $\begin{array}{c}0.155 \\
(0.157)\end{array}$ & $\begin{array}{c}0.196 \\
(0.164)\end{array}$ \\
\hline $\begin{array}{l}\Delta d_{q i \tau} \\
\Delta d_{c \tau} \\
\Delta d_{i c \tau}\end{array}$ & $\begin{array}{l}\text { yes } \\
\text { yes }\end{array}$ & $\begin{array}{l}\text { yes } \\
\text { yes }\end{array}$ & $\begin{array}{l}\text { yes } \\
\text { yes }\end{array}$ & $\begin{array}{l}\text { yes } \\
\text { yes }\end{array}$ & $\begin{array}{l}\text { yes } \\
\text { yes }\end{array}$ & $\begin{array}{l}\text { yes } \\
\text { yes }\end{array}$ & $\begin{array}{l}\text { yes } \\
\text { yes }\end{array}$ & $\begin{array}{l}\text { yes } \\
\text { yes }\end{array}$ & $\begin{array}{l}\text { yes } \\
\text { yes }\end{array}$ & yes & $\begin{array}{l}\text { yes } \\
\text { yes }\end{array}$ & $\begin{array}{l}\text { yes } \\
\text { yes }\end{array}$ \\
\hline $\begin{array}{l}\text { Instrument set } \\
\text { F-stat. } \\
\text { Over-id. p-val. } \\
\text { AP p-val. } \\
\text { Observations }\end{array}$ & 6632 & $\begin{array}{r}\text { set I } \\
41.88 \\
0.29 \\
0.00 \\
6632\end{array}$ & $\begin{array}{c}\text { set II } \\
35.15 \\
0.15 \\
0.00 \\
6632\end{array}$ & 6632 & $\begin{array}{r}\text { set I } \\
26.52 \\
0.08 \\
0.00 \\
6632\end{array}$ & $\begin{array}{c}\text { set II } \\
25.24 \\
0.10 \\
0.00 \\
6632\end{array}$ & 4974 & $\begin{array}{r}\text { set I } \\
14.99 \\
0.22 \\
0.00 \\
4974\end{array}$ & $\begin{array}{c}\text { set II } \\
15.73 \\
0.15 \\
0.00 \\
4974\end{array}$ & 4974 & $\begin{array}{r}\text { set I } \\
21.59 \\
0.15 \\
0.00 \\
4974\end{array}$ & $\begin{array}{c}\text { set II } \\
17.76 \\
0.17 \\
0.00 \\
4974\end{array}$ \\
\hline
\end{tabular}


Diagnostic tests are satisfactory at any conventional level. The IV estimates on the variable of interest are positive and statistically significant at the $1 \%$ level across specifications, while the coefficient on the employment variable is, with one exception, statistically insignificant. ${ }^{16}$ Therefore, while the previous table suggests that the treatment of mobility across jobs matters for the identification of search and bargaining mechanisms, Table 5 indicates that the restrictions placed on technology and prices are not an important source of bias. Specifically, it appears that the instruments coupled with both occupation-industry-specific and city-specific time-varying dummies do a good job in isolating productivity from independent effects of workers' outside options on wages. In what follows, specification (20) is refered to as baseline specification. Retaining column (2), the estimate obtained suggests that a $10 \%$ increase in workers' outside options generates a $7 \%$ wage increase, which is remarkable considering that this estimate only captures first-round wage impacts.

\subsection{Allowing the productivity term to depend upon previous job}

The production function $Y_{i c}$ assumes that in a particular job-city cell, workers with the same set of individual characteristics all share the same productivity. This assumption implies that, whichever restrictions are placed on technology, productive components do not depend on previous job and neither do values of the marginal product of labour. This section discusses the implications of relaxing this specific assumption and instead assuming that productive terms are of the form $\theta_{k c \mid q i}$, where $q i$ indexes previous job. ${ }^{17}$

A direct implication of relaxing this assumption is that the unit of analysis of the discounted values for firms and workers becomes a job in a city, conditional on previous job. This means that the indices in equations (3), (4), (6) and (7) are adjusted to reflect a worker's previous job. Although the form of these discounted values remain unaltered, the wage equation will have an additional component relfecting the fact that skills accumulated in the previous job can be transported to the next job and can therefore affect productivity.

To see where this difference is coming from it is useful to write down the discounted utility of being employed and unemployed in job $k$ and city $c$, conditional on previously being employed in

\footnotetext{
${ }^{16}$ Allowing the effect of employment to vary across occupations has no impact on the estimate of interest.

${ }^{17}$ For clarity, I omit $n$, the firm's managerial ability, in the discussion that follows. Omitting this term has no implications since the wage equation is aggregated at the job-city level later on.
} 
$q i$. Letting these terms be denoted by $U_{k c \mid q i}^{e}$ and $U_{k c}^{u}$, respectively, one obtains,

$$
\rho U_{k c \mid q i}^{e}=w_{k c \mid q i}-\delta\left(U_{k c \mid q i}^{e}-U_{k c}^{u}\right)
$$

where $w_{k c \mid q i}$ denotes the wage offered in cell $k c$ conditional on $q i$, and

$$
\rho U_{k c}^{u}=\psi_{c} \sum_{k^{\prime} \in S} \psi_{k^{\prime} c \mid k} U_{k^{\prime} c \mid k}^{e}-\psi_{c} U_{k c}^{u}
$$

Note that since it only depends on future potential employment opportunities, the utility of being unemployed only depends on where the person was employed prior to becoming unemployed. Combining (33) and (34), one can express the utility of being unemployed as follows

$$
U_{k c}^{u}=\frac{\psi_{c}}{\rho+\psi_{c}} \cdot \frac{1}{\rho+\delta}\left[\frac{\rho\left(\rho+\delta+\psi_{c}\right)+\delta \psi_{c}}{\rho\left(\rho+\delta+\psi_{c}\right)} \sum_{k^{\prime} \in S} \psi_{k^{\prime} c \mid k} w_{k^{\prime} c}+\sum_{k^{\prime} \in S} \psi_{k^{\prime} c \mid k} \nu_{k^{\prime} c \mid k}\right]
$$

where $\nu_{k^{\prime} \mid k}=w_{k^{\prime} c \mid k}-w_{k^{\prime} c}$. The term $\nu_{k^{\prime} \mid k}$ corresponds to the wage premium in job $k^{\prime}$ and city $c$ paid to workers previously employed in job $k$, relative to the average wage paid in job $k^{\prime}$ and city $c$. The main difference between this equation and the baseline framework is captured by the wage premia component $\sum_{k^{\prime} \in S} \psi_{k^{\prime} c \mid k} \nu_{k^{\prime} c \mid k}$. Equation (35) implies that outside options will also have to reflect the fact that workers in a job are compensated for any additional contribution above the average productivity in that particular job.

Solving for the Nash bargaining solution and averaging at the job-city level, one obtains the following wage equation

$w_{k c \mid q i}=\gamma_{1 c} V M P L_{k c \mid q i}+\gamma_{2 c} \frac{\rho}{\rho+\psi_{c}}\left[\frac{\rho+\delta+\psi_{c}(1+\delta)}{\rho+\delta} \sum_{k^{\prime} \in S} \psi_{k^{\prime} c \mid k} w_{k^{\prime} c}+\frac{\rho+\delta+\psi_{c}}{\rho+\delta} \sum_{k^{\prime} \in S} \psi_{k^{\prime} c \mid k} \nu_{k^{\prime} c \mid k}\right]$.

This equation suggests that differences in wages within the same job-city cell are fully explained by differences in the value of the marginal product of labour. One can obtain the equation of interest by averaging (36) within job $k$ and $c$.

This wage equation suggests that if the assumption placed on productive terms in the baseline framework is too restrictive, the coefficient $\gamma_{2}$ estimated in Table 5 may suffer from an upward bias. Ideally, one would want to estimate (36) at the job-city level using the traceablility of 
individuals in Germany to construct the premium component $\sum_{k^{\prime} \in S} \psi_{k^{\prime} c \mid k} \nu_{k^{\prime} c \mid k}$. However, with a $2 \%$ random sample of the population only, constructing a measure of $\nu_{k^{\prime}} \mid k$ that perfectly matches the predictions of the model is impossible. This is the case because, at a particular point in time, the number of individuals with similar observable characteristics per job-city cell, conditional on previous job would be insufficient. Nevertheless, the paper proposes to proxy the wage premium with $\nu_{k^{\prime} \mid k}=w_{k^{\prime} \mid k}-w_{k c}$, where $w_{k^{\prime} \mid k}$ is the counter-part of $w_{k^{\prime} \mid k}$, computed at the national level. While this is certainly not perfect, this approach does at least give sense of how large the bias may be. Instruments for $\sum_{k^{\prime} \in S} \psi_{k^{\prime} c \mid k} \nu_{k^{\prime} c \mid k}$ are constructed in a way similar to that of the baseline measure of outside options.

Results are shown in Table 6. The wage premia component does not appear to have any statistically significant impact on wage determination and more importantly, its inclusion does not alter the estimates on measured outside options. Thus, this table suggests that the restrictions placed on the productive term in the baseline framework is not an important source of bias.

Table 6: Allowing productive terms to depend on previous job.

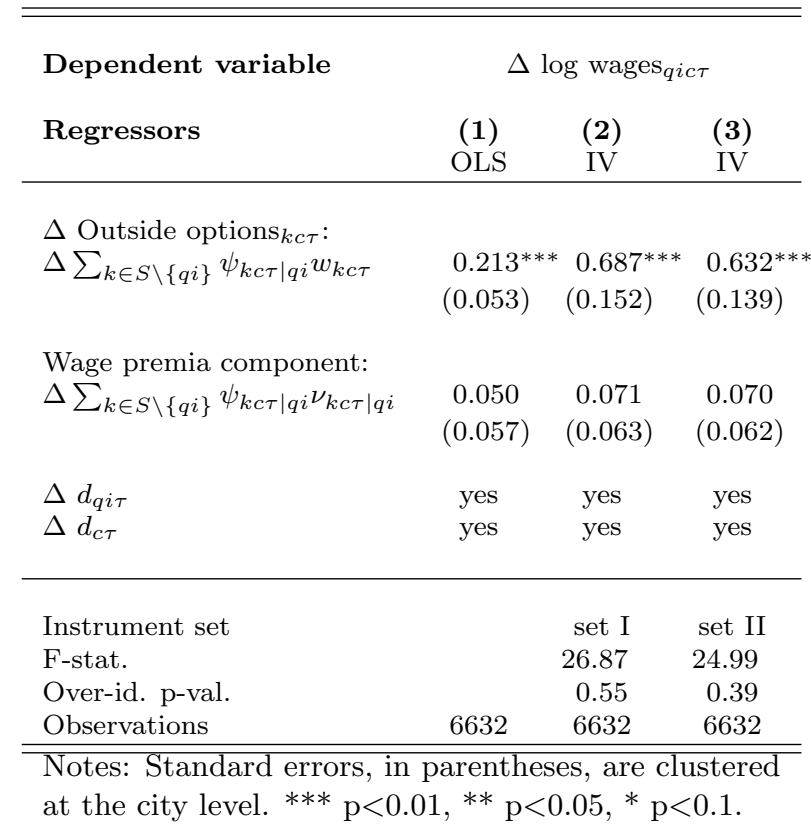


Robustness tests Appendix K of the Supplementary Material provides a number of robustness tests: Appendix K-1 presents results from a specification that replaces industry-city time-varying dummies with occupation-city time-varying dummies. Appendix K-2 tackles the issue of selfselection into cities and occupations. Appendix K-3 studies the implications of on-the-job search. ${ }^{18}$ Overall, none of these changes alter the estimates on measured outside options in a way that would change the fundamental conclusions on this paper.

\section{The total effect of a shift in workers' outside options}

Although the main objective of the paper is to estimate the coefficient $\tilde{\gamma}_{2}$, it is useful to derive an expression for the total effect of a shift in workers' outside options. This expression is then used for two purposes: first, to perform a test of the validity of the model and second, to compute the fraction of the variance of the wage growth across cities that is due to the effects of outside options.

\subsection{Deriving the total effect}

In order to derive the total effect of a shift in workers' outside options, the paper first uses (16) to set out equations for wages determined by productivity, the wages paid elsewhere in the local economy and city-specific employment rate. That is,

$$
W_{c}=\Theta_{c}+\tilde{\gamma}_{2} \Psi_{c} W_{c}+\alpha_{5} \Xi_{c}
$$

where $W_{c}$ is a $Q I \mathrm{x} 1$ vector with a typical element being $w_{q i c} ; \Theta_{c}$ is a $Q I \mathrm{x} 1$ vector with typical element $\left(\alpha_{0}+\tilde{\gamma}_{1} \alpha_{1} p_{i c}+\tilde{\gamma}_{1} \alpha_{2} f_{i c}+\tilde{\gamma}_{1} \alpha_{3} \theta_{q i c}+\tilde{\gamma}_{1} \alpha_{4} N_{q i c}\right) ; \Psi_{c}$ is a $Q I \mathrm{x} Q I$ matrix with typical element $\psi_{k c \mid q i}, k$ and $q i$ being the column and row indexes in the matrix; and $\Xi_{c}$ is a $Q I x 1$ vector with a typical element being local employment rate. Solving (37) for the vector of wages, one obtains

$$
W_{c}=\Theta_{c}+\tilde{\gamma}_{2} \Psi_{c}\left[M-\tilde{\gamma}_{2} \Psi_{c}\right]^{-1} \Theta_{c}+\alpha_{5} \Lambda_{c} \Xi_{c},
$$

\footnotetext{
${ }^{18}$ Appendix K-4 discusses the top-coding issue affecting individual wages in the IABS sample. Appendix K-5 proposes alternative measure of mobility. In Appendix K-6, the paper examines the effect of interest differs before and after the fall of the Iron Curtain. Appendix K-7 proposes to average the data over three and eight years, as an alternative to five years. In Appendix K-8, standard errors are clustered at the city-time, industry or industry-time level. Finally, Appendix K-9 investigates whether the baseline estimate differs across industries and occupations.
} 
where $M$ is a $Q I \times Q I$ identify matrix and $\Lambda_{c}=\tilde{\gamma}_{2} \Psi_{c}\left[M-\tilde{\gamma}_{2} \Psi_{c}\right]^{-1}+M$.

The second step consists in writing the vector of productivities $\Theta_{c}$ as a function of the vector of national wage premia. To achieve this goal, one first has to obtain an expression for the national wage premia. Let $\nu_{q i}$ denote the national wage premium in job $q i$, i.e. the nation-wide wage paid in job qi relative to the nation-wide wage paid in some numeraire job, say occupation-industry 11. Using equation (13), the wage premium in job qi is given by

$$
\begin{aligned}
\nu_{q i} & =\sum_{c}\left(w_{q i c}-w_{11 c}\right) \\
& =\sum_{c} \tilde{\gamma}_{1 c}\left(V M P L_{q i c}-V M P L_{11 c}\right)+\sum_{c} \tilde{\gamma}_{2 c} \sum_{k \in S \backslash\{q i\}}\left(\psi_{k c \mid q i}-\psi_{k c \mid 11}\right) w_{k c} .
\end{aligned}
$$

Taking a linear approximation in a way similar to that described earlier (i.e. around the point where cities have identical employment rates and where employment is uniformly distributed across jobs), one obtains

$$
\nu_{q i}=\tilde{\gamma}_{1} \sum_{c}\left[\alpha_{1}\left(p_{i c}-p_{1 c}\right)+\alpha_{2}\left(f_{i c}-f_{1 c}\right)+\alpha_{3}\left(\theta_{q i c}-\theta_{11 c}\right)+\alpha_{4}\left(\ln N_{q i c}-\ln N_{11 c}\right)\right]
$$

Equation (40) can be further simplified by rewriting the value of the marginal product of labour as a function of two components: a national job-specific and a local job-specific term. In particular, $p_{i c}=p_{i}+\varepsilon_{i c}^{p}, f_{i c}=f_{i}+\varepsilon_{i c}^{f}, \theta_{q i c}=\theta_{q i}+\varepsilon_{q i c}^{\theta}$ and $N_{q i c}=N_{q i}+\varepsilon_{q i c}^{N}$, where by definition $\sum_{c} \varepsilon_{i c}^{p}=0$, $\sum_{c} \varepsilon_{i c}^{f}=0, \sum_{c} \varepsilon_{q i c}^{\theta}=0$ and $\sum_{c} \varepsilon_{q i c}^{N}=0$. Using this rewrite, equation (40) reduces to

$$
\nu_{q i}=\tilde{\gamma}_{1}\left[\alpha_{1}\left(p_{i}-p_{1}\right)+\alpha_{2}\left(f_{i}-f_{1}\right)+\alpha_{3}\left(\theta_{q i}-\theta_{11}\right)+\alpha_{4}\left(\ln N_{q i}-\ln N_{11}\right)\right]
$$

As in Beaudry et al. (2012), job wage premia depend on industrial prices. However, since this paper relies on a more flexible production function, job wage premia also depend on the nationwide components of the marginal product of labour. Using equation (39), the vector of productivities can now be rewritten as a function of the vector of national wage premia, i.e.

$$
\Theta_{c}=V+\varpi_{c}+A
$$

where $V$ is a $Q I \times 1$ vector of national wage premia with typical element $\nu_{q i} ; \varpi_{c}$ is a $Q I \times 1$ vec- 
tor with typical element being $\left(\alpha_{0}+\tilde{\gamma}_{1} \alpha_{1} \varepsilon_{i c}^{p}+\tilde{\gamma}_{1} \alpha_{2} \varepsilon_{i c}^{f}+\tilde{\gamma}_{1} \alpha_{3} \varepsilon_{q i c}+\tilde{\gamma}_{1} \alpha_{4} \varepsilon_{q i c}^{h}\right)$, the job-city specific components of the value of the marginal product of labour; and $A$ is a $Q I x 1$ vector of constant terms.

Substituting equation (42) into (38), one obtains equations for wages determined by productivity, national wage premia and local employment rate. Specifically,

$$
\begin{aligned}
W_{c} & =\Theta_{c}+\tilde{\gamma}_{2} \Psi_{c}\left[M-\tilde{\gamma}_{2} \Psi_{c}\right]^{-1}\left[V+\varpi_{c}+A\right]+\alpha_{5} \Lambda_{c} \Xi_{c} \\
& =\Upsilon+\Theta_{c}+\tilde{\gamma}_{2} \Psi_{c}\left[M-\tilde{\gamma}_{2} \Psi_{c}\right]^{-1} V+\alpha_{5} \Lambda_{c} \Xi_{c}+\tilde{\gamma}_{2} \Psi_{c}\left[M-\tilde{\gamma}_{2} \Psi_{c}\right]^{-1} \varpi_{c},
\end{aligned}
$$

where $\Upsilon_{c}=\tilde{\gamma}_{2} \Psi_{c}\left[M-\tilde{\gamma}_{2} \Psi_{c}\right]^{-1} A$. Since $A$ is a vector of constant terms, the typical element of $\Upsilon$ is a job-specific term, independent of local components.

In equation (43), the relevant measure of workers' outside option is a weighted average of job national wage premia. Unlike equation (16), the weights combine the transition probabilities with the parameter $\tilde{\gamma}_{2}$ itself, making direct estimation of this type of relationship infeasible. Nevertheless, the total effect of a shift in workers' outside options can be computed by substituting $\tilde{\gamma}_{2}$ with its estimated counterpart, $\hat{\tilde{\gamma}}_{2}$. Specifically, the total effect of a shift in workers' outside option can be measured as

$$
\hat{\tilde{\gamma}}_{2} \Delta\left(\Psi_{c}\left[M-\hat{\tilde{\gamma}}_{2} \Psi_{c}\right]^{-1} V\right)
$$

where $\Delta$ denote a time first difference.

\subsection{Model testing}

The previous subsection suggests that if the model is sound, estimating the wage equation using $\Delta\left(\Psi_{c}\left[M-\hat{\tilde{\gamma}}_{2} \Psi_{c}\right]^{-1} V\right)$ as an alternative measure of outside options should yield an estimate of $\tilde{\gamma}_{2}$ that does not statistically differ from the baseline estimate. Table 7 shows the results obtained when taking $0.55,0.6$ and 0.65 as reference parameters. ${ }^{19}$ For all columns, the estimates are positive and statistically significant at the $1 \%$ level. The size of the $I V$ s coefficients is close to that estimated in the baseline, suggesting that the model proposed in this paper provides a good approximation

\footnotetext{
${ }^{19}$ Repeating this exercise for parameter values over the range 0.55 to 0.65 , the paper finds that using $\hat{\tilde{\gamma}}_{2}=0.6235$ as the reference parameter to create the new measure of workers' outside options yields an estimate of $\tilde{\gamma}_{2}$ of 0.6235 .
} 
of the wage determination process.

Table 7: Testing the validity of the model.

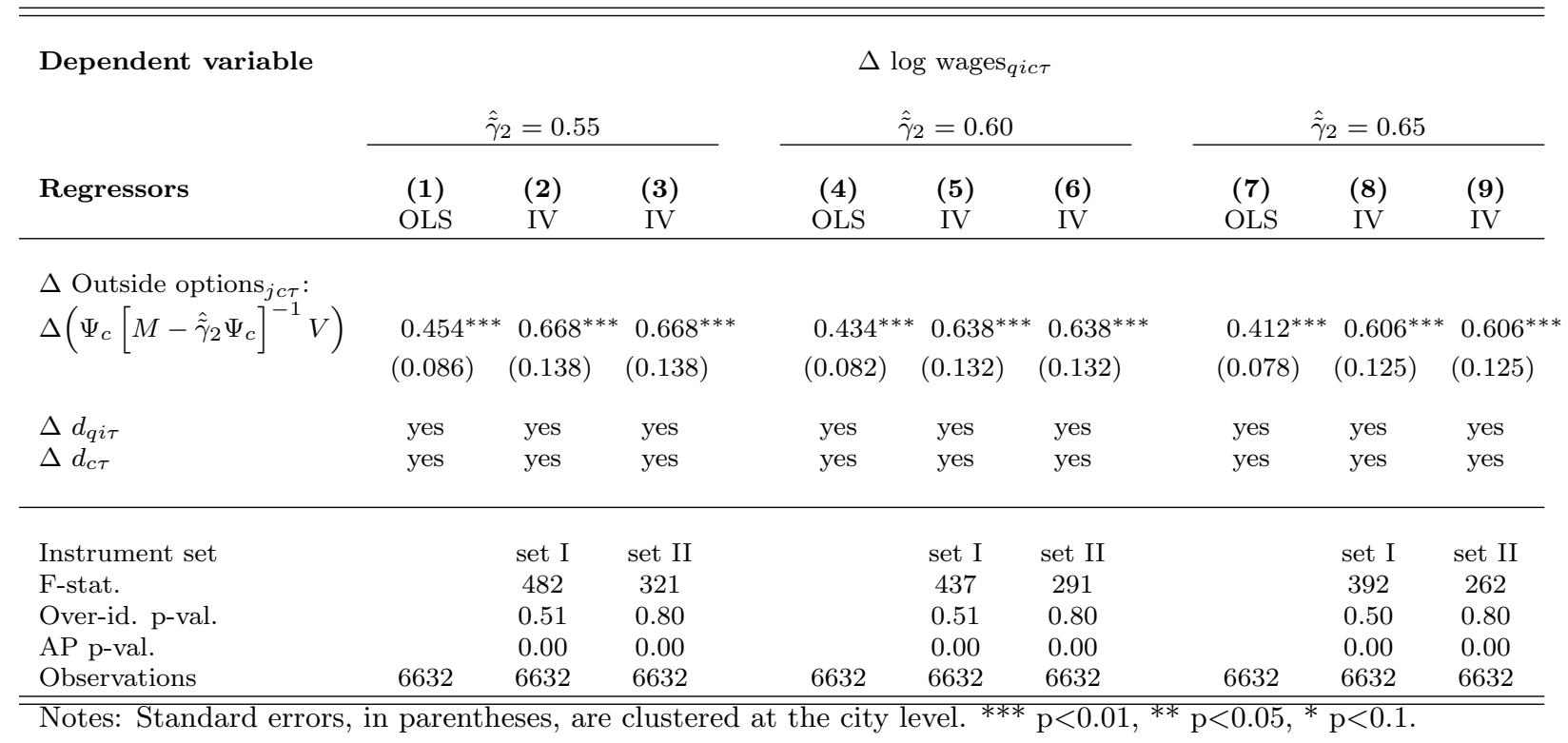

\subsection{Variance decomposition}

The objective of this subsection is to quantify the importance of changes in workers' outside options in explaining the cross-sectional variance in city wage growth. To achieve this goal, the paper focuses on changes induced by shifts in the composition of job local employment and compares the fraction of the variance that is explained by changes in outside options to the fraction of the variance that would be explained in the absence of search and bargaining effects. In addition, to evaluate the role of the treatment of mobility in measuring outside options, the paper distinguishes between a framework with constant mobility and a model with heterogeneous job-specific skill transferability.

If wages are determined by productivity only, then changes in the industrial and occupational structure of employment have no effect on wage formation. In such a case, the total effect on cross-sectional variance reflects employment composition changes only and can be measured by the 
following ratio of variances

$$
\frac{\operatorname{Var}\left[\sum_{k \in S} \eta_{k c \tau} w_{k c(\tau-1)}-\sum_{k \in S} \eta_{k c(\tau-1)} w_{k c(\tau-1)}\right]}{\operatorname{Var}\left[\sum_{k \in S} \eta_{k c \tau} w_{k c \tau}-\sum_{k \in S} \eta_{k c(\tau-1)} w_{k c(\tau-1)}\right]}
$$

where the denominator corresponds to the variance of city wage growth over two periods.

In the presence of search and bargaining effects, employment composition-induced changes in outside options modify job-city wages and generate an additional indirect effect on city wage growth. As a result, the nominator in (45) is augmented by an additional term capturing the total effect of changes in outside options on job-city wages. In a framework where job-skill transferability is irrelevant for wage formation, the variance ratio is computed as

$$
\frac{\operatorname{Var}\left[\sum_{k \in S} \eta_{k c \tau}\left(w_{k c(\tau-1)}+\hat{\gamma}_{2} \Delta \sum_{k^{\prime} \in S} \eta_{k^{\prime} c \tau} \nu_{k^{\prime} \tau}\right)-\sum_{k \in S} \eta_{k c(\tau-1)} w_{k c(\tau-1)}\right]}{\operatorname{Var}\left[\sum_{k \in S} \eta_{k c \tau} w_{k c \tau}-\sum_{k \in S} \eta_{k c(\tau-1)} w_{k c(\tau-1)}\right]} .
$$

If, instead, differences in workers' mobility matter, the variance ratio can be measured with

$$
\frac{\operatorname{Var}\left[\sum_{k \in S} \eta_{k c \tau}\left(w_{k c(\tau-1)}+\hat{\tilde{\gamma}}_{2} \Delta\left[\Psi_{c}\left(M-\hat{\tilde{\gamma}}_{2} \Psi_{c}\right)^{-1} V\right]\right)-\sum_{k \in S} \eta_{k c(\tau-1)} w_{k c(\tau-1)}\right]}{\operatorname{Var}\left[\sum_{k \in S} \eta_{k c \tau} w_{k c \tau}-\sum_{k \in S} \eta_{k c(\tau-1)} w_{k c(\tau-1)}\right]} .
$$

These ratios are reported in column (1)-(3) of Table 8. The first column corresponds to (45), the second one to (46) and the last one to (47). The results indicate that the predicted direct effect of changes in the composition of job local employment ranges from $4 \%$ to $20 \%$ in a model where wages are determined by productivity only. Columns (2) and (3) suggest a framework that accounts for search and bargaining effects always explains a much larger fraction of the cross-sectional variance in city wage movements. This fraction ranges from $6 \%$ to $36 \%$ in the case of constant mobility and from $33 \%$ to more than $100 \%$ in the case where mobility differs across any two pairs of jobs. The results of columns (2) and (3) also indicate that the treatment of mobility plays an crucial role in determining the fraction of the variance that can be explained by changes the within-city composition of employment. 
Table 8: Variance ratios.

\begin{tabular}{lccc}
\hline \hline & & \multicolumn{2}{c}{ Outside options } \\
\cline { 3 - 4 } & $\begin{array}{c}\text { Productivity } \\
(1)\end{array}$ & $\begin{array}{c}\eta_{k c \tau} \\
(2)\end{array}$ & $\begin{array}{c}\psi_{k c \tau \mid q i} \\
(3)\end{array}$ \\
\hline & & & \\
$(1982-86)$ to $(1977-81)$ & 0.040 & 0.063 & 0.337 \\
$(1982-86)$ to $(1987-91)$ & 0.070 & 0.130 & 0.584 \\
$(1987-91)$ to $(1992-96)$ & 0.144 & 0.201 & 0.534 \\
$(1992-96)$ to $(1997-01)$ & 0.205 & 0.363 & 1.296 \\
Average & 0.115 & 0.189 & 0.688 \\
\hline \hline
\end{tabular}

Interestingly, these results are consistent with the finding of Card et al. (2013) according to which a considerable fraction of the increase in wage inequality is due to rising dispersion in the wage premia that are offered by different employers. In this paper, search and bargaining mechanisms create wage disparities across employers for workers with otherwise similar characteristics and imply that the rise in workplace heterogeneity may have been caused by an increase in the variance of workers' outside options. Columns (2) and (3) of Table 8 show an increase in the variance ratio over time and therefore seem to support this idea.

\section{Concluding remarks}

This paper empirically demonstrates that workers' outside options are important determinants of wages. The paper proposes novel strategies to identify changes in workers' outside options that are independent of changes in the marginal product of labour, the main challenge of estimating search and bargaining effects. To do so, the paper adapts a multi-city multi-sector model of search and bargaining to allow for multiple occupations and for differences in job-specific skill transferability. It then shows how differences in job-specific skill transferability can be used as a source of variation for identification. The main result is that a 10\% increase in workers' outside options generates a $7 \%$ wage increase. This estimate is remarkably robust to a various range of sensitivity checks, which indicates that search and bargaining mechanisms play a substantial role in wage determination. 


\section{References}

D. Acemoglu and J. Angrist. How Large Are Human-Capital Externalities? Evidence from Compulsory Schooling Laws. NBER Macroeconomics Annual, 15:9-59, 2000.

P. Beaudry, D. Green, and B. Sand. Does Industrial Composition Matter for Wages: An Empirical Evaluation Based on Search and Bargaining Theory. Econometrica, 80(3):1063-1104, 2012.

S. Bender, A. Haas, and C. Klose. IAB Employment Subsample 1975-1995: Opportunities for Analysis Provided by the Anonymised Subsample. IZA Discussion Paper Series, 2000.

O. J. Blanchard and L.F. Katz. Regional Evolutions. Brookings Papers on Economic Activity, 1: $1-76,1992$.

D. Card, J. Heining, and P. Kline. Workplace Heterogeneity and The Rise of West German Wage Inequality. The Quarterly Journal of Economics, 128(3):967-1015, 2013.

R. Fonseca, Lopez-Garcia P., and Pissarides C. A. Entrepreneurship, Start-up Costs and Employment. European Economic Review, 45(4-6):692-705, 2001.

C. Gathmann and U. Schoenberg. How General is Human Capital? A Task-Based Approach. Journal of Labor Economics, 28:1-49, 2010.

E. Glaeser and J. Gottlieb. The Wealth of Cities: Agglomeration Economies and Spatial Equilibrium in the United States. Journal of Economic Literature, 47(4), 2009.

E. Glaeser, H. Kallal, J. Scheinkman, and A. Shleifer. Growth in cities. Journal of Political Economy, 100(6):1126-1152, 1992.

A. Hassel and B. Rehder. Institutional Change in the German Wage Bargaining System - The Role of Big companies. Working Paper, 2001.

P. Kropp and B. Schwengler. Abgrenzung von Arbeitsmarktregionen: ein Methodenvorschlag. Raumforschung und Raumordnung, 69(1):45-62, 2011.

C.F. Manski. Identification of Endogenous Social Effects: The Reflection Problem. Review of Economic Studies, 60(3):531-42, 1993. 
R.A. Moffitt. Policy Interventions, Low-Level Equilibria And Social Interactions. In Social Dynamics, MIT Press, 2001.

E. Moretti. Estimating the Social Returns to Higher Education: Evidence from Longitudinal and Repeated Cross-Sectional Data. Journal of Econometrics, 121(1-2):175-212, 2004.

E. Moretti. Local Labor Markets. In Handbook of Labor Economics, Ashenfelter and Card (ed.), 2011.

R. Rogerson, R. Shimer, and R. Wright. Search-Theoretic Models of the Labor Market: A Survey. Journal of Economic Literature, 43:959-988, 2005. 


\title{
Supplementary Material: Appendix
}

\author{
- NOT INTENDED FOR PUBLICATION -
}

Wage Formation: Towards Isolating Search and Bargaining Effects

from the Marginal Product.

Jeanne Tschopp*

August 2015

*Department of Economics, Ryerson University, 350 - Victoria St., Toronto, ON, Canada, M5B 2K3; jtschopp@economics.ryerson.ca. 


\section{A Derivation of the wage equation}

This section provides a detailed explanation on how equation (12) in the manuscript is derived. Wages are set according to the following Nash bargaining rule

$$
\left[V_{j c}^{f}(n)-V_{j c}^{v}(n)\right]=\left[U_{j c}^{e}(n)-U_{j c}^{u}(n)\right] \kappa
$$

To obtain the wage equation one has to derive the match surplus for both the firm and the worker. Deriving the match surplus for the firm is straightforward and implies the following equation

$$
V_{j c}^{f}(n)-V_{j c}^{v}(n)=\frac{V M P L_{j c}(n)-w_{j c}(n)}{\rho+\delta+\psi_{c}}
$$

Deriving the match surplus for the worker deserves more attention and is described in details in what follows.

\section{Deriving the match surplus for the worker}

First, the paper rewrites the discounted value of employment as a function of the discounted value of unemployment. An employed worker in job $j$, city $c$ and firm with managerial ability $n$ receives the wage $w_{j c}(n)$ and is laid off with probability $\delta$ in the next period. Therefore, the discounted value to a worker of being employed is

$$
\rho U_{j c}^{e}(n)=w_{j c}(n)-\delta\left[U_{j c}^{e}(n)-U_{j c}^{u}(n)\right]
$$

Solving for the discounted value of employment one obtains

$$
\rho U_{j c}^{e}(n)=\frac{1}{\rho+\delta} w_{j c}(n)+\frac{\delta}{\rho+\delta} U_{j c}^{u}(n)
$$

Second, the discounted value of unemployment is rewritten as a function of averaged discounted values of employment. The probability of an unemployed worker previously employed in $j c$ being matched to $k c$ is $\psi_{c} \psi_{k c \mid j}$. The probability of him or her remaining unemployed in the coming period 
is $\left(1-\psi_{c}\right)$. Thus, the discounted value of being unemployed is given by

$$
\rho U_{j c}^{u}(n)=\psi_{c} \sum_{k \in S} \psi_{k c \mid j} U_{k c}^{e}-\psi_{c} U_{j c}^{u}(n)
$$

where $U_{k c}^{e}$ is the average discounted utility of employment in job $k$ and city $c$, averaged over all firms that operate in city $c$. Solving for the discounted value of unemployment, one obtains

$$
\rho U_{j c}^{u}(n)=\frac{\psi_{c}}{\rho+\psi_{c}} \sum_{k \in S} \psi_{k c \mid j} U_{k c}^{e}
$$

where the summation term reflects the outside options of a worker in job $j$ and city $c$, and is independent of a firm's managerial ability $n$.

Third, the paper obtains an expression for the discounted value of employment as a function of averaged discounted values of employment. Substituting (6) into (4), one can rewrite the discounted value of being employed as follows

$$
U_{j c}^{e}(n)=\frac{1}{\rho+\delta} w_{j c}(n)+\frac{\delta \psi_{c}}{(\rho+\delta)\left(\rho+\psi_{c}\right)} \sum_{k \in S} \psi_{k c \mid j} U_{k c}^{e}
$$

Averaging equation (7) over all firms that operate in city $c$, one obtains that

$$
U_{j c}^{e}=\frac{1}{\rho+\delta} w_{j c}+\frac{\delta \psi_{c}}{(\rho+\delta)\left(\rho+\psi_{c}\right)} \sum_{k \in S} \psi_{k c \mid j} U_{k c}^{e}
$$

where $w_{j c}$ is the average wage in job $j$ and city $c$, averaged over all firms that operate in city $c$.

Fourth, the paper solves for the weighted average of averaged discounted values of employment $\sum_{k \in S} \psi_{k c \mid j} U_{k c}^{e}$. Multiplying the average discounted value of employment given by equation (8) by the corresponding transition probabilities and summing over jobs, one obtains

$$
\sum_{k \in S} \psi_{k c \mid j} U_{k c}^{e}=\frac{1}{\rho+\delta} \sum_{k \in S} \psi_{k c \mid j} w_{k c}+\frac{\delta \psi_{c}}{(\rho+\delta)\left(\rho+\psi_{c}\right)} \sum_{k \in S} \psi_{k c \mid j} \sum_{k^{\prime} \in S} \psi_{k^{\prime} c \mid k} U_{k^{\prime} c}^{e}
$$

This paper assumes that if an unemployed worker is matched to a particular job, then he or she develops skills which are identical to those of his co-workers, which means that the measures of relative mobility satisfy $\chi_{k^{\prime} \mid k} \chi_{k c \mid j}=\chi_{k^{\prime} c \mid j}$. Recalling that $\psi_{k c \mid j}=\chi_{k c \mid j} \eta_{k c}$, one can rewrite (9) as 
follows

$$
\begin{aligned}
\sum_{k \in S} \psi_{k c \mid j} U_{k c}^{e} & =\frac{1}{\rho+\delta} \sum_{k \in S} \psi_{k c \mid j} w_{k c}+\frac{\delta \psi_{c}}{(\rho+\delta)\left(\rho+\psi_{c}\right)} \sum_{k^{\prime} \in S} \chi_{k^{\prime} c \mid j} \eta_{k^{\prime}} U_{k^{\prime} c}^{e} \underbrace{\sum_{k \in S} \eta_{k c}}_{=1} \\
& =\frac{1}{\rho+\delta} \sum_{k \in S} \psi_{k c \mid j} w_{k c}+\frac{\delta \psi_{c}}{(\rho+\delta)\left(\rho+\psi_{c}\right)} \sum_{k^{\prime} \in S} \psi_{k^{\prime} c \mid j} U_{k^{\prime} c}^{e} .
\end{aligned}
$$

Since the summation term on the right-hand side is $j c$-specific, then $\sum_{k^{\prime} \in S} \psi_{k^{\prime} c \mid j} U_{k^{\prime} c}^{e}=\sum_{k \in S} \psi_{k c \mid j} U_{k c}^{e}$. Solving for the weighted average of averaged discounted values of employment, one obtains

$$
\sum_{k \in S} \psi_{k c \mid j} U_{k c}^{e}=\frac{\rho+\psi_{c}}{\rho\left(\rho+\delta+\psi_{c}\right)} \sum_{k \in S} \psi_{k c \mid j} w_{k c}
$$

Finally, the paper obtains the match surplus for the worker. To do so, equation (11) can be used to express both, the discounted value of being employed and unemployed as a function of wages. That is,

$$
U_{j c}^{e}(n)=\frac{1}{\rho+\delta} w_{j c}(n)+\frac{\delta \psi_{c}}{\rho(\rho+\delta)\left(\rho+\delta+\psi_{c}\right)} \sum_{k \in S} \psi_{k c \mid j} w_{k c}
$$

and

$$
U_{j c}^{u}=\frac{\psi_{c}}{\rho\left(\rho+\delta+\psi_{c}\right)} \sum_{k \in S} \psi_{k c \mid j} w_{k c}
$$

Combining equations (12) and (13), the match surplus for a worker is given by

$$
U_{j c}^{e}(n)-U_{j c}^{u}=\frac{1}{\rho+\delta} w_{j c}(n)-\frac{\psi_{c}}{(\rho+\delta)\left(\rho+\delta+\psi_{c}\right)} \sum_{k \in S} \psi_{k c \mid j} w_{k c}
$$

\section{Deriving the wage equation from the Nash bargaining rule}

Substituting the expressions (2) and (14) into (1), one obtains

$$
\frac{V M P L_{j c}(n)-w_{j c}(n)}{\kappa\left(\rho+\delta+\phi_{c}\right)}=\left[\frac{1}{\rho+\delta} w_{j c}(n)-\frac{\psi_{c}}{(\rho+\delta)\left(\rho+\delta+\psi_{c}\right)} \sum_{k \in S} \psi_{k c \mid j} w_{k c}\right]
$$

Solving for the wage in job $j$ and city $c$ offered in a firm with managerial ability $n$, equation (15) 
rewrites

$$
w_{j c}(n)=\gamma_{1 c} V M P L_{j c}(n)+\gamma_{2 c} \sum_{k \in S} \psi_{k c \mid j} w_{k c}
$$

where $\gamma_{1 c}=\frac{(\rho+\delta)}{(\rho+\delta)+\kappa\left(\rho+\delta+\phi_{c}\right)}$ and $\gamma_{2 c}=\frac{\kappa\left(\rho+\delta+\phi_{c}\right)}{(\rho+\delta)+\kappa\left(\rho+\delta+\phi_{c}\right)} \frac{\psi_{c}}{\left(\rho+\delta+\psi_{c}\right)}$. Averaging (16) over all firms which operate in the market in city $c$, one obtains the following expression for the wage in job $j$ and city $c$

$$
w_{j c}=\gamma_{1 c} V M P L_{j c}+\gamma_{2 c} \sum_{k \in S} \psi_{k c \mid j} w_{k c}
$$

where $V M P L_{j c}$ is the value of the marginal product of labour associated with job $j$ and city $c$.

In order to avoid estimating a tautological relationship, the wage in job $j$ and city $c$ can be expressed as a function of wages in alternate jobs only. Using the fact that $\psi_{k c \mid j}=\mu$ if $k=j$, equation (17) can be rewritten as

$$
w_{j c}=\gamma_{1 c} V M P L_{j c}+\gamma_{2 c} \mu w_{j c}+\gamma_{2 c}(1-\mu) \sum_{k \in S \backslash\{j\}} \psi_{k c \mid j} w_{k c}
$$

and solving for $w_{j c}$

$$
w_{j c}=\tilde{\gamma}_{1 c} V M P L_{j c}+\tilde{\gamma}_{2 c} \sum_{k \in S \backslash\{j\}} \psi_{k c \mid j} w_{k c}
$$

where $\tilde{\gamma}_{1 c}=\frac{\gamma_{1 c}}{1-\gamma_{2 c} \mu}$ and $\tilde{\gamma}_{2 c}=\frac{\gamma_{2 c}(1-\mu)}{1-\gamma_{2 c} \mu}$. The parameters $\tilde{\gamma}_{1 c}$ and $\tilde{\gamma}_{2 c}$ are functions of the city-specific employment rate, as captured by $\gamma_{1 c}$ and $\gamma_{2 c}$.

\section{B Log linear approximation of the wage equation}

In order to make the relationship between job-city wages, a city's employment rate and the components of the value of the marginal product explicit, the paper performs a first-order linear approximation of equation (13) in the manuscript.

Let $\mathbf{e}=\left[p_{i c}, f_{i c}, \theta_{q i c}, \ln N_{q i c}, \sum_{k \in S \backslash\{q i\}} \psi_{k c \mid q i} w_{k c}, E R_{c}\right]$ be the vector of variables affecting the wage equation and with respect to which the log linear approximation is taken. Making this relationship 
explicit and taking logs on both sides of equation (13) in the manuscript, on obtains

$$
\ln \left[w_{q i c}(\mathbf{e})\right]=\ln \left[\tilde{\gamma}_{1 c}(\mathbf{e}) V M P L_{q i c}(\mathbf{e})+\tilde{\gamma}_{2 c}(\mathbf{e}) \sum_{k \in S \backslash\{q i\}} \psi_{k c \mid q i}(\mathbf{e}) w_{k c}(\mathbf{e})\right],
$$

where $V M P L_{q i c}(\mathbf{e})=f_{i c}(\mathbf{e}) g_{q i c}(\mathbf{e}) h_{q i c}(\mathbf{e})$. The linear approximation is expanded around the point where cities have identical employment rates $\left(E R_{c}=E R\right)$ and where employment is uniformly distributed across jobs $\left(\eta_{q i c}=\frac{1}{Q I}\right)$. This occurs at the point $\mathbf{e}_{\mathbf{0}}=[p, f, \theta, \ln N, w, E R]$, when both the value of the marginal product of labour and mobility costs are constant across jobs and cities (i.e. when $V M P L_{q i c}=V M P L=p f g h$ and $\varphi_{k \mid q i}=\varphi$ ). The approximation is given by

$$
\ln \left[w_{q i c}(\mathbf{e})\right] \approx \ln \left[w_{q i c}\left(\mathbf{e}_{\mathbf{0}}\right)\right]+\nabla \ln \left[w_{q i c}\left(\mathbf{e}_{\mathbf{0}}\right)\right]\left(\mathbf{e}-\mathbf{e}_{\mathbf{0}}\right)
$$

In what follows, the paper derives both components of the right-hand side of (21) separately.

Deriving $w_{q i c}\left(\mathbf{e}_{\mathbf{0}}\right)$ :

$$
\ln \left[w_{q i c}\left(\mathbf{e}_{\mathbf{0}}\right)\right]=\ln \left[\tilde{\gamma}_{1 c}\left(\mathbf{e}_{\mathbf{0}}\right) V M P L_{q i c}\left(\mathbf{e}_{\mathbf{0}}\right)+\tilde{\gamma}_{2 c}\left(\mathbf{e}_{\mathbf{0}}\right) \sum_{k \in S \backslash\{q i\}} \psi_{k c \mid q i}\left(\mathbf{e}_{\mathbf{0}}\right) w_{k c}\left(\mathbf{e}_{\mathbf{0}}\right)\right]
$$

Since $E R_{c}\left(\mathbf{e}_{\mathbf{0}}\right)=E R$, then $\tilde{\gamma}_{1 c}\left(\mathbf{e}_{\mathbf{0}}\right)=\tilde{\gamma}_{1}$ and $\tilde{\gamma}_{2 c}\left(\mathbf{e}_{\mathbf{0}}\right)=\tilde{\gamma}_{2}$. Moreover, since mobility costs are constant across jobs and cities, then $\psi_{k c \mid q i}\left(\mathbf{e}_{\mathbf{0}}\right)=\frac{1}{Q I-1}$ and $\sum_{k \in S \backslash\{q i\}} \psi_{k c \mid q i}\left(\mathbf{e}_{\mathbf{0}}\right) w_{k c}\left(\mathbf{e}_{\mathbf{0}}\right)=w$. Therefore, equation (22) can be rewritten as

$$
\ln \left[w_{q i c}\left(\mathbf{e}_{\mathbf{0}}\right)\right]=\ln \left[\tilde{\gamma}_{1} V M P L+\tilde{\gamma}_{2} w\right]
$$


Deriving $\nabla w_{q i c}\left(\mathbf{e}_{\mathbf{0}}\right)\left(\mathbf{e}-\mathbf{e}_{\mathbf{0}}\right)$ :

$$
\left.\begin{aligned}
\nabla \ln \left[w_{q i c}\left(\mathbf{e}_{\mathbf{0}}\right)\right]\left(\mathbf{e}-\mathbf{e}_{\mathbf{0}}\right) & =\left(\begin{array}{c}
\tilde{\gamma}_{1 c} M P L_{q i c} \\
\tilde{\gamma}_{1 c} p_{i c} g_{q i c} h_{q i c} \\
\tilde{\gamma}_{1 c} p_{i c}\left(\frac{\partial M P L_{q i c}}{\partial \theta_{q i c}}\right) \\
\tilde{\gamma}_{1 c} p_{i c}\left(\frac{\partial M P L_{q i c}}{\partial \ln N_{q i c}}\right) \\
\tilde{\gamma}_{2 c} \\
\left(\frac{\partial \tilde{\gamma}_{1 c}}{\partial E R_{c}}\right) V M P L_{q i c}+\left(\frac{\partial \tilde{\gamma}_{2 c}}{\partial E R_{c}}\right) \sum_{k \in S \backslash\{q i\}} \psi_{k c \mid q i} w_{k c}
\end{array}\right)
\end{aligned}\right|_{\left(\mathbf{e}_{\mathbf{0}}\right)} \cdot\left(\mathbf{e}-\mathbf{e}_{\mathbf{0}}\right),
$$

where $\frac{\partial M P L_{q i c}}{\partial \theta_{q i c}}=\left[\left(\frac{\partial f_{i c}}{\partial \theta_{q i c}}\right) g_{q i c} h_{q i c}+f_{i c}\left(\frac{\partial g_{q i c}}{\partial \theta_{q i c}}\right) h_{q i c}\right]$ and $\frac{\partial M P L_{q i c}}{\partial \ln N_{q i c}}=\left[\left(\frac{\partial f_{i c}}{\partial \ln N_{q i c}}\right) g_{q i c} h_{q i c}+f_{i c} g_{q i c}\left(\frac{\partial h_{q i c}}{\partial \ln N_{q i c}}\right)\right]$. Evaluating the vector of derivatives at the point $\mathbf{e}_{\mathbf{0}}=[p, f, \theta, \ln N, w, E R]$ and recalling that $\tilde{\gamma}_{1 c}\left(\mathbf{e}_{\mathbf{0}}\right)=\tilde{\gamma}_{1}$ and $\tilde{\gamma}_{2 c}\left(\mathbf{e}_{\mathbf{0}}\right)=\tilde{\gamma}_{2}$, one obtains

$$
\begin{aligned}
\nabla \ln \left[w_{q i c}\left(\mathbf{e}_{\mathbf{0}}\right)\right]\left(\mathbf{e}-\mathbf{e}_{\mathbf{0}}\right) & = \\
\frac{1}{\gamma_{1} V M P L+\gamma_{2} w} & \left(\begin{array}{c}
\tilde{\gamma}_{1} f g h \\
\tilde{\gamma}_{1} p g h \\
\tilde{\gamma}_{1} p\left[\left(\frac{\partial f}{\partial \theta}\right) g h+f\left(\frac{\partial g}{\partial \theta}\right) h\right] \\
\tilde{\gamma}_{1} p\left[\left(\frac{\partial f}{\partial \ln N}\right) g h+f g\left(\frac{\partial h}{\partial \ln N}\right)\right] \\
\tilde{\gamma}_{2} \\
\left(\frac{\partial \tilde{\gamma}_{1}}{\partial E R}\right) f g h+\left(\frac{\partial \tilde{\gamma}_{2}}{\partial E R}\right) w
\end{array}\right)\left(\begin{array}{c}
p_{i c}-p \\
f_{i c}-f \\
\theta_{q i c}-\theta \\
\ln N_{q i c}-\ln N \\
\sum_{k \in S \backslash\{q i\}} \psi_{k c \mid q i} w_{k c}-w \\
E R_{c}-E R
\end{array}\right) .
\end{aligned}
$$

\section{Obtaining the linear approximation:}

Combining (22) and (24), one obtains

$$
\ln w_{q i c}=\alpha_{0}+\tilde{\gamma}_{1} \alpha_{1} p_{i c}+\tilde{\gamma}_{1} \alpha_{2} f_{i c}+\tilde{\gamma}_{1} \alpha_{3} \theta_{q i c}+\tilde{\gamma}_{1} \alpha_{4} \ln N_{q i c}+\tilde{\gamma}_{2} \sum_{k \in S \backslash\{q i\}} \psi_{k c \mid q i} w_{k c}+\alpha_{5} E R_{c}
$$


where $\alpha_{0}-\alpha_{5}$ are constant terms obtained from the linear approximation. Specifically,

$$
\begin{aligned}
\alpha_{1} & =\frac{f g h}{\gamma_{1} V M P L+\gamma_{2} w} \\
\alpha_{2} & =\frac{p g h}{\gamma_{1} V M P L+\gamma_{2} w} \\
\alpha_{3} & =\frac{p}{\gamma_{1} V M P L+\gamma_{2} w}\left[\left(\frac{\partial f}{\partial \theta}\right) g h+f\left(\frac{\partial g}{\partial \theta}\right) h\right] \\
\alpha_{4} & =\frac{p}{\gamma_{1} V M P L+\gamma_{2} w}\left[\left(\frac{\partial f}{\partial \ln N}\right) g h+f g\left(\frac{\partial h}{\partial \ln N}\right)\right] \\
\alpha_{5} & =\frac{1}{\gamma_{1} V M P L+\gamma_{2} w}\left[\left(\frac{\partial \tilde{\gamma}_{1}}{\partial E R}\right) f g h+\left(\frac{\partial \tilde{\gamma}_{2}}{\partial E R}\right) w\right]
\end{aligned}
$$

and

$$
\alpha_{0}=\ln \left[\gamma_{1} p f g h+\gamma_{2} w\right]-\frac{\gamma_{1} \alpha_{1} p+\tilde{\gamma}_{2} \alpha_{2} f+\tilde{\gamma}_{1} \alpha_{3} \theta+\tilde{\gamma}_{1} \alpha_{4} \ln N+\tilde{\gamma}_{2} w+\alpha_{5} E R}{\gamma_{1} V M P L+\gamma_{2} w} .
$$

\section{Implications of workers' mobility across cities}

This section discusses the implications of allowing for labour mobility across cities. Such an extension modifies the value of being unemployed by expanding the set of a worker's outside options. Whether modeled as random or directed search, this extension generates an additional occupationindustry-specific term. This term reflects the option of searching for a job across all cities and is captured by job time-varying dummies in the empirical section. Therefore, including labour mobility across cities has no impact on the estimate of interest.

To see why, consider first random search. An unemployed worker has probability $(1-\Gamma)$ of getting a random draw in his city; probability $\Gamma$ of getting a draw in any city. In this case, the value of being unemployed in job $j$ and city $c$ can be expressed as

$$
\rho U_{j c}^{u}=(1-\Gamma) \psi_{c} \sum_{k \in S} \psi_{k c \mid j} U_{k c}^{e}+\Gamma \underbrace{\sum_{c^{\prime}=1}^{C} \psi_{c^{\prime}} \sum_{k \in S} \psi_{k c^{\prime} \mid j} U_{k c^{\prime}}^{e}}_{\text {j-specific term }}-\psi_{c} U_{j c}^{u},
$$

where $\Gamma \sum_{c^{\prime}=1}^{C} \psi_{c^{\prime}} \sum_{k \in S} \psi_{k c^{\prime} \mid j} U_{k c^{\prime}}^{e}$ captures the option to search across cities. Since job-specific skill transferability $\varphi_{k \mid j}$ is measured at the national level, workers' mobility across cities will be captured 
by a job-specific term.

Consider now directed search. An unemployed worker has probability $\Lambda$ of being able to change geographic location and choosing to move to the city which maximises his value of being employed. Then,

$$
\rho U_{j c}^{u}=(1-\Lambda) \psi_{c} \sum_{k \in S} \psi_{k c \mid j} U_{k c}^{e}+\Lambda \underbrace{\max _{c^{\prime}}\left[\psi_{c^{\prime}} \sum_{k \in S} \psi_{k c^{\prime} \mid j} U_{k c^{\prime}}^{e}\right]}_{\text {j-specific term }}-\psi_{c} U_{j c}^{u},
$$

where $\max _{c^{\prime}}\left[\psi_{c^{\prime}} \sum_{k \in S} \psi_{k c^{\prime} \mid j} U_{k c^{\prime}}^{e}\right]$ results from a directed search across cities. As for a given job there is only one location which maximises the value of being unemployed, workers' mobility across cities can be captured by an occupation-industry-specific term.

\section{Implications of directed search across occupations}

As for the case of directed search across cities, directed search across occupations modifies the value of being unemployed by expanding the set of a worker's outside options. Assume that an unemployed worker has probability $\Lambda^{\prime}$ of being able to direct his search towards the occupation that maximises his value of being employed. Then, the vaule of being unemployed in job $j$ and city $c$ is given by

$$
\rho U_{j c}^{u}=\left(1-\Lambda^{\prime}\right) \psi_{c} \sum_{k \in S} \psi_{k c \mid j} U_{k c}^{e}+\Lambda^{\prime} \underbrace{\max _{q^{\prime}}\left[\sum_{c^{\prime}=1}^{C} \psi_{c^{\prime}} \sum_{k \in S} \psi_{k c^{\prime} \mid j} U_{k c^{\prime}}^{e}\right]}_{\text {j-specific term }}-\psi_{c} U_{j c}^{u}
$$

where the term $\max _{q^{\prime}}\left[\sum_{c^{\prime}=1}^{C} \psi_{c^{\prime}} \sum_{k \in S} \psi_{k c^{\prime} \mid j} U_{k c^{\prime}}^{e}\right]$ results from a directed search across occupations. Since the occupation that maximises a worker's utility of employment is similar for all workers of a particular job-type, implications of directed search across occupations will be captured by job time-varying dummies in the empirical section. 


\section{E Examining consistency}

\section{Writing the transition probability as a function of comparative advantages:}

In order to examine consistency, it is helpful to first explicitly express the transition probability as a function of comparative advantages. To achieve this goal, one can rewrite $\varepsilon_{q i c}$ as the sum of a term common to all jobs of the same city $\varepsilon_{c}$, and another comparative advantage component, $v_{q i c}^{\varepsilon}$, where by definition $\sum_{q=1}^{Q} \sum_{i=1}^{I} v_{q i c}^{\varepsilon}=0 .{ }^{1}$ By the same token, define $\Omega_{i c}=\Omega_{c}+v_{i c}^{\Omega}$, where $\sum_{i=1}^{I} v_{i c}^{\Omega}=0$. Using this formulation, one can rewrite equation (23) of the manuscript as

$$
\begin{aligned}
\psi_{q^{\prime} i^{\prime} c \mid q i} & \approx \frac{1}{Q I-1}+\pi_{1}\left[v_{i^{\prime} c}^{\Omega}+\frac{1}{Q I-1} v_{i c}^{\Omega}\right]+\pi_{2}\left[v_{q^{\prime} i^{\prime} c}^{\varepsilon}+\frac{1}{Q I-1} v_{q i c}^{\varepsilon}\right] \\
& +\pi_{3}\left[\varphi_{q^{\prime} i^{\prime} \mid q i}-\frac{1}{Q I-1}\left(1-\varphi_{q i \mid q i}\right)\right] .
\end{aligned}
$$

A similar expression can be obtained for the predicted transition probability. However, instead of being a function of current components, $\hat{\psi}_{q^{\prime} i^{\prime} c \tau \mid q i}$ depends on past sources of comparative advantages, i.e.

$$
\begin{aligned}
\hat{\psi}_{q^{\prime} i^{\prime} c \tau \mid q i} & \approx \frac{1}{Q I-1}+\pi_{1}\left[v_{i^{\prime} c(\tau-1)}^{\Omega}+\frac{1}{Q I-1} v_{i c(\tau-1)}^{\Omega}\right]+\pi_{2}\left[v_{q^{\prime} i^{\prime} c(\tau-1)}^{\varepsilon}+\frac{1}{Q I-1} v_{q i c(\tau-1)}^{\varepsilon}\right] \\
& +\pi_{3}\left[\varphi_{q^{\prime} i^{\prime} \mid q i}-\frac{1}{Q I-1}\left(1-\varphi_{q i \mid q i}\right)\right]
\end{aligned}
$$

where $\tau$ is the time subscript. Equation (30) has been obtained using the fact that predicted employment shares can be written as

$$
\hat{\eta}_{q i c \tau}=\eta_{q i c(\tau-1)} \frac{g_{q i \tau}}{\sum_{q^{\prime}=1}^{Q} \sum_{i^{\prime}=1}^{I} \eta_{q^{\prime} i^{\prime} c(\tau-1)} g_{q^{\prime} i^{\prime} \tau}}
$$

where $g_{q i \tau}=\frac{N_{q i \tau}}{N_{q i(\tau-1)}}$.

\footnotetext{
${ }^{1}$ Note that the comparative advantage of city $c$ for job $q i$ is given by:

$$
\begin{aligned}
\left(\theta_{q i c}-\sum_{c} \theta_{q i c}\right)-\left(\sum_{q^{\prime}=1}^{Q} \sum_{i^{\prime}=1}^{I}\left[\theta_{q^{\prime} i^{\prime} c}-\sum_{c} \theta_{q^{\prime} i^{\prime} c}\right]\right) & =\varepsilon_{q i c}-\varepsilon_{c} \\
& =v_{q i c}^{\varepsilon}
\end{aligned}
$$
}




\section{Evaluating the validity of the instruments:}

In what follows, the paper examines the validity of the first set of instruments $I V_{1 q i c \tau}$ and $I V_{2 q i c \tau}$. Examining consistency for the second set of instruments is analogous. This first set of instruments is given by

$$
I V_{1 q i c \tau}=\sum_{k \in S \backslash\{q i\}} \hat{\psi}_{k c \tau \mid q i} \Delta \nu_{k \tau} \quad \text { and } \quad I V_{2 q i c \tau}=\sum_{k \in S \backslash\{q i\}} \nu_{k(\tau-1)} \Delta \hat{\psi}_{k c \tau \mid q i}
$$

$I V_{1 q i c \tau}$ is uncorrelated with the error term if ${ }^{2}$

$$
\frac{1}{1-\mu} \tilde{\gamma}_{1} \alpha_{3} \lim _{Q, I, C \rightarrow \infty} \sum_{c=1}^{C} \sum_{q=1}^{Q} \sum_{i=1}^{I}\left(\sum_{k \in S} \hat{\psi}_{k c \tau \mid q i} \Delta \nu_{k \tau}-\mu \Delta \nu_{q i \tau}\right) \Delta \varepsilon_{q i c \tau}=0 .
$$

Since the wage premia do not vary across cities, condition (31) can be rearranged as follows

$$
\lim _{Q, I, C \rightarrow \infty}\left(\sum_{k \in S} \Delta \nu_{k \tau} \cdot \sum_{c=1}^{C} \sum_{q=1}^{Q} \sum_{i=1}^{I} \hat{\psi}_{k c \tau \mid q i} \Delta \varepsilon_{q i c \tau}-\mu \sum_{q=1}^{Q} \sum_{i=1}^{I} \Delta \nu_{q i \tau} \sum_{c=1}^{C} \Delta \varepsilon_{q i c \tau}\right)=0 .
$$

where the second term on the left-hand side is zero because $\sum_{c=1}^{C} \varepsilon_{q i c \tau}=0$. Allowing $C \rightarrow \infty$ first, condition (32) is satisfied if

$$
\lim _{C \rightarrow \infty} \sum_{c=1}^{C} \sum_{q=1}^{Q} \sum_{i=1}^{I} \hat{\psi}_{k c \tau \mid q i} \Delta \varepsilon_{q i c \tau}=0
$$

Hence, the validity of $I V_{1 q i c \tau}$ hinges on the exogeneity of the prediction $\hat{\psi}_{k c \mid q i}$ with respect to shocks to $\varepsilon_{q i c \tau}$. Using (30) together with the fact that $\sum_{k \in S} v_{k c}^{\varepsilon}=0, \sum_{i=1}^{I} v_{i c}^{\Omega}=0$ and $\sum_{c=1}^{C} \varepsilon_{q i c \tau}=0$, condition (33) rewrites

$\lim _{C \rightarrow \infty} \sum_{c=1}^{C} \sum_{q=1}^{Q} \sum_{i=1}^{I} \hat{\psi}_{k c \tau \mid q i} \Delta \varepsilon_{q i c \tau}=\sum_{q=1}^{Q} \sum_{i=1}^{I} \lim _{C \rightarrow \infty} \sum_{c=1}^{C}\left[\pi_{1} \frac{1}{Q I-1} v_{i c(\tau-1)}^{\Omega} \Delta \varepsilon_{q i c \tau}+\pi_{2} \frac{1}{Q I-1} v_{q i c(\tau-1)}^{\varepsilon} \Delta \varepsilon_{q i c \tau}\right]$.

Therefore, $I V_{1 q i c \tau}$ is exogeneous if $E\left(v_{i c(\tau-1)}^{\Omega} \Delta \varepsilon_{q i c \tau}\right)=0$ and $E\left(v_{q i c(\tau-1)}^{\varepsilon} \Delta \varepsilon_{q i c \tau}\right)=0$ and $E\left(\Delta v_{q i c \tau}^{\varepsilon}\right)=$

\footnotetext{
${ }^{2}$ Note that in writing this condition, the paper uses the fact that $\sum_{k \in S} \psi_{k c \mid q i} \nu_{k}=\mu \nu_{q i}+(1-\mu) \sum_{k \in S \backslash\{q i\}} \psi_{k c \mid q i} \nu_{k}$ and that $\Delta \tilde{\xi}_{q i c \tau}=\tilde{\gamma}_{1} \alpha_{3} \Delta \varepsilon_{q i c \tau}$.
} 
0, i.e. if shocks to the source of comparative advantages $\Delta \varepsilon_{q i c \tau}^{\varepsilon}$ are independent of past comparative advantages $v_{i c \tau}^{\Omega}, v_{q i c \tau}^{\varepsilon}$.

Similarly, $I V_{2 q i c \tau}$ is a valid instrument if it satisfies

$$
\frac{1}{1-\mu} \tilde{\gamma}_{1} \alpha_{3} \lim _{Q, I, C \rightarrow \infty} \sum_{c=1}^{C} \sum_{q=1}^{Q} \sum_{i=1}^{I}\left(\sum_{k \in S} \nu_{k(\tau-1)} \Delta \hat{\psi}_{k c \tau \mid q i}-\nu_{q i(\tau-1)} \Delta \mu\right) \Delta \varepsilon_{q i c \tau}=0 .
$$

As for $I V_{1 q i c \tau}$, this limiting argument can be developed to obtain the following expression

$\lim _{C \rightarrow \infty} \sum_{c=1}^{C} \sum_{q=1}^{Q} \sum_{i=1}^{I} \Delta \hat{\psi}_{k c \tau \mid q i} \Delta \varepsilon_{q i c \tau}=\sum_{q=1}^{Q} \sum_{i=1}^{I} \lim _{C \rightarrow \infty} \sum_{c=1}^{C}\left[\pi_{1} \frac{1}{Q I-1} \Delta v_{i c(\tau-1)}^{\Omega} \Delta \varepsilon_{q i c \tau}+\pi_{2} \frac{1}{Q I-1} \Delta v_{q i c(\tau-1)}^{\varepsilon} \Delta \varepsilon_{q i c \tau}\right]$.

Therefore, $I V_{2 q i c \tau}$ is exogeneous if $E\left(\Delta v_{i c(\tau-1)}^{\Omega} \Delta \varepsilon_{q i c \tau}\right)=0$ and $E\left(\Delta v_{q i c(\tau-1)}^{\varepsilon} \Delta \varepsilon_{q i c \tau}\right)=0$, i.e. if shocks to the source of comparative advantages $\Delta \varepsilon_{q i c \tau}^{\varepsilon}$ are independent of past changes in comparative advantages. 


\section{F Definition of cities}

Cities are constructed in accordance with the definition of labour markets proposed by Kropp and Schwengler (2011; KS labour markets henceforth). ${ }^{3}$ According to their definition, Western Germany comprises 38 labour markets and 9 regions. The constraint of 20 individuals per cell requires merging KS labour markets since without any further aggregation, some labour markets would represent less than 1500 individuals per year, i.e. on average, less than 6 individuals per cell if one would work with 250 occupation-industry cells. In order to obtain 5000 individuals per city-year, KS labour markets are merged in two steps. The first one aggregates KS labour markets at a higher digit in conformity with the official classification. The second one aggregates zones with an insufficiant number of individuals to their neighbours. To maintain geographical coherence, this study makes sure that the aggregated labour markets belong to the same region. It follows that the original $38 \mathrm{KS}$ labour markets are merged into 19 geographical areas ('cities'), of which 10 correspond to KS labour markets and 9 are aggregates. Table 1 describes these steps.

\footnotetext{
${ }^{3}$ Online material including Kropp and Schwengler's (2011) correspondence table between districts, labour markets and regions can be downloaded at http://www.iab.de/389/section.aspx/Publikation/k110222301
} 
Table 1: Aggregation of labour markets

\begin{tabular}{|c|c|c|c|c|c|}
\hline \multicolumn{2}{|c|}{ Labour markets as defined in Kropp and Schwengler } & \multirow[b]{2}{*}{$\begin{array}{c}25 \\
\text { official }\end{array}$} & \multirow[b]{2}{*}{ bridges } & \multirow{2}{*}{$\begin{array}{c}\text { 'Cities' } \\
19 \\
\text { merged }\end{array}$} & \multirow{2}{*}{$\begin{array}{c}\text { Regions } \\
9 \\
\text { official }\end{array}$} \\
\hline $\mathrm{N}$ & $\begin{array}{c}38 \\
\text { official }\end{array}$ & & & & \\
\hline Hamburg & 2000000 & 20 & 20 & 2 & 2 \\
\hline Braunschweig/Wolfsburg & 3101000 & 31 & 31 & 31 & 3 \\
\hline Göttingen & 3152012 & 31 & 31 & 31 & 3 \\
\hline Hannover & 3241001 & 32 & 32 & 32 & 3 \\
\hline Oldenburg(O.) & 3403000 & 34 & 34 & 34 & 3 \\
\hline Osnabrck & 3404000 & 34 & 34 & 34 & 3 \\
\hline Bremen & 4011000 & 40 & 40 & 4 & 4 \\
\hline Düsseldorf-Ruhr & 5113000 & 51 & 51 & 51 & 5 \\
\hline Aachen & 5313000 & 53 & 53 & 53 & 5 \\
\hline Köln & 5315000 & 53 & 53 & 53 & 5 \\
\hline Münster & 5515000 & 55 & 55 & 55 & 5 \\
\hline Bielefeld/Paderborn & 5711000 & 57 & 57 & 57 & 5 \\
\hline Siegen & 5970040 & 59 & merged with 53 & 53 & 5 \\
\hline Frankfurt a.M. & 6412000 & 64 & 64 & 6 & 6 \\
\hline Kassel & 6611000 & 66 & merged with 64 & 6 & 6 \\
\hline Koblenz & 7111000 & 71 & 71 & 7 & 7 \\
\hline Trier & 7211000 & 72 & merged with 71 & 7 & 7 \\
\hline Stuttgart & 8111000 & 81 & 81 & 81 & 8 \\
\hline Karlsruhe & 8212000 & 82 & 82 & 82 & 8 \\
\hline Mannheim & 8222000 & 82 & 82 & 82 & 8 \\
\hline Freiburg i.Br. & 8311000 & 83 & 83 & 83 & 8 \\
\hline Offenburg & 8317096 & 83 & 83 & 83 & 8 \\
\hline Villingen-Schwenningen & 8326074 & 83 & 83 & 83 & 8 \\
\hline Konstanz & 8335075 & 83 & 83 & 83 & 8 \\
\hline Lörrach & 8336050 & 83 & 83 & 83 & 8 \\
\hline Ulm & 8421000 & 84 & 84 & 84 & 8 \\
\hline Ravensburg & 8436064 & 84 & 84 & 84 & 8 \\
\hline München & 9162000 & 91 & 91 & 91 & 9 \\
\hline Passau & 9262000 & 92 & 92 & 92 & 9 \\
\hline Regensburg & 9362000 & 93 & merged with 92 & 92 & 9 \\
\hline Weiden i.d.OPf. & 9363000 & 93 & merged with 92 & 92 & 9 \\
\hline Bayreuth & 9462000 & 94 & merged with 95 & 95 & 9 \\
\hline Coburg & 9463000 & 94 & merged with 95 & 95 & 9 \\
\hline Hof & 9464000 & 94 & merged with 95 & 95 & 9 \\
\hline Nürnberg & 9564000 & 95 & 95 & 95 & 9 \\
\hline Schweinfurt & 9662000 & 96 & merged with 95 & 95 & 9 \\
\hline Würzburg & 9663000 & 96 & merged with 95 & 95 & 9 \\
\hline Saarbrücken & 10041100 & 100 & 100 & 10 & 10 \\
\hline
\end{tabular}




\section{G Industrial classification into 16 categories}

Table 2: Industrial classification into 16 categories.

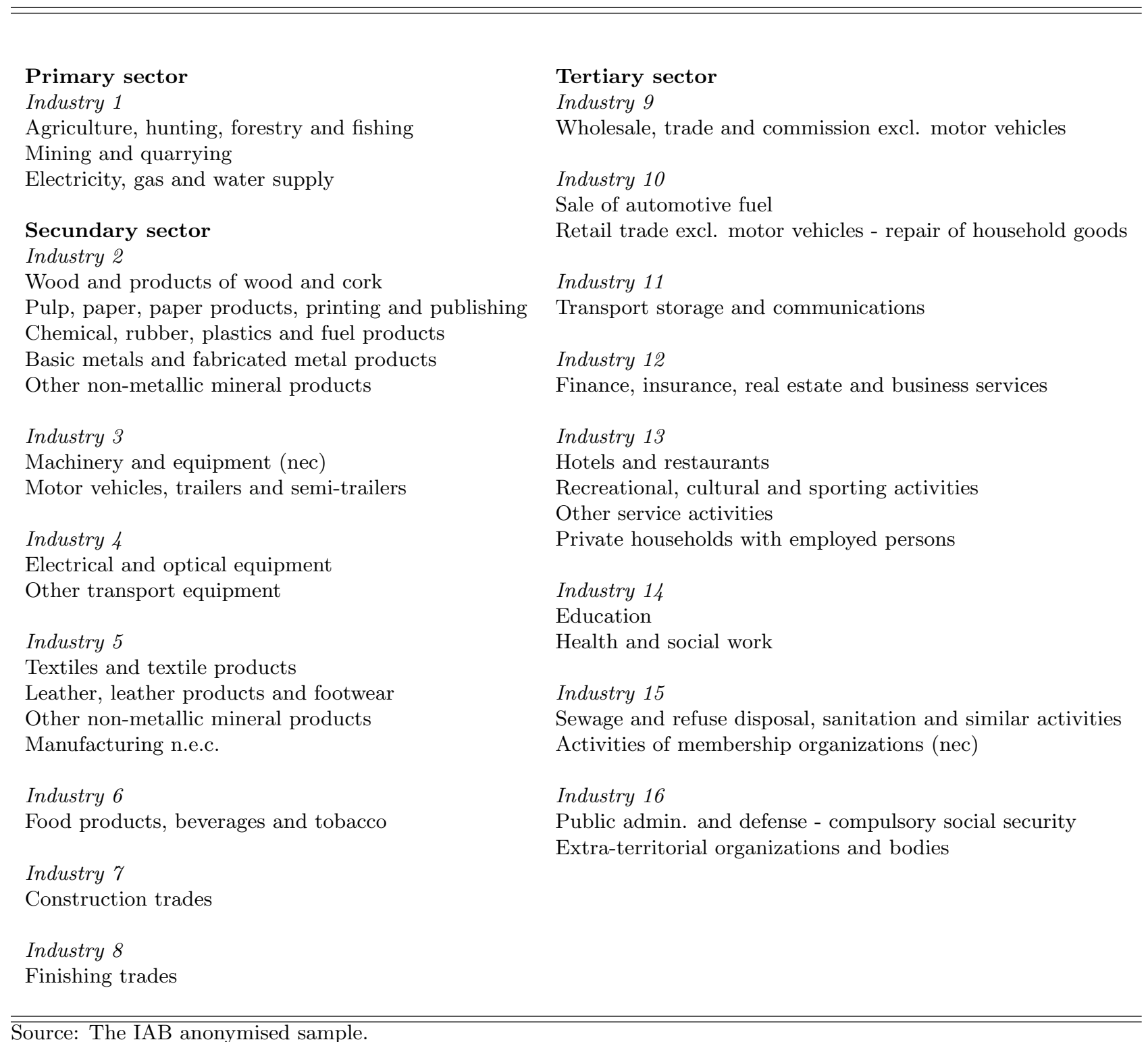




\section{H Occupational classification into 32 categories}

Table 3: Occupational classification into 32 categories.

\section{Agricultural}

Occupation 106:

Mining and quarrywork

Occupation 709:

Manufacturing

Occupation 1011:

Occupation 1213:

Occupation 1415:

Occupation 161\%:

Occupation 18:

Occupation 1924:

Occupation 2530:

Occupation 31:

Occupation 32:

Occupation 3336:

Occupation 37:

Occupation 3943:

Occupation 444\%:

Occupation 4849:

Occupation 50:

Occupation 51:

Occupation 52:

Occupation 53:

Occupation 54:

\section{Technicians}

Occupation 6061:

Occupation 6263:

\section{Services and professionals}

Occupation 68:

Occupation 6970:

Occupation 8283:

Occupation 9093:

Occupation 7174:

Occupation 7578:

Occupation 7981:

Occupation 8485:

Occupation 8689:
Farming, forestry, gardening, fishing

Mining and quarrywork

Stone, jewelery, brickwork

Glass and ceramics

Chemicals, plastics and rubber

Paper and printing

Woodwork

Metalworkers, primary product

Skilled metal work and related

Electrical

Metal and assembly / installation

Textiles

Leather goods

Food, drink and tobacco

Construction

Building

Carpenters

Painters

Goods sorters, packagers

Assistants

Machine operators

Technicians - engineers and related

Technicians - manufacturing and science

Buying and selling

Banking, insurance, agents

Arts, creative and recreational

Other services, personal and leisure services

Travel and transport

Administration and bureaucracy

Public order, safety and security

Health services

Teaching and social employment

$\overline{\text { Note: Occupations in the IAB anonymised sample are classified into } 32 \text { broader categories }}$ according to the 1975 German classification of occupations. 


\section{Occupation-industry mix}

An important step of the data work consists in defining the aggregation level of occupations, industries and cities. To ensure the precision of the measures reflecting wage premia, employment shares and employment transitions, this paper requires that each occupation-industry-city cell contains at least 20 employed individuals every year. Finally, an occupation-industry cell is retained if it is present over the years 1977-2001 and if it is observed in at least 5 cities. 135 occupationindustry cells meet these two criteria. Table 4 shows which occupation-industry mix is retained for this study. The table also informs on the representation of occupations within industries and across cities. The figures indicate the number of cities in which an occupation-industry cell (which satisfies the aforementioned criteria) is observed.

Table 4: Occupation-industry mix

\begin{tabular}{|c|c|c|c|c|c|c|c|c|c|c|c|c|c|c|c|c|}
\hline Occupation/Industry & 1 & 2 & 3 & 4 & 5 & 6 & 7 & 8 & 9 & 10 & 11 & 12 & 13 & 14 & 15 & 16 \\
\hline 106 & 19 & 0 & 0 & 0 & 0 & 0 & 0 & 0 & 0 & 0 & 0 & 0 & 0 & 0 & 0 & 10 \\
\hline 709 & 0 & 0 & 0 & 0 & 0 & 0 & 0 & 0 & 0 & 0 & 0 & 0 & 0 & 0 & 0 & 0 \\
\hline 1011 & 0 & 10 & 0 & 0 & 0 & 0 & 0 & 0 & 0 & 0 & 0 & 0 & 0 & 0 & 0 & 0 \\
\hline 1213 & 0 & 0 & 0 & 0 & 9 & 0 & 0 & 0 & 0 & 0 & 0 & 0 & 0 & 0 & 0 & 0 \\
\hline 1415 & 0 & 18 & 0 & 9 & 18 & 0 & 0 & 0 & 0 & 0 & 0 & 0 & 0 & 0 & 0 & 0 \\
\hline 1617 & 0 & 16 & 0 & 0 & 17 & 0 & 0 & 0 & 0 & 0 & 0 & 0 & 0 & 0 & 0 & 0 \\
\hline 18 & 0 & 5 & 0 & 0 & 5 & 0 & 0 & 0 & 0 & 0 & 0 & 0 & 0 & 0 & 0 & 0 \\
\hline 1924 & 0 & 17 & 19 & 19 & 0 & 0 & 0 & 0 & 0 & 0 & 0 & 0 & 0 & 0 & 0 & 0 \\
\hline 2530 & 9 & 19 & 19 & 19 & 17 & 0 & 8 & 19 & 10 & 16 & 10 & 5 & 0 & 0 & 0 & 9 \\
\hline 31 & 13 & 7 & 13 & 19 & 0 & 0 & 0 & 19 & 0 & 6 & 9 & 0 & 0 & 0 & 0 & 0 \\
\hline 32 & 0 & 0 & 17 & 18 & 0 & 0 & 0 & 0 & 0 & 0 & 0 & 0 & 0 & 0 & 0 & 0 \\
\hline 3336 & 0 & 0 & 0 & 0 & 14 & 0 & 0 & 0 & 0 & 0 & 0 & 0 & 0 & 0 & 0 & 0 \\
\hline 37 & 0 & 0 & 0 & 0 & 6 & 0 & 0 & 0 & 0 & 0 & 0 & 0 & 0 & 0 & 0 & 0 \\
\hline 3943 & 0 & 0 & 0 & 0 & 0 & 19 & 0 & 0 & 0 & 0 & 0 & 0 & 19 & 14 & 0 & 0 \\
\hline 4447 & 0 & 7 & 0 & 0 & 0 & 0 & 19 & 0 & 0 & 0 & 0 & 0 & 0 & 0 & 0 & 14 \\
\hline 4849 & 0 & 0 & 0 & 0 & 6 & 0 & 11 & 10 & 0 & 0 & 0 & 0 & 0 & 0 & 0 & 0 \\
\hline 50 & 0 & 0 & 0 & 0 & 19 & 0 & 0 & 0 & 0 & 0 & 0 & 0 & 0 & 0 & 0 & 0 \\
\hline 51 & 0 & 0 & 7 & 5 & 0 & 0 & 0 & 18 & 0 & 0 & 0 & 0 & 0 & 0 & 0 & 0 \\
\hline 52 & 0 & 8 & 10 & 12 & 13 & 12 & 0 & 0 & 7 & 7 & 0 & 0 & 0 & 0 & 0 & 0 \\
\hline 53 & 0 & 0 & 9 & 0 & 7 & 0 & 0 & 0 & 0 & 0 & 0 & 0 & 0 & 0 & 0 & 0 \\
\hline 54 & 5 & 6 & 0 & 0 & 0 & 0 & 12 & 0 & 0 & 0 & 0 & 0 & 0 & 0 & 0 & 0 \\
\hline 6061 & 0 & 6 & 11 & 12 & 0 & 0 & 7 & 0 & 0 & 0 & 0 & 10 & 0 & 6 & 0 & 9 \\
\hline 6263 & 8 & 16 & 16 & 19 & 13 & 0 & 0 & 5 & 8 & 0 & 0 & 13 & 0 & 7 & 0 & 12 \\
\hline 68 & 0 & 9 & 11 & 10 & 10 & 19 & 0 & 0 & 19 & 19 & 0 & 0 & 11 & 0 & 0 & 0 \\
\hline 6970 & 0 & 0 & 0 & 0 & 0 & 0 & 0 & 0 & 0 & 0 & 11 & 19 & 0 & 0 & 0 & 0 \\
\hline 8283 & 0 & 0 & 0 & 0 & 0 & 0 & 0 & 0 & 0 & 0 & 0 & 0 & 10 & 0 & 0 & 0 \\
\hline 9093 & 0 & 0 & 0 & 0 & 0 & 0 & 0 & 0 & 0 & 7 & 0 & 13 & 19 & 19 & 12 & 19 \\
\hline 7174 & 0 & 19 & 16 & 12 & 14 & 14 & 8 & 0 & 19 & 18 & 19 & 6 & 5 & 0 & 5 & 19 \\
\hline 7578 & 15 & 19 & 19 & 19 & 19 & 17 & 18 & 12 & 19 & 19 & 18 & 19 & 14 & 19 & 18 & 19 \\
\hline 7981 & 0 & 0 & 0 & 0 & 0 & 0 & 0 & 0 & 0 & 0 & 0 & 7 & 0 & 8 & 5 & 13 \\
\hline 8485 & 0 & 0 & 0 & 0 & 0 & 0 & 0 & 0 & 0 & 6 & 0 & 0 & 0 & 19 & 19 & 0 \\
\hline 8689 & 0 & 0 & 0 & 0 & 0 & 0 & 0 & 0 & 0 & 0 & 0 & 0 & 0 & 19 & 14 & 11 \\
\hline
\end{tabular}




\section{J Industrial and occupational employment shares}

Table 5 shows summary statistics of yearly local industrial employment shares (i.e. of $\eta_{i c t}=\frac{N_{i c t}}{N_{c t}}$, where $t$ is the time subscript), computed over the entire sample. The rest of the table computes the summary statistics of local industrial employment shares (i.e. of $\eta_{i c}=\frac{N_{i c}}{N_{c}}$ ) by industry. Table 6 presents the occupational counterpart of Table 5. Both tables suggest substantial variation in the industrial and occupational composition of employment across cities.

Table 5: Industrial employment shares

\begin{tabular}{lccccc}
\hline \multicolumn{1}{c}{ Variable } & Mean & Std. Dev. & Min. & Max. & N \\
\hline Overall & 0.063 & 0.035 & 0.006 & 0.250 & 7904 \\
& & & & & \\
Primary sector & & & & & \\
Primary sector & 0.017 & 0.007 & 0.007 & 0.034 & 19 \\
& & & & & \\
Secondary sector & & & & & \\
Wood, chemicals, basic metals & 0.066 & 0.028 & 0.029 & 0.130 & 19 \\
Machinery, motor vehicles & 0.109 & 0.045 & 0.056 & 0.228 & 19 \\
Electrical & 0.091 & 0.032 & 0.050 & 0.166 & 19 \\
Texiles, leather & 0.075 & 0.041 & 0.029 & 0.172 & 19 \\
Food, beverages, tobacco & 0.036 & 0.013 & 0.024 & 0.068 & 19 \\
Construction trades & 0.054 & 0.013 & 0.042 & 0.093 & 19 \\
Finishing trades & 0.028 & 0.004 & 0.019 & 0.034 & 19 \\
& & & & & \\
Tertiary sector & & & & & \\
Wholesale & 0.055 & 0.010 & 0.035 & 0.075 & 19 \\
Retail trade & 0.084 & 0.012 & 0.062 & 0.107 & 19 \\
Transport and communications & 0.044 & 0.017 & 0.030 & 0.095 & 19 \\
Finance, insurance, real estate & 0.092 & 0.022 & 0.059 & 0.130 & 19 \\
Restauration, recreational & 0.043 & 0.008 & 0.033 & 0.062 & 19 \\
Education, health, social & 0.104 & 0.014 & 0.074 & 0.127 & 19 \\
Sewage, sanitation & 0.039 & 0.008 & 0.024 & 0.052 & 19 \\
Public administration & 0.064 & 0.014 & 0.035 & 0.086 & 19 \\
& & & & & \\
\hline \hline
\end{tabular}


Table 6: Occupational employment shares

\begin{tabular}{|c|c|c|c|c|c|}
\hline Variable & Mean & Std. Dev. & Min. & Max. & $\mathbf{N}$ \\
\hline Overall & 5.7 & 2.0 & 1.6 & 17.2 & 18315 \\
\hline \multicolumn{6}{|l|}{ Agricultural } \\
\hline \multicolumn{6}{|l|}{ Manufacturing } \\
\hline Stone, jewelery, brickwork & 0.004 & 0.003 & 0.002 & 0.010 & 10 \\
\hline Glass, ceramics & 0.008 & 0.009 & 0.001 & 0.029 & 9 \\
\hline Chemicals, plastics, rubber & 0.021 & 0.008 & 0.009 & 0.043 & 18 \\
\hline Paper, printing & 0.013 & 0.004 & 0.007 & 0.022 & 17 \\
\hline Woodwork & 0.005 & 0.005 & 0.001 & 0.015 & 6 \\
\hline Metalworkers, primary product & 0.034 & 0.013 & 0.015 & 0.064 & 19 \\
\hline Skilled metal work & 0.089 & 0.01 & 0.073 & 0.106 & 19 \\
\hline Electrical & 0.025 & 0.005 & 0.015 & 0.032 & 19 \\
\hline Metal assembly, installation & 0.026 & 0.010 & 0.007 & 0.047 & 18 \\
\hline Textiles & 0.016 & 0.011 & 0.003 & 0.038 & 14 \\
\hline Leather goods & 0.008 & 0.011 & 0.002 & 0.030 & 6 \\
\hline Food, drink, tobacco & 0.028 & 0.008 & 0.018 & 0.053 & 19 \\
\hline Construction & 0.045 & 0.014 & 0.029 & 0.087 & 19 \\
\hline Building & 0.007 & 0.002 & 0.003 & 0.013 & 14 \\
\hline Carpenters & 0.011 & 0.006 & 0.005 & 0.026 & 19 \\
\hline Painters & 0.008 & 0.002 & 0.005 & 0.016 & 18 \\
\hline Goods sorters, packagers & 0.014 & 0.006 & 0.006 & 0.028 & 18 \\
\hline Assistants & 0.009 & 0.008 & 0.002 & 0.031 & 12 \\
\hline Machine operators & 0.006 & 0.002 & 0.003 & 0.010 & 13 \\
\hline \multicolumn{6}{|l|}{ Technicians } \\
\hline Eengineers & 0.018 & 0.009 & 0.003 & 0.030 & 15 \\
\hline Manufacturing, science & 0.037 & 0.012 & 0.016 & 0.058 & 19 \\
\hline \multicolumn{6}{|l|}{ Services, professionals } \\
\hline Buying, selling & 0.087 & 0.008 & 0.076 & 0.107 & 19 \\
\hline Banking, insurance, agents & 0.042 & 0.008 & 0.030 & 0.057 & 19 \\
\hline Arts, creative, recreational & 0.004 & 0.001 & 0.002 & 0.006 & 10 \\
\hline \multicolumn{6}{|l|}{ Other services, personal, leisure services } \\
\hline Travel, transport & 0.076 & 0.008 & 0.065 & 0.098 & 19 \\
\hline Administration, bureaucracy & 0.223 & 0.015 & 0.196 & 0.243 & 19 \\
\hline Public order, safety, security & 0.007 & 0.003 & 0.003 & 0.012 & 13 \\
\hline Health services & 0.065 & 0.009 & 0.048 & 0.082 & 19 \\
\hline Teaching, social employment & 0.038 & 0.006 & 0.027 & 0.052 & 19 \\
\hline
\end{tabular}




\section{K Additional results}

\section{K-1 Occupation-city time-varying dummies}

Table 7 presents a specification that includes occupation-city time-varying dummies $\left(d_{q c \tau}\right)$. Such a specification does not arise naturally within the framework of the paper, yet it is interesting to see how far the identification can go. When occupation-city-time dummies are included, the triple difference estimation focuses on periodical changes in wages across industries in the same occupation and city, which means for instance comparing wage differentials in the manufacturing sector with those in the tertiary sector for secretaries in city A. To allow for identification, such a comparison requires that there be sufficient variation in observed mobility of secretaries across industries within city A. The IV estimates are positive and similar to those of the baseline but quite imprecisely measured. This result is not too surprising as one would expect variation across sectoral switches to be much less pronounced than occupational movements.

Table 7: Occupation-city time-varying dummies.

\begin{tabular}{|c|c|c|c|}
\hline \multirow[t]{2}{*}{ Dependent variable } & \multicolumn{3}{|c|}{$\Delta \log$ wages $_{q i c \tau}$} \\
\hline & $\begin{array}{c}(\mathbf{1}) \\
\text { OLS } \\
\end{array}$ & $\begin{array}{l}(2) \\
\text { IV }\end{array}$ & $\begin{array}{l}\text { (3) } \\
\text { IV }\end{array}$ \\
\hline $\begin{array}{l}\Delta \text { Outside options }{ }_{q i c \tau} \text { : } \\
\Delta \sum_{k \in S \backslash\{q i\}} \psi_{k c \tau \mid q i} w_{k c \tau}\end{array}$ & $\begin{array}{l}-0.279^{* * *} \\
(0.102)\end{array}$ & $\begin{array}{c}0.723 \\
(0.440)\end{array}$ & $\begin{array}{r}0.569^{*} \\
(0.332)\end{array}$ \\
\hline $\begin{array}{l}\Delta d_{q i \tau} \\
\Delta d_{q c \tau}\end{array}$ & $\begin{array}{l}\text { yes } \\
\text { yes }\end{array}$ & $\begin{array}{l}\text { yes } \\
\text { yes }\end{array}$ & $\begin{array}{l}\text { yes } \\
\text { yes }\end{array}$ \\
\hline Instrument Set & & set I & set II \\
\hline F-stat. & & 13.60 & 35.61 \\
\hline Over-id. p-val. & & 0.690 & 0.518 \\
\hline AP p-val. & & 0.00 & 0.00 \\
\hline Observations & 6449 & 6449 & 6449 \\
\hline
\end{tabular}




\section{K-2 Unobserved abilities}

The baseline estimates rely on the assumption that the sample is a random draw of the population. However, in practice workers tend to self-select into cities (Dahl, 2002) and occupations (Gibbons et al., 2005; Groes et al., 2009) for unobserved earnings-related reasons. The baseline specification may provide a biased estimate of search and bargaining mechanisms if the structure of employment within cities correlates with unobserved abilities.

To deal with that issue, this section exploits the traceability of individuals in the database and estimates adjusted wages using workers who stay within the same firm, occupation, industry and city from one year to the next (the 'stayers' henceforth). Specifically, this section pools the years 1976 to 2001 together and regresses yearly changes in stayers' wages on an entire set of jobcity-specific time-varying dummies. The estimates on the dummies correspond to yearly changes in job-city-specific wages, purged of workers and firms' unobserved fixed characteristics. These estimates are then used to construct both the dependent variable and the national wage premia in a similar way to the baseline. Results are shown in Table 8.

Columns (1)-(3) correspond to the baseline specification, estimated using changes in wages for stayers. As for the previous specifications, diagnostic tests are satisfactory at any conventional level. The IV estimates do not statistically differ from the baseline estimates and are comparable across sets of IVs, which again supports the identifying assumption. Columns (4)-(6) introduce industry-city-time dummies. Relative to the preceding three columns, this exercise is particularly demanding as the estimate is now identifed by comparing wages along an additional dimension, i.e. by focusing on periodical changes in stayers' wages across occupations of the same industry and city. The next three columns add changes in log job-city employment. The last columns interact the employment variable with occupational dummies. Importantly, once the endogeneity of workers' outside options is taken into account, the estimate of interest is qualitatively similar to the baseline estimate. Finally, it is interesting to note that, since the estimates are identified on stayers only, this set of results also suggests that wages tend to be renegotiated over time. 
Table 8: Focusing on firm-job-city stayers.

\begin{tabular}{|c|c|c|c|c|c|c|c|c|c|c|c|c|}
\hline \multirow{2}{*}{$\begin{array}{l}\text { Dependent variable } \\
\text { Regressors }\end{array}$} & \multicolumn{12}{|c|}{$\Delta \log$ wages $_{q i c \tau}$} \\
\hline & $\begin{array}{l}\text { (1) } \\
\text { OLS }\end{array}$ & $\begin{array}{l}(2) \\
\text { IV }\end{array}$ & $\begin{array}{l}(3) \\
\text { IV }\end{array}$ & $\begin{array}{l}(4) \\
\text { OLS }\end{array}$ & $\begin{array}{l}(5) \\
\text { IV }\end{array}$ & $\begin{array}{l}(6) \\
\text { IV }\end{array}$ & $\begin{array}{l}(7) \\
\text { OLS }\end{array}$ & $\begin{array}{l}(8) \\
\text { IV }\end{array}$ & $\begin{array}{l}(9) \\
\text { IV }\end{array}$ & $\begin{array}{l}(\mathbf{1 0}) \\
\text { OLS }\end{array}$ & $\begin{array}{c}(11) \\
\text { IV }\end{array}$ & $\begin{array}{c}\text { (12) } \\
\text { IV }\end{array}$ \\
\hline $\begin{array}{l}\Delta \text { Outside options }{ }_{q i c \tau}: \\
\Delta \sum_{k \in S \backslash\{q i\}} \psi_{k c \tau \mid q i} w_{k c \tau}\end{array}$ & $\begin{array}{l}0.150^{* * *} \\
(0.036)\end{array}$ & $\begin{array}{l}0.613^{* * *} \\
(0.167)\end{array}$ & $\begin{array}{c}* 0.609^{* * *} \\
(0.168)\end{array}$ & $\begin{array}{c}-0.099 \\
(0.067)\end{array}$ & $\begin{array}{l}0.708^{* * *} \\
(0.245)\end{array}$ & $\begin{array}{c}0.627^{* * *} \\
(0.147)\end{array}$ & $\begin{array}{l}-0.223^{* * *} \\
(0.073)\end{array}$ & 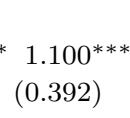 & $\begin{array}{l}1.117^{* * *} \\
(0.357)\end{array}$ & $\begin{array}{l}-0.230^{* * *} \\
(0.071)\end{array}$ & $\begin{array}{c}* 0.839^{* * *} \\
(0.271)\end{array}$ & $\begin{array}{c}0.849^{* *} \\
(0.253)\end{array}$ \\
\hline$\Delta \log$ employment $_{q i c \tau}$ & & & & & & & $\begin{array}{c}-0.001 \\
(0.012)\end{array}$ & $\begin{array}{c}0.339^{* *} \\
(0.147)\end{array}$ & $\begin{array}{c}0.339^{* *} \\
(0.147)\end{array}$ & & & \\
\hline $\begin{array}{l}\Delta\left(\log \mathrm{empl}_{q i c \tau} * d_{q}\right) \\
\Delta d_{q i \tau} \\
\Delta d_{c \tau} \\
\Delta d_{i c \tau}\end{array}$ & $\begin{array}{l}\text { yes } \\
\text { yes }\end{array}$ & $\begin{array}{l}\text { yes } \\
\text { yes }\end{array}$ & $\begin{array}{l}\text { yes } \\
\text { yes }\end{array}$ & $\begin{array}{l}\text { yes } \\
\text { yes }\end{array}$ & yes & yes & yes & yes & $\begin{array}{l}\text { yes } \\
\text { yes }\end{array}$ & $\begin{array}{l}\text { yes } \\
\text { yes }\end{array}$ & $\begin{array}{l}\text { yes } \\
\text { yes } \\
\text { yes }\end{array}$ & $\begin{array}{l}\text { yes } \\
\text { yes } \\
\text { yes }\end{array}$ \\
\hline $\begin{array}{l}\text { Instrument set } \\
\text { F-stat. } \\
\text { Over-id. p-val. } \\
\text { AP p-val. } \\
\text { Observations }\end{array}$ & 5334 & $\begin{array}{r}\text { set I } \\
39.34 \\
0.15 \\
0.00 \\
5334 \\
\end{array}$ & $\begin{array}{c}\text { set II } \\
26.26 \\
0.25 \\
0.00 \\
5334 \\
\end{array}$ & 5334 & $\begin{array}{r}\text { set I } \\
19.58 \\
0.35 \\
0.00 \\
5334 \\
\end{array}$ & $\begin{array}{c}\text { set II } \\
13.58 \\
0.58 \\
0.00 \\
5334 \\
\end{array}$ & 4845 & $\begin{array}{r}\text { set I } \\
11.10 \\
0.44 \\
0.00 \\
4845 \\
\end{array}$ & $\begin{array}{l}\text { set II } \\
8.35 \\
0.74 \\
0.00 \\
4845 \\
\end{array}$ & 4845 & $\begin{array}{r}\text { set I } \\
16.79 \\
0.37 \\
0.00 \\
4845 \\
\end{array}$ & $\begin{array}{c}\text { set II } \\
11.35 \\
0.67 \\
0.00 \\
4845 \\
\end{array}$ \\
\hline
\end{tabular}




\section{K-3 On-the-job search}

This section discusses the implications of allowing workers to search while on the job. Such an extension modifies the utility of being employed in the following way.

If a worker is not laid off, the probability of which is $\beta(1-\delta)$, the probability of him or her receiving an offer from $k c$ is $(1-\delta) \psi_{c} \psi_{k c \mid j}$. The worker accepts the offer if the utility of being employed with $k c$ exceeds the utility derived in his current job. Thus,

$$
\begin{aligned}
U_{j c}^{e} & =w_{j c}+\beta \delta U_{j c}^{u}+\beta(1-\delta)\left\{\left(1-\psi_{c}\right) U_{j c}^{e}+\psi_{c} \sum_{k \in S} \psi_{k c \mid j}\left[\operatorname{Pr}\left(U_{k c}^{e}<U_{j c}^{e}\right) U_{j c}^{e}+\operatorname{Pr}\left(U_{k c}^{e} \geq U_{j c}^{e}\right) U_{k c}^{e}\right]\right\} \\
& =w_{j c}+\beta \delta U_{j c}^{u}+\beta \Lambda_{j c} U_{j c}^{e}+\beta(1-\delta) \psi_{c} \sum_{k \in S} \psi_{k c \mid j} \operatorname{Pr}\left(U_{k c}^{e} \geq U_{j c}^{e}\right) U_{k c}^{e}
\end{aligned}
$$

where $\Lambda_{j c}=(1-\delta)\left[\left(1-\psi_{c}\right)+\psi_{c} \sum_{k \in S} \psi_{k c \mid j} \operatorname{Pr}\left(U_{k c}^{e}<U_{j c}^{e}\right)\right]$ is the probability that a worker remains in his current job (either because he or she did not receive any other offer or rejected an outside offer). Including on-the-job search augments the utility of employment by two additional terms: a first term that reflects the probability of being a stayer $\left(\Lambda_{j c}\right)$, and a second one which captures workers' outside options when on the job $\left(\psi_{c} \sum_{k \in S} \psi_{k c \mid j} \operatorname{Pr}\left[U_{k c}^{e} \geq U_{j c}^{e}\right] U_{k c}^{e}\right)$.

To understand the empirical implications of on-the-job search, it is useful to take a linear approximation of equation $35 .{ }^{4}$ One obtains

$$
U_{j c}^{e}=\Upsilon_{0}+\Upsilon_{1} w_{j c}+\Upsilon_{2} U_{j c}^{u}+\Upsilon_{3} \psi_{c}+\Upsilon_{4} \Lambda_{j c}+\Upsilon_{5} \underbrace{\sum_{k \in S} U_{k c}^{e}}_{\text {city-specific }}
$$

where the $\Upsilon_{\mathrm{S}}$ are constant terms obtained from the linear approximation. Equation 36 implies that one can control for the wage effects of on-the-job search by adding the probability $\Lambda_{j c}$ to the baseline specification. The city-specific variables $\psi_{c}$ and $\sum_{k \in S} U_{k c}^{e}$ are absorbed by the city-specific time-varying dummies. Table 9 shows that controlling for the probability of being a stayer leaves the baseline results unchanged.

\footnotetext{
${ }^{4}$ As previously, the linear approximation is taken around the point where cities have identical employment rates $\left(E R_{c}=E R\right)$ and where employment is uniformly distributed across jobs $\left(\eta_{k c}=\frac{1}{Q I}\right)$.
} 
Table 9: On-the-job search.

\begin{tabular}{|c|c|c|c|}
\hline \multirow{2}{*}{$\begin{array}{l}\text { Dependent variable } \\
\text { Regressors }\end{array}$} & \multicolumn{3}{|c|}{$\Delta \log$ wages $_{q i c \tau}$} \\
\hline & (1) & $(2)$ & (3) \\
\hline \multirow{3}{*}{ 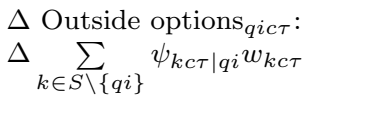 } & & & \\
\hline & $0.263^{* * *}$ & * $0.721^{* * *}$ & $0.662^{* * *}$ \\
\hline & $(0.049)$ & $(0.166)$ & $(0.154)$ \\
\hline$\Delta$ Probability of staying $q i c \tau$ & $\begin{array}{c}0.021 \\
(0.022)\end{array}$ & $\begin{array}{c}0.033 \\
(0.022)\end{array}$ & $\begin{array}{c}0.031 \\
(0.022)\end{array}$ \\
\hline$\Delta d_{q i \tau}$ & yes & yes & yes \\
\hline$\Delta d_{c \tau}$ & yes & yes & yes \\
\hline Instrument set & & set I & set II \\
\hline F-stat. & & 41.73 & 35.55 \\
\hline Over-id. p-val. & & 0.29 & 0.15 \\
\hline AP p-val. & & 0.00 & 0.00 \\
\hline Observations & 6632 & 6632 & 6632 \\
\hline
\end{tabular}




\section{K-4 Top coding}

The IABS sample is top-coded at the highest level of earnings that are subject to social security contributions. Top coding affects around $10 \%$ of the observations each year. The issue can be severe for highly educated groups: $50 \%$ of the wage observations for university and polytechnic graduates are right-censored. Columns (1)-(3) and (4)-(6) of Table 10 show the estimates obtained when dropping top-coded observations and highly educated individuals, respectively. This exercise does not alter the qualitative aspect of the results.

Table 10: Using uncensored wages only and excluding highly educated.

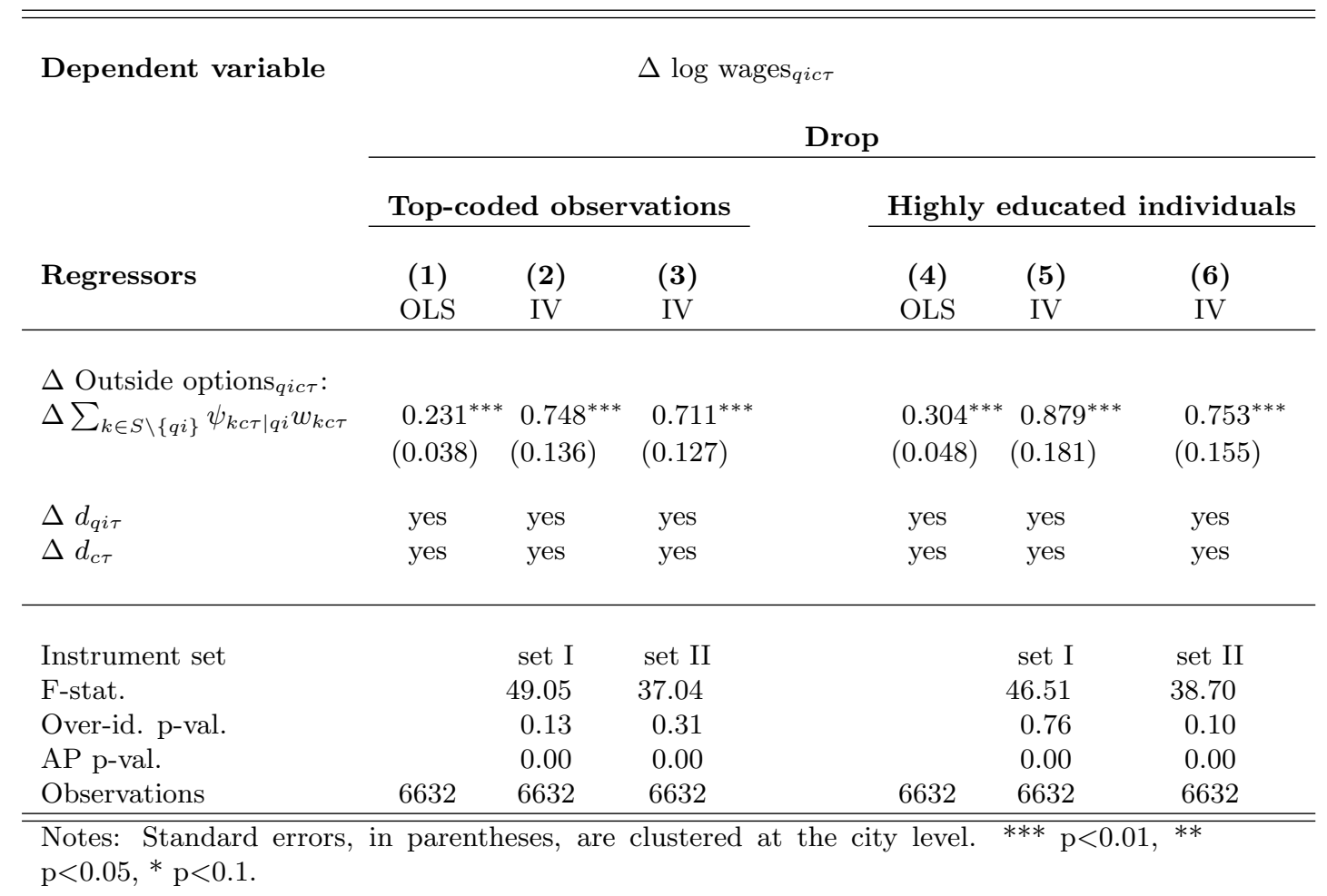




\section{K-5 Alternative mobility measures}

Table 11 introduces some flexibility in computing the mobility measure $\varphi_{k \mid q i}$ from job $q i$ to $k$. In columns (1)-(3), $\varphi_{k \mid q i}$ is computed over two different intervals, 1976-1991 and 1992-2001. Columns (4)-(6) introduce spatial flexibility by separating the sample between Northwest and Southwest Germany. Since the constraint of 20 individuals per job-city-year cell leaves little room for manoeuvre in the construction of $\varphi_{k \mid q i}$, it is difficult to allow for even more flexibility. Whichever column one looks at, the estimates remain robust to using period-specific or region-specific measures of mobility.

Table 11: Computing the mobility measures over two periods/regions.

\begin{tabular}{|c|c|c|c|c|c|c|}
\hline \multirow{3}{*}{$\begin{array}{l}\text { Dependent variable } \\
\text { Regressors }\end{array}$} & \multicolumn{6}{|c|}{$\Delta \log$ wages $_{q i c \tau}$} \\
\hline & \multicolumn{3}{|c|}{ Two periods } & \multicolumn{3}{|c|}{ Two regions } \\
\hline & $\begin{array}{l}(1) \\
\text { OLS }\end{array}$ & $\begin{array}{l}(2) \\
\text { IV }\end{array}$ & $\begin{array}{l}(3) \\
\text { IV }\end{array}$ & $\begin{array}{l}(4) \\
\text { OLS }\end{array}$ & $\begin{array}{l}(5) \\
\text { IV }\end{array}$ & $\begin{array}{l}(6) \\
\text { IV }\end{array}$ \\
\hline $\begin{array}{l}\Delta \text { Outside options } \text { qict }_{q i} \text { : } \\
\Delta \sum_{k \in S \backslash\{q i\}} \psi_{k c \tau \mid q i} w_{k c \tau}\end{array}$ & $\begin{array}{l}0.264^{* * *} \\
(0.042)\end{array}$ & $\begin{array}{l}0.513^{* * *} \\
(0.132)\end{array}$ & $\begin{array}{l}0.515^{* * *} \\
(0.130)\end{array}$ & $\begin{array}{l}0.294^{* * *} \\
(0.048)\end{array}$ & $\begin{array}{l}0.591^{* * *} \\
(0.123)\end{array}$ & $\begin{array}{l}0.611^{* * *} \\
(0.111)\end{array}$ \\
\hline $\begin{array}{l}\Delta d_{q i \tau} \\
\Delta d_{c \tau}\end{array}$ & $\begin{array}{l}\text { yes } \\
\text { yes }\end{array}$ & $\begin{array}{l}\text { yes } \\
\text { yes }\end{array}$ & $\begin{array}{l}\text { yes } \\
\text { yes }\end{array}$ & $\begin{array}{l}\text { yes } \\
\text { yes }\end{array}$ & $\begin{array}{l}\text { yes } \\
\text { yes }\end{array}$ & $\begin{array}{l}\text { yes } \\
\text { yes }\end{array}$ \\
\hline $\begin{array}{l}\text { Instrument set } \\
\text { F-stat. } \\
\text { Over-id. p-val. } \\
\text { AP p-val. } \\
\text { Observations }\end{array}$ & 6552 & $\begin{array}{r}\text { set I } \\
52.14 \\
0.27 \\
0.00 \\
6552\end{array}$ & $\begin{array}{c}\text { set II } \\
41.80 \\
0.50 \\
0.00 \\
6552\end{array}$ & 6458 & $\begin{array}{r}\text { set I } \\
102.60 \\
0.42 \\
0.00 \\
6458\end{array}$ & $\begin{array}{c}\text { set II } \\
80.41 \\
0.39 \\
0.00 \\
6458\end{array}$ \\
\hline
\end{tabular}




\section{K-6 Sample split}

Table 12 examines whether the effect of interest exhibits anything particular after the accession of East Germany to the IAB sample in 1991 (or the fall of the Iron Curtain in 1989). The pre-1991 period experienced relatively higher pressure from trade unions. If, as a result, wage premia were relatively smaller, one may be worried that the baseline estimate is driven by the post-1991 period only. To investigate this possibility, this section splits the sample into two intervals, the pre- and post-1991 periods. Whichever period one considers, the estimates remain statistically significant and similar to those of the baseline specification.

Table 12: Sample split.

\begin{tabular}{|c|c|c|c|c|c|c|}
\hline \multirow{3}{*}{$\begin{array}{l}\text { Dependent variable } \\
\text { Regressors }\end{array}$} & \multicolumn{6}{|c|}{$\Delta \log$ wages $_{q i c \tau}$} \\
\hline & \multicolumn{3}{|c|}{ 1977-1991 } & \multicolumn{3}{|c|}{ 1992-2001 } \\
\hline & $\begin{array}{l}(1) \\
\text { OLS }\end{array}$ & $\begin{array}{l}(2) \\
\text { IV }\end{array}$ & $\begin{array}{l}(3) \\
\text { IV }\end{array}$ & $\begin{array}{l}(4) \\
\text { OLS }\end{array}$ & $\begin{array}{l}(5) \\
\text { IV }\end{array}$ & $\begin{array}{l}\text { (6) } \\
\text { IV }\end{array}$ \\
\hline $\begin{array}{l}\Delta \text { Outside options }{ }_{q i c \tau}: \\
\Delta \sum_{k \in S \backslash\{q i\}} \psi_{k c \tau \mid q i} w_{k c \tau}\end{array}$ & $\begin{array}{l}0.245^{* * *} \\
(0.066)\end{array}$ & $\begin{array}{l}0.709^{* * *} \\
(0.254)\end{array}$ & $\begin{array}{l}0.784^{* * *} \\
(0.224)\end{array}$ & $\begin{array}{l}0.277^{* * *} \\
(0.055)\end{array}$ & $\begin{array}{l}0.708^{* * *} \\
(0.177)\end{array}$ & $\begin{array}{l}0.557^{* * *} \\
(0.188)\end{array}$ \\
\hline $\begin{array}{l}\Delta d_{q i \tau} \\
\Delta d_{c \tau}\end{array}$ & $\begin{array}{l}\text { yes } \\
\text { yes }\end{array}$ & $\begin{array}{l}\text { yes } \\
\text { yes }\end{array}$ & $\begin{array}{l}\text { yes } \\
\text { yes }\end{array}$ & $\begin{array}{l}\text { yes } \\
\text { yes }\end{array}$ & $\begin{array}{l}\text { yes } \\
\text { yes }\end{array}$ & $\begin{array}{l}\text { yes } \\
\text { yes }\end{array}$ \\
\hline $\begin{array}{l}\text { Instrument set } \\
\text { F-stat. } \\
\text { Over-id. p-val. } \\
\text { AP p-val. } \\
\text { Observations }\end{array}$ & 3316 & $\begin{array}{r}\text { set I } \\
40.18 \\
0.90 \\
0.00 \\
3316 \\
\end{array}$ & $\begin{array}{c}\text { set II } \\
29.13 \\
0.79 \\
0.00 \\
3316 \\
\end{array}$ & 3316 & $\begin{array}{r}\text { set I } \\
11.97 \\
0.24 \\
0.00 \\
3316 \\
\end{array}$ & $\begin{array}{c}\text { set II } \\
11.01 \\
0.10 \\
0.00 \\
3316 \\
\end{array}$ \\
\hline
\end{tabular}




\section{K-7 Alternative time frame}

Table 13 shows that averaging the data over three or eight years, as an alternative to five years, generates results which are qualitatively similar to the baseline estimates.

Table 13: Alternative time frame.

\begin{tabular}{|c|c|c|c|c|c|c|}
\hline \multirow{3}{*}{$\begin{array}{l}\text { Dependent variable } \\
\text { Regressors }\end{array}$} & \multicolumn{6}{|c|}{$\Delta \log$ wages $_{q i c \tau}$} \\
\hline & \multicolumn{3}{|c|}{ Three-years averages } & \multicolumn{3}{|c|}{ Eight-years averages } \\
\hline & $\begin{array}{l}(1) \\
\text { OLS }\end{array}$ & $\begin{array}{l}(2) \\
\text { IV }\end{array}$ & $\begin{array}{l}(3) \\
\text { IV }\end{array}$ & $\begin{array}{l}(4) \\
\text { OLS }\end{array}$ & $\begin{array}{l}(5) \\
\text { IV }\end{array}$ & $\begin{array}{l}(6) \\
\text { IV }\end{array}$ \\
\hline 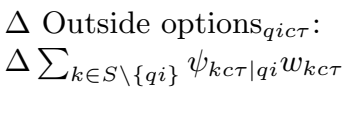 & $\begin{array}{l}0.255^{* * *} \\
(0.041)\end{array}$ & $\begin{array}{l}0.599^{* * *} \\
(0.161)\end{array}$ & $\begin{array}{l}0.566^{* * *} \\
(0.153)\end{array}$ & $\begin{array}{l}0.397^{* * *} \\
(0.063)\end{array}$ & $\begin{array}{l}0.942^{* * *} \\
(0.200)\end{array}$ & $\begin{array}{l}0.866^{* * *} \\
(0.208)\end{array}$ \\
\hline $\begin{array}{l}\Delta d_{q i \tau} \\
\Delta d_{c \tau}\end{array}$ & $\begin{array}{l}\text { yes } \\
\text { yes }\end{array}$ & $\begin{array}{l}\text { yes } \\
\text { yes }\end{array}$ & $\begin{array}{l}\text { yes } \\
\text { yes }\end{array}$ & $\begin{array}{l}\text { yes } \\
\text { yes }\end{array}$ & $\begin{array}{l}\text { yes } \\
\text { yes }\end{array}$ & $\begin{array}{l}\text { yes } \\
\text { yes }\end{array}$ \\
\hline $\begin{array}{l}\text { Instrument set } \\
\text { F-stat. } \\
\text { Over-id. p-val. } \\
\text { AP p-val. } \\
\text { Observations }\end{array}$ & 11606 & $\begin{array}{c}\text { set I } \\
35.98 \\
0.310 \\
0.00 \\
11606\end{array}$ & $\begin{array}{c}\text { set II } \\
27.64 \\
0.249 \\
0.00 \\
11606\end{array}$ & 3316 & $\begin{array}{c}\text { set I } \\
19.92 \\
0.516 \\
0.00 \\
3316\end{array}$ & $\begin{array}{c}\text { set II } \\
17.84 \\
0.372 \\
0.00 \\
3316\end{array}$ \\
\hline
\end{tabular}




\section{K-8 Alternative clusterings}

Table 14 shows that using alternative clusterings of the data does not alter the statistical significance of the results.

Table 14: Alternative clusterings.

\begin{tabular}{|c|c|c|c|c|c|c|c|c|c|}
\hline \multirow{3}{*}{$\begin{array}{l}\text { Dependent variable } \\
\text { Regressors }\end{array}$} & \multicolumn{9}{|c|}{$\Delta \log$ wages $_{q i c \tau}$} \\
\hline & \multicolumn{3}{|c|}{ City-time clustering } & \multicolumn{3}{|c|}{ Industry clustering } & \multicolumn{3}{|c|}{ Industry-time clustering } \\
\hline & $\begin{array}{l}(1) \\
\text { OLS }\end{array}$ & $\begin{array}{l}(2) \\
\text { IV }\end{array}$ & $\begin{array}{l}(3) \\
\text { IV }\end{array}$ & $\begin{array}{l}(4) \\
\text { OLS }\end{array}$ & $\begin{array}{l}(5) \\
\text { IV }\end{array}$ & $\begin{array}{l}(6) \\
\text { IV }\end{array}$ & $\begin{array}{l}(7) \\
\text { OLS }\end{array}$ & $\begin{array}{l}(8) \\
\text { IV }\end{array}$ & $\begin{array}{l}(9) \\
\text { IV }\end{array}$ \\
\hline $\begin{array}{l}\Delta \text { Outside options }{ }_{q i c \tau}: \\
\Delta \sum_{k \in S \backslash\{q i\}} \psi_{k c \tau \mid q i} w_{k c \tau}\end{array}$ & $\begin{array}{l}0.262^{* * * *} \\
(0.041)\end{array}$ & $\begin{array}{l}0.713^{* * *} \\
(0.181)\end{array}$ & $\begin{array}{l}0.655^{* * *} \\
(0.168)\end{array}$ & $\begin{array}{l}0.262^{* * *} \\
(0.046)\end{array}$ & $\begin{array}{l}* 0.713^{* * *} \\
(0.185)\end{array}$ & $\begin{array}{c}* 0.655^{* * *} \\
(0.178)\end{array}$ & $\begin{array}{l}0.262^{* * *} \\
(0.041)\end{array}$ & $\begin{array}{l}0.713^{* * *} \\
(0.181)\end{array}$ & $\begin{array}{l}0.655^{* * *} \\
(0.168)\end{array}$ \\
\hline$\Delta d_{q i \tau}$ & yes & yes & yes & yes & yes & yes & yes & yes & yes \\
\hline$\Delta d_{c \tau}$ & yes & yes & yes & yes & yes & yes & yes & yes & yes \\
\hline Instrument set & & set I & set II & & set I & set II & & set I & set II \\
\hline F-stat. & & 35.96 & 24.76 & & 56.86 & 40.84 & & 0.27 & 0.37 \\
\hline Over-id. p-val. & & 0.27 & 0.37 & & 0.31 & 0.25 & & 0.263 & 0.362 \\
\hline AP p-val. & & 0.00 & 0.00 & & 0.00 & 0.00 & & 0.00 & 0.00 \\
\hline Observations & 6632 & 6632 & 6632 & 6632 & 6632 & 6632 & 6632 & 6632 & 6632 \\
\hline
\end{tabular}




\section{K-9 Industry/Occupation effects}

Tables 15 and 16 investigate whether the baseline estimate differs across industries and occupations. For each industry (occupation), Tables 15 (Table 16) runs a regression interacting the measure of workers' outside options with a dummy for the corresponding industry (occupation). Columns (1), (3) and (5) show the main effect. Columns (2), (4) and (6) present the estimate for the interaction

term. In general, the coefficient on the interaction term is statistically insignificant, which suggests that decentralisation forces are similar across industries (occupations), whichever the unionisation degree they exhibit. 
Table 15: Transition index, by industry.

\begin{tabular}{|c|c|c|c|c|c|c|}
\hline \multirow[t]{3}{*}{ Dependent variable } & \multicolumn{6}{|c|}{$\Delta \log$ wages $_{q i c \tau}$} \\
\hline & \multicolumn{2}{|c|}{ OLS } & \multicolumn{2}{|c|}{ IV - set I } & \multicolumn{2}{|c|}{ IV - set II } \\
\hline & $\begin{array}{l}\text { Main } \\
\text { (1) }\end{array}$ & $\begin{array}{l}\text { Interaction } \\
\quad(\mathbf{2})\end{array}$ & $\begin{array}{l}\text { Main } \\
\mathbf{( 3 )}\end{array}$ & $\begin{array}{c}\text { Interaction } \\
\text { (4) }\end{array}$ & $\begin{array}{l}\text { Main } \\
(5)\end{array}$ & $\begin{array}{c}\text { Interaction } \\
\text { (6) }\end{array}$ \\
\hline \multicolumn{7}{|l|}{ Primary sector } \\
\hline Industry 1 & $\begin{array}{c}0.285^{* * *} \\
(0.0503)\end{array}$ & $\begin{array}{c}-0.152^{*} \\
(0.0750)\end{array}$ & $\begin{array}{l}0.707^{* * *} \\
(0.157)\end{array}$ & $\begin{array}{c}-0.670 \\
(1.264)\end{array}$ & $\begin{array}{l}0.715^{* * *} \\
(0.162)\end{array}$ & $\begin{array}{c}-0.184 \\
(0.196)\end{array}$ \\
\hline \multicolumn{7}{|l|}{ Secondary sector } \\
\hline Industry 2 & $\begin{array}{l}0.259^{* * *} \\
(0.055)\end{array}$ & $\begin{array}{c}0.039 \\
(0.101)\end{array}$ & $\begin{array}{l}0.666^{* * *} \\
(0.191)\end{array}$ & $\begin{array}{c}0.246 \\
(0.360)\end{array}$ & $\begin{array}{l}0.666^{* * *} \\
(0.191)\end{array}$ & $\begin{array}{c}0.244 \\
(0.360)\end{array}$ \\
\hline Industry 3 & $\begin{array}{l}0.242^{* * *} \\
(0.050)\end{array}$ & $\begin{array}{c}0.263^{* *} \\
(0.081)\end{array}$ & $\begin{array}{l}0.618^{* * *} \\
(0.170)\end{array}$ & $\begin{array}{c}0.482 \\
(0.413)\end{array}$ & $\begin{array}{l}0.620^{* * *} \\
(0.169)\end{array}$ & $\begin{array}{c}0.477 \\
(0.388)\end{array}$ \\
\hline Industry 4 & $\begin{array}{l}0.254^{* * *} \\
(0.051)\end{array}$ & $\begin{array}{c}0.119 \\
(0.062)\end{array}$ & $\begin{array}{l}0.785^{* * *} \\
(0.173)\end{array}$ & $\begin{array}{c}-0.618 \\
(0.418)\end{array}$ & $\begin{array}{l}0.787^{* * *} \\
(0.174)\end{array}$ & $\begin{array}{c}-0.623 \\
(0.419)\end{array}$ \\
\hline Industry 5 & $\begin{array}{l}0.285^{* * *} \\
(0.053)\end{array}$ & $\begin{array}{c}-0.213 \\
(0.134)\end{array}$ & $\begin{array}{l}0.710^{* * *} \\
(0.191)\end{array}$ & $\begin{array}{c}-0.094 \\
(0.444)\end{array}$ & $\begin{array}{l}0.706^{* * *} \\
(0.192)\end{array}$ & $\begin{array}{c}-0.146 \\
(0.416)\end{array}$ \\
\hline Industry 6 & $\begin{array}{l}0.270^{* * *} \\
(0.048)\end{array}$ & $\begin{array}{r}-0.275^{*} \\
(0.122)\end{array}$ & $\begin{array}{l}0.709^{* * *} \\
(0.163)\end{array}$ & $\begin{array}{c}-0.091 \\
(0.497)\end{array}$ & $\begin{array}{l}0.704^{* * *} \\
(0.164)\end{array}$ & $\begin{array}{c}-0.065 \\
(0.491)\end{array}$ \\
\hline Industry 7 & $\begin{array}{l}0.262^{* * *} \\
(0.049)\end{array}$ & $\begin{array}{c}-0.019 \\
(0.187)\end{array}$ & $\begin{array}{l}0.730^{* * *} \\
(0.162)\end{array}$ & $\begin{array}{c}-0.221 \\
(0.339)\end{array}$ & $\begin{array}{l}0.742^{* * *} \\
(0.169)\end{array}$ & $\begin{array}{c}-0.190 \\
(0.348)\end{array}$ \\
\hline Industry 8 & $\begin{array}{l}0.261^{* * *} \\
(0.049)\end{array}$ & $\begin{array}{c}0.0019 \\
(0.164)\end{array}$ & $\begin{array}{l}0.669^{* * *} \\
(0.167)\end{array}$ & $\begin{array}{c}0.202 \\
(0.248)\end{array}$ & $\begin{array}{l}0.664^{* * *} \\
(0.167)\end{array}$ & $\begin{array}{c}0.239 \\
(0.242)\end{array}$ \\
\hline \multicolumn{7}{|l|}{ Tertiary sector } \\
\hline Industry 9 & $\begin{array}{l}0.257^{* * *} \\
(0.050)\end{array}$ & $\begin{array}{c}0.198 \\
(0.132)\end{array}$ & $\begin{array}{l}0.718^{* * *} \\
(0.158)\end{array}$ & $\begin{array}{c}-0.300 \\
(1.833)\end{array}$ & $\begin{array}{l}0.721^{* * *} \\
(0.158)\end{array}$ & $\begin{array}{c}-0.552 \\
(1.960)\end{array}$ \\
\hline Industry 10 & $\begin{array}{l}0.252^{\text {*** }} \\
(0.049)\end{array}$ & $\begin{array}{c}0.330^{*} \\
(0.139)\end{array}$ & $\begin{array}{l}0.710^{* * *} \\
(0.163)\end{array}$ & $\begin{array}{c}0.523 \\
(0.534)\end{array}$ & $\begin{array}{l}0.712^{* * *} \\
(0.161)\end{array}$ & $\begin{array}{c}0.438 \\
(0.676)\end{array}$ \\
\hline Industry 11 & $\begin{array}{l}0.263^{* * *} \\
(0.049)\end{array}$ & $\begin{array}{c}-0.0922 \\
(0.114)\end{array}$ & $\begin{array}{l}0.795^{* * *} \\
(0.193)\end{array}$ & $\begin{array}{r}-1.925^{*} \\
(0.926)\end{array}$ & $\begin{array}{l}0.795^{* * *} \\
(0.193)\end{array}$ & $\begin{array}{r}-1.956^{*} \\
(0.925)\end{array}$ \\
\hline Industry 12 & $\begin{array}{l}0.254^{* * *} \\
(0.051)\end{array}$ & $\begin{array}{c}0.150 \\
(0.087)\end{array}$ & $\begin{array}{l}0.653^{* * *} \\
(0.177)\end{array}$ & $\begin{array}{c}1.194 \\
(1.377)\end{array}$ & $\begin{array}{l}0.643^{* * *} \\
(0.166)\end{array}$ & $\begin{array}{c}0.682 \\
(1.142)\end{array}$ \\
\hline Industry 13 & $\begin{array}{l}0.241^{* * *} \\
(0.054)\end{array}$ & $\begin{array}{c}0.244 \\
(0.140)\end{array}$ & $\begin{array}{l}0.678^{* * *} \\
(0.169)\end{array}$ & $\begin{array}{l}1.951^{* *} \\
(0.721)\end{array}$ & $\begin{array}{l}0.686^{* * *} \\
(0.169)\end{array}$ & $\begin{array}{c}1.783^{*} \\
(0.707)\end{array}$ \\
\hline Industry 14 & $\begin{array}{l}0.282^{\text {*** }} \\
(0.051)\end{array}$ & $\begin{array}{c}-0.251^{* *} \\
(0.084)\end{array}$ & $\begin{array}{l}0.759^{* * *} \\
(0.192)\end{array}$ & $\begin{array}{c}-0.412 \\
(1.092)\end{array}$ & $\begin{array}{l}0.761^{* * *} \\
(0.193)\end{array}$ & $\begin{array}{c}-0.508 \\
(1.006)\end{array}$ \\
\hline Industry 15 & $\begin{array}{l}0.249^{* * *} \\
(0.047)\end{array}$ & $\begin{array}{c}0.405 \\
(0.220)\end{array}$ & $\begin{array}{l}0.709^{* * *} \\
(0.156)\end{array}$ & $\begin{array}{c}0.224 \\
(0.935)\end{array}$ & $\begin{array}{l}0.710^{* * *} \\
(0.159)\end{array}$ & $\begin{array}{c}0.176 \\
(0.722)\end{array}$ \\
\hline Industry 16 & $\begin{array}{l}0.283^{* * *} \\
(0.047)\end{array}$ & $\begin{array}{r}-0.224^{*} \\
(0.090)\end{array}$ & $\begin{array}{l}0.743^{* * *} \\
(0.161)\end{array}$ & $\begin{array}{c}-0.326 \\
(0.469)\end{array}$ & $\begin{array}{l}0.730^{* * *} \\
(0.160)\end{array}$ & $\begin{array}{c}-0.444 \\
(0.462)\end{array}$ \\
\hline
\end{tabular}

Notes: Standard errors are clustered at the city level. Standard errors in parentheses. ${ }^{* * *} \mathrm{p}<0.01,{ }^{* *} \mathrm{p}<0.05$, $* \mathrm{p}<0.1$. $\mathrm{p}$-values in brackets. 
Table 16: Transition index, by occupation.

\begin{tabular}{|c|c|c|c|c|c|c|}
\hline \multirow[t]{3}{*}{ Dependent variable } & \multicolumn{6}{|c|}{$\Delta \log$ wages $_{q i c \tau}$} \\
\hline & \multicolumn{2}{|c|}{ OLS } & \multicolumn{2}{|c|}{ IV - set I } & \multicolumn{2}{|c|}{ IV - set II } \\
\hline & $\begin{array}{l}\text { Main } \\
(\mathbf{1})\end{array}$ & $\begin{array}{c}\text { Interaction } \\
(\mathbf{2})\end{array}$ & $\begin{array}{l}\text { Main } \\
(\mathbf{3}) \\
\end{array}$ & $\begin{array}{c}\text { Interaction } \\
(4)\end{array}$ & $\begin{array}{l}\text { Main } \\
(5)\end{array}$ & $\begin{array}{c}\text { Interaction } \\
\mathbf{( 6 )}\end{array}$ \\
\hline \multicolumn{7}{|l|}{ Agricultural } \\
\hline $\begin{array}{l}\text { Occupation } 106 \\
\text { Manufacturing }\end{array}$ & $\begin{array}{l}0.259^{* * *} \\
(0.051)\end{array}$ & $\begin{array}{c}0.154 \\
(0.325)\end{array}$ & $\begin{array}{l}0.723^{* * *} \\
(0.162)\end{array}$ & $\begin{array}{c}-2.051 \\
(1.670)\end{array}$ & $\begin{array}{l}0.726^{* * *} \\
(0.165)\end{array}$ & $\begin{array}{c}-1.636 \\
(1.189)\end{array}$ \\
\hline Occupation 1415 & $\begin{array}{l}0.266^{* * *} \\
(0.048)\end{array}$ & $\begin{array}{c}-0.246 \\
(0.198)\end{array}$ & $\begin{array}{l}0.792^{* * *} \\
(0.179)\end{array}$ & $\begin{array}{c}-0.782 \\
(0.448)\end{array}$ & $\begin{array}{l}0.794^{* * *} \\
(0.179)\end{array}$ & $\begin{array}{c}-0.818 \\
(0.461)\end{array}$ \\
\hline Occupation 1617 & $\begin{array}{l}0.274^{* * *} \\
(0.054)\end{array}$ & $\begin{array}{r}-0.554^{*} \\
(0.235)\end{array}$ & $\begin{array}{l}0.737^{* * *} \\
(0.153)\end{array}$ & $\begin{array}{c}-0.568 \\
(0.352)\end{array}$ & $\begin{array}{l}0.736^{* * *} \\
(0.155)\end{array}$ & $\begin{array}{c}-0.556 \\
(0.326)\end{array}$ \\
\hline Occupation 1924 & $\begin{array}{l}0.258^{* * *} \\
(0.050)\end{array}$ & $\begin{array}{c}0.163 \\
(0.137)\end{array}$ & $\begin{array}{l}0.697^{* * *} \\
(0.172)\end{array}$ & $\begin{array}{c}0.141 \\
(0.301)\end{array}$ & $\begin{array}{l}0.695^{* * *} \\
(0.169)\end{array}$ & $\begin{array}{c}0.129 \\
(0.303)\end{array}$ \\
\hline Occupation 2530 & $\begin{array}{c}0.275^{* * *} \\
(0.0479)\end{array}$ & $\begin{array}{c}-0.106 \\
(0.0936)\end{array}$ & $\begin{array}{l}0.763^{* * *} \\
(0.188)\end{array}$ & $\begin{array}{r}-0.274 \\
(0.319)\end{array}$ & $\begin{array}{l}0.773^{* * *} \\
(0.191)\end{array}$ & $\begin{array}{r}-0.162 \\
(0.272)\end{array}$ \\
\hline Occupation 31 & $\begin{array}{l}0.251^{* * *} \\
(0.053)\end{array}$ & $\begin{array}{c}0.099 \\
(0.087)\end{array}$ & $\begin{array}{l}0.719^{* * *} \\
(0.168)\end{array}$ & $\begin{array}{c}0.347 \\
(0.414)\end{array}$ & $\begin{array}{l}0.713^{* * *} \\
(0.163)\end{array}$ & $\begin{array}{c}0.173 \\
(0.345)\end{array}$ \\
\hline Occupation 32 & $\begin{array}{l}0.255^{* * *} \\
(0.049)\end{array}$ & $\begin{array}{c}0.592^{* *} \\
(0.215)\end{array}$ & $\begin{array}{l}0.752^{* * *} \\
(0.172)\end{array}$ & $\begin{array}{c}-1.143 \\
(0.613)\end{array}$ & $\begin{array}{l}0.762^{* * *} \\
(0.173)\end{array}$ & $\begin{array}{c}-1.178 \\
(0.620)\end{array}$ \\
\hline Occupation 3943 & $\begin{array}{l}0.256^{* * *} \\
(0.048)\end{array}$ & $\begin{array}{c}0.206 \\
(0.144)\end{array}$ & $\begin{array}{l}0.708^{* * *} \\
(0.167)\end{array}$ & $\begin{array}{c}-0.118 \\
(0.336)\end{array}$ & $\begin{array}{l}0.715^{* * *} \\
(0.167)\end{array}$ & $\begin{array}{c}0.0626 \\
(0.286)\end{array}$ \\
\hline Occupation 4447 & $\begin{array}{l}0.263^{* * *} \\
(0.049)\end{array}$ & $\begin{array}{c}-0.080 \\
(0.167)\end{array}$ & $\begin{array}{l}0.702^{* * *} \\
(0.166)\end{array}$ & $\begin{array}{c}-0.013 \\
(0.411)\end{array}$ & $\begin{array}{l}0.714^{* * *} \\
(0.171)\end{array}$ & $\begin{array}{c}-0.0571 \\
(0.393)\end{array}$ \\
\hline Occupation 4849 & $\begin{array}{l}0.260^{* * *} \\
(0.049)\end{array}$ & $\begin{array}{c}0.152 \\
(0.204)\end{array}$ & $\begin{array}{c}0.645^{*} \\
(0.251)\end{array}$ & $\begin{array}{l}-7.647 \\
(26.17)\end{array}$ & $\begin{array}{l}0.720^{* * *} \\
(0.175)\end{array}$ & $\begin{array}{c}1.611 \\
(1.960)\end{array}$ \\
\hline Occupation 52 & $\begin{array}{l}0.266^{* * *} \\
(0.048)\end{array}$ & $\begin{array}{c}-0.105 \\
(0.141)\end{array}$ & $\begin{array}{l}0.707^{* * *} \\
(0.165)\end{array}$ & $\begin{array}{c}-2.211 \\
(1.529)\end{array}$ & $\begin{array}{l}0.709^{* * *} \\
(0.163)\end{array}$ & $\begin{array}{c}-2.117 \\
(1.233)\end{array}$ \\
\hline Occupation 53 & $\begin{array}{l}0.268^{* * *} \\
(0.049)\end{array}$ & $\begin{array}{c}-0.338 \\
(0.189)\end{array}$ & $\begin{array}{l}0.784^{* *} \\
(0.252)\end{array}$ & $\begin{array}{c}16.16 \\
(29.12)\end{array}$ & $\begin{array}{l}0.663^{* * *} \\
(0.170)\end{array}$ & $\begin{array}{c}-0.437 \\
(0.944)\end{array}$ \\
\hline Technicians & & & & & & \\
\hline Occupation 6061 & $\begin{array}{l}0.265^{* * *} \\
(0.049)\end{array}$ & $\begin{array}{c}-0.142 \\
(0.285)\end{array}$ & $\begin{array}{l}0.759^{* * *} \\
(0.193)\end{array}$ & $\begin{array}{c}5.707 \\
(8.219)\end{array}$ & $\begin{array}{l}0.766^{* * *} \\
(0.199)\end{array}$ & $\begin{array}{c}6.455 \\
(9.088)\end{array}$ \\
\hline Occupation 6263 & $\begin{array}{l}0.270^{* * *} \\
(0.053)\end{array}$ & $\begin{array}{c}-0.111 \\
(0.096)\end{array}$ & $\begin{array}{l}0.705^{* * *} \\
(0.172)\end{array}$ & $\begin{array}{c}0.0272 \\
(0.391)\end{array}$ & $\begin{array}{l}0.702^{* * *} \\
(0.171)\end{array}$ & $\begin{array}{r}0.0247 \\
(0.391)\end{array}$ \\
\hline Services and professionals & & & & & & \\
\hline Occupation 68 & $\begin{array}{c}0.257^{* * *} \\
(0.0508)\end{array}$ & $\begin{array}{c}0.117 \\
(0.132)\end{array}$ & $\begin{array}{l}0.697^{* * *} \\
(0.162)\end{array}$ & $\begin{array}{c}0.577 \\
(0.443)\end{array}$ & $\begin{array}{l}0.695^{* * *} \\
(0.165)\end{array}$ & $\begin{array}{c}0.622 \\
(0.424)\end{array}$ \\
\hline Occupation 6970 & $\begin{array}{c}0.262^{* * *} \\
(0.0514)\end{array}$ & $\begin{array}{c}-0.031 \\
(0.125)\end{array}$ & $\begin{array}{l}0.723^{* * *} \\
(0.170)\end{array}$ & $\begin{array}{c}-0.007 \\
(0.494)\end{array}$ & $\begin{array}{l}0.715^{* * *} \\
(0.167)\end{array}$ & $\begin{array}{c}0.194 \\
(0.542)\end{array}$ \\
\hline Occupation 7174 & $\begin{array}{c}0.258^{* * *} \\
(0.0473)\end{array}$ & $\begin{array}{c}0.075 \\
(0.125)\end{array}$ & $\begin{array}{l}0.623^{* * *} \\
(0.176)\end{array}$ & $\begin{array}{c}0.594^{*} \\
(0.244)\end{array}$ & $\begin{array}{l}0.630^{* * *} \\
(0.175)\end{array}$ & $\begin{array}{l}0.684^{* *} \\
(0.252)\end{array}$ \\
\hline Occupation 7578 & $\begin{array}{c}0.269^{* * *} \\
(0.0473)\end{array}$ & $\begin{array}{c}-0.0902 \\
(0.105)\end{array}$ & $\begin{array}{l}0.841^{* * *} \\
(0.181)\end{array}$ & $\begin{array}{c}-2.874 \\
(3.596)\end{array}$ & $\begin{array}{l}0.859^{* * *} \\
(0.201)\end{array}$ & $\begin{array}{c}-3.455 \\
(3.683)\end{array}$ \\
\hline Occupation 7981 & $\begin{array}{c}0.257^{* * *} \\
(0.0503)\end{array}$ & $\begin{array}{c}0.111 \\
(0.175)\end{array}$ & $\begin{array}{l}0.714^{* * *} \\
(0.176)\end{array}$ & $\begin{array}{c}0.152 \\
(1.881)\end{array}$ & $\begin{array}{l}0.720^{* * *} \\
(0.173)\end{array}$ & $\begin{array}{c}-0.241 \\
(0.979)\end{array}$ \\
\hline Occupation 8485 & $\begin{array}{c}0.269^{* * *} \\
(0.0491)\end{array}$ & $\begin{array}{c}-0.221 \\
(0.138)\end{array}$ & $\begin{array}{l}0.708^{* * *} \\
(0.177)\end{array}$ & $\begin{array}{c}0.139 \\
(0.776)\end{array}$ & $\begin{array}{l}0.709^{* * *} \\
(0.177)\end{array}$ & $\begin{array}{c}0.0681 \\
(0.660)\end{array}$ \\
\hline Occupation 8689 & $\begin{array}{c}0.267^{* * *} \\
(0.0519)\end{array}$ & $\begin{array}{c}-0.183 \\
(0.253)\end{array}$ & $\begin{array}{l}0.717^{* * *} \\
(0.168)\end{array}$ & $\begin{array}{c}-0.344 \\
(1.645)\end{array}$ & $\begin{array}{l}0.726^{* * *} \\
(0.166)\end{array}$ & $\begin{array}{c}-0.899 \\
(0.835)\end{array}$ \\
\hline Occupation 9093 & $\begin{array}{c}0.243^{* * *} \\
(0.0477)\end{array}$ & $\begin{array}{r}0.375^{*} \\
(0.158) \\
\end{array}$ & $\begin{array}{l}0.671^{* * *} \\
(0.159)\end{array}$ & $\begin{array}{c}1.259 \\
(0.721) \\
\end{array}$ & $\begin{array}{l}0.660^{* * *} \\
(0.157) \\
\end{array}$ & $\begin{array}{c}1.276 \\
(0.720) \\
\end{array}$ \\
\hline
\end{tabular}

Note: Standard errors are clustered at the city level. Standard errors in parentheses. ${ }^{* * *} \mathrm{p}<0.01,{ }^{* *} \mathrm{p}<0.05,{ }^{*}$ $\mathrm{p}<0.1$. $\mathrm{p}$-values in brackets. Industry-specific occupations are not reported. 


\section{References}

S. Bender, A. Haas, and C. Klose. IAB Employment Subsample 1975-1995: Opportunities for Analysis Provided by the Anonymised Subsample. IZA Discussion Paper Series, 2000.

G. B. Dahl. Mobility and the Return to Education: Testing a Roy Model with Multiple Markets. Econometrica, 70(6):2367-2420, 2002.

R. Gibbons, L. Katz, T. Lemieux, and D. Parent. Comparative Advantage, Learning, and Sectoral Wage Determination. Journal of Labor Economics, 23:681-724, 2005.

F. Groes, P. Kircher, and I. Manovskii. The U-Shapes of Occupational Mobility. University of Pennsylvania mimeo, 2009.

P. Kropp and B. Schwengler. Abgrenzung von Arbeitsmarktregionen: ein Methodenvorschlag. Raumforschung und Raumordnung, 69(1):45-62, 2011. 